\title{
A reexamination of the distributive politics model and the allocation of federal Community Development Block Grant (CDBG) dollars
}

Howard A. Stern

West Virginia University

Follow this and additional works at: https://researchrepository.wvu.edu/etd

\section{Recommended Citation}

Stern, Howard A., "A reexamination of the distributive politics model and the allocation of federal Community Development Block Grant (CDBG) dollars" (2006). Graduate Theses, Dissertations, and Problem Reports. 2498.

https://researchrepository.wvu.edu/etd/2498

This Dissertation is protected by copyright and/or related rights. It has been brought to you by the The Research Repository @ WVU with permission from the rights-holder(s). You are free to use this Dissertation in any way that is permitted by the copyright and related rights legislation that applies to your use. For other uses you must obtain permission from the rights-holder(s) directly, unless additional rights are indicated by a Creative Commons license in the record and/ or on the work itself. This Dissertation has been accepted for inclusion in WVU Graduate Theses, Dissertations, and Problem Reports collection by an authorized administrator of The Research Repository @ WVU.

For more information, please contact researchrepository@mail.wvu.edu. 


\title{
A Reexamination of the Distributive Politics Model and the Allocation of Federal Community Development Block Grant (CDBG) Dollars
}

\author{
Howard A. Stern
}

Dissertation submitted to the Eberly College of Arts and Sciences at West Virginia University in partial fulfillment of the requirements for the degree of

\author{
Doctor of Philosophy \\ in \\ Political Science
}

\author{
Neil Berch, Ph.D., Chair \\ Richard A. Brisbin, Jr., Ph.D. \\ Brian J. Gerber, Ph.D. \\ John C. Kilwein, Ph.D. \\ Jeffrey S. Worsham, Ph.D. \\ Department of Political Science \\ Morgantown, West Virginia \\ 2006
}

Keywords: CDBG, distributive politics, federal allocations, pork barrel politics

Copyright 2006 Howard A. Stern 


\begin{abstract}
A Reexamination of the Distributive Politics Model and the Allocation of Federal Community Development Block Grant (CDBG) Dollars
\end{abstract}

\author{
Howard A. Stern
}

The literature on the distributive politics model suggests that elected officials strategically allocate public benefits to curry favors, secure votes and gain reelection. In other words, elected officials distribute public benefits in such a way as to enhance their own personal careers and goals. Unfortunately, this centralized, top-down perspective (Rich 1989), which focuses exclusively on the motivations of the elected officials, fails to consider the political, economic and social characteristics of the governmental unit represented by the officials. These contextual factors may influence the allocation decisions made by the elected officials. Thus, an expanded distributive politics model -one that takes into account the form of government, size of city, geographical region, per capita income and poverty level of the jurisdiction -- may better explain allocation decisions made by elected officials than the traditional model. Specifically, this research will examine how and why cities and their elected representatives allocate federal community development block grant (CDBG) dollars. The main contribution of this work is to offer a more comprehensive approach that considers a variety of contextual factors ignored by the traditional distributive politics model. Expanding the traditional distributive politics model to include a thorough understanding of the saliency and role of contextual factors will result in easier and more reliable predictions about how public benefits are likely to be allocated. 


\section{Dedication}

I dedicate this dissertation to Rhonda Wasserman, my best friend and partner, and to Eric Wasserman Stern, Scott Wasserman Stern, and Benjamin Wasserman Stern, whose love and very being have changed my life. 


\section{Acknowledgements}

I would like to thank Rhonda Wasserman, my wife, for her invaluable editorial support and suggestions on earlier drafts of this dissertation. Her comments were insightful, thoughtful, and most of all, very kind. I would also like to thank Rich Bellisario, for taking the time to explain and educate me on the CDBG process and to unselfishly share his vast knowledge and expertise with the program. I would also like to recognize and thank Mary Grusong and Linda Heidelberg for their constant support and encouragement throughout my studies and this project. They are two of the kindest and most thoughtful people I know and I would not have been able to complete this dissertation without their patient help and support. Last but not least, I would like to thank Amelia Haviland for her guidance and unwavering reassurance.

I offer special thanks to my committee chair, Dr. Neil B. Berch, for his expert advice and comments. I am grateful to my committee members, Dr. Richard A. Brisbin, Jr., Dr. Brian J. Gerber, Dr. John C. Kilwein, and Dr. Jeffrey S. Worsham for their guidance and support throughout this long process. Their constructive input and suggestions was both needed and very much appreciated.

Finally, I thank Dr. Robert Dilger, Mike Doyle, Rosette Fisher, Dr. Larry Grossback, Gary Jastrzab, Mary Johnson, Sophie Masloff, Tom Murphy, Robert Price, Rebecca Rieger, John Tolbert III, and Sala Udin for graciously meeting with me and sharing their wealth of experience and expertise of the CDBG program and process. 


\section{Table of Contents}

\section{Chapter One}

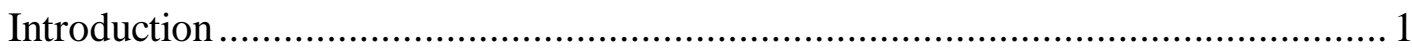

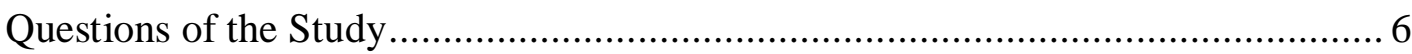

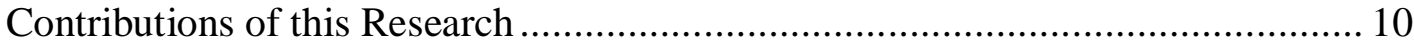

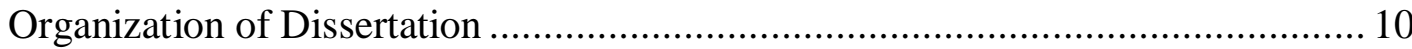

\section{Chapter Two: Distributive Politics}

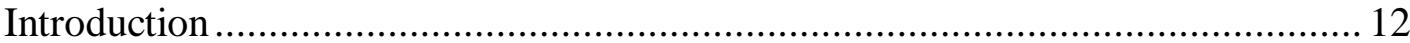

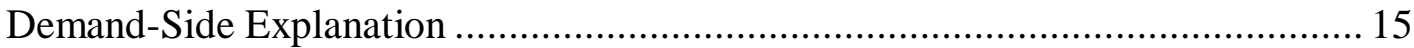

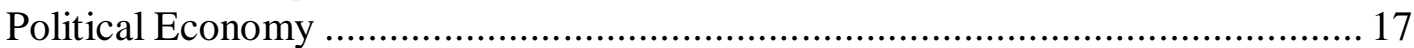

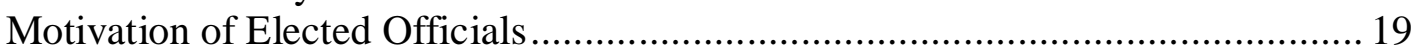

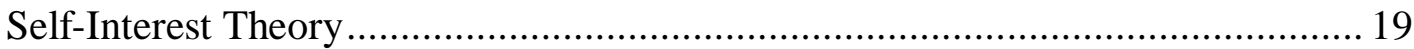

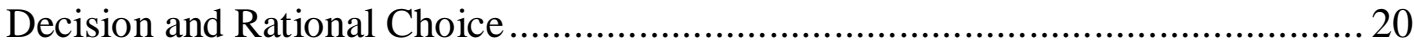

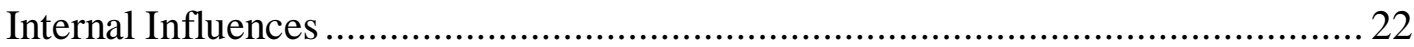

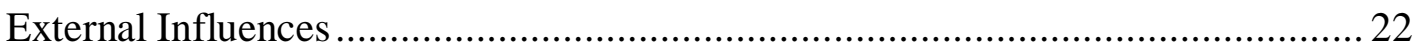

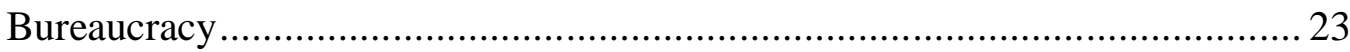

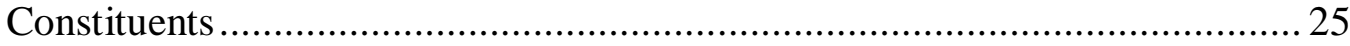

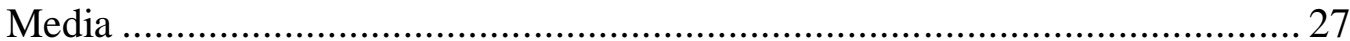

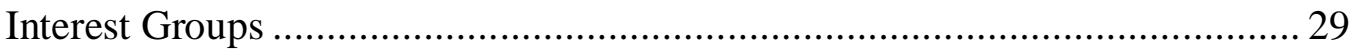

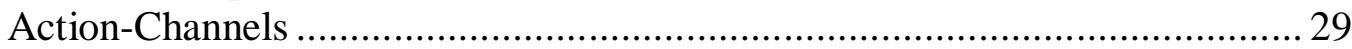

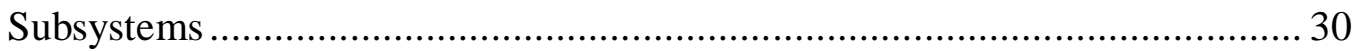

Symbiotic Approach to the Distributive Politics Model........................................... 30

An Economic Model of Supply and Demand ............................................... 33

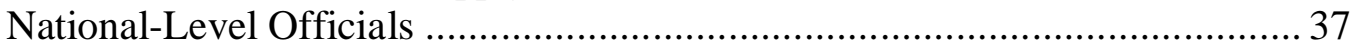

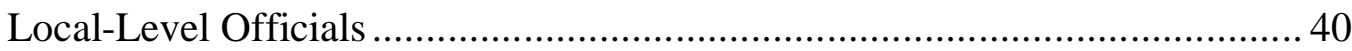

Bureaucratic-Level Officials (National \& Local)........................................... 41

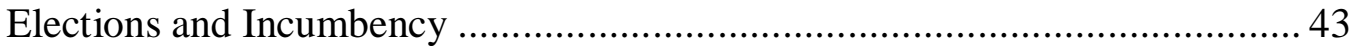

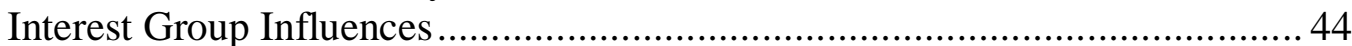

Expanding the Distributive Politics Model and Demand-Side Explanation ...... 45

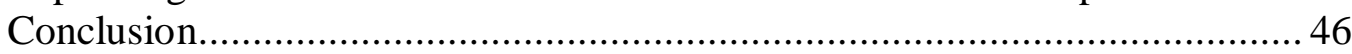

\section{Chapter Three: The Community Development Block Grant (CDBG) Program}

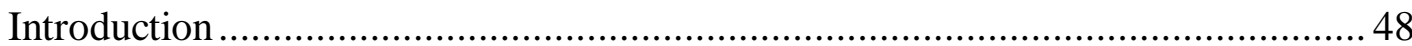

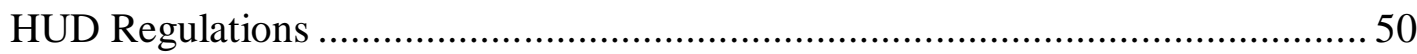

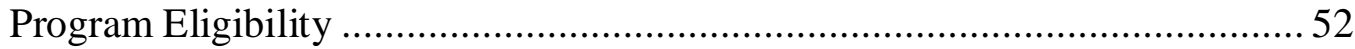

Devolution from Federal Government to the Cities ………...................................5 55

Advantages of Devolution to the Cities .......................................................56

Disadvantages of Devolution to the Cities......................................................5 58

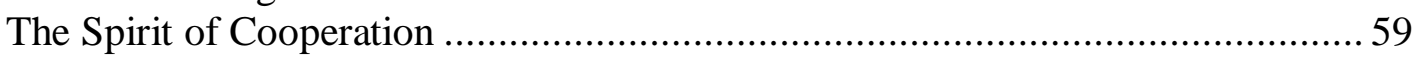

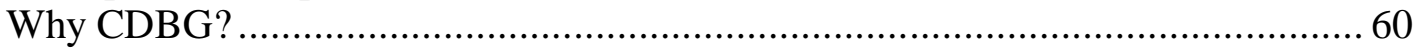

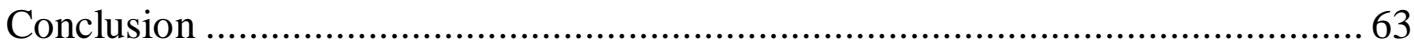




\section{Chapter Four: Case Study}

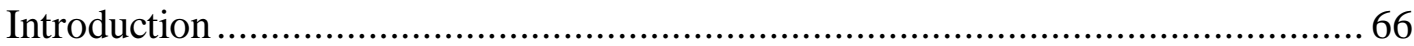

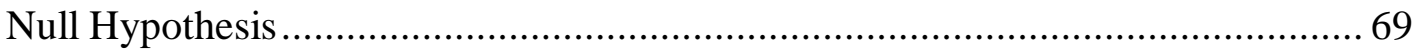

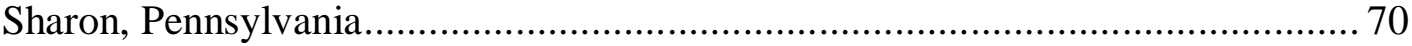

Sharon's CDBG Program History …………………................................ 72

How Sharon's CDBG Process Works ........................................................... 74

Contrasting CDBG Allocations Under Differing Mayoral Administrations ..... 74

Symbiotic Model Applied to Sharon ............................................................ 75

Local-level bureaucrats responsive to local-level elected officials.................. 75

Local-level elected officials responsive to national-level elected officials...... 78

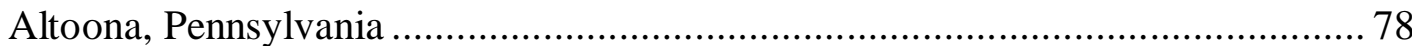

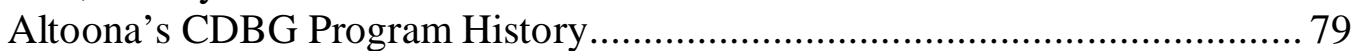

How Altoona's CDBG Process Works ................................................................ 80

Contrasting CDBG Allocations Under Differing Mayoral Administrations ..... 82

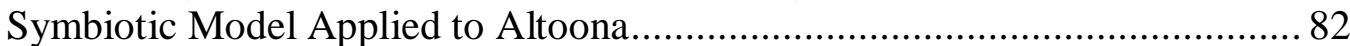

Local-level bureaucrats responsive to local-level elected officials.................. 82

Local-level elected officials responsive to national-level elected officials...... 83

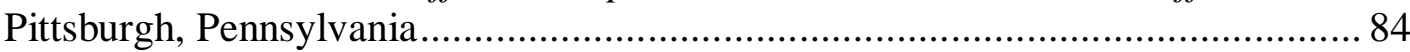

Pittsburgh's CDBG Program History …………………............................... 86

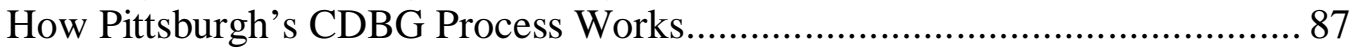

Contrasting CDBG Allocations Under Differing Mayoral Administrations ..... 90

Symbiotic Model Applied to Pittsburgh .......................................................... 91

Local-level bureaucrats responsive to local-level elected officials................ 91

Local-level elected officials responsive to national-level elected officials...... 94

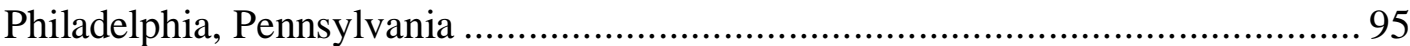

Philadelphia's CDBG Program History ...................................................... 95

How Philadelphia's CDBG Process Works .................................................... 96

Contrasting CDBG Allocations Under Differing Mayoral Administrations ..... 98

Symbiotic Model Applied to Philadelphia......................................................... 99

Local-level bureaucrats responsive to local-level elected officials................. 99

Local-level elected officials responsive to national-level elected officials.... 101

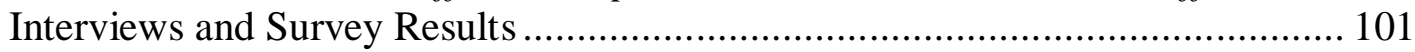

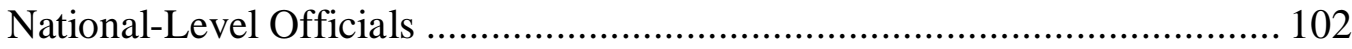

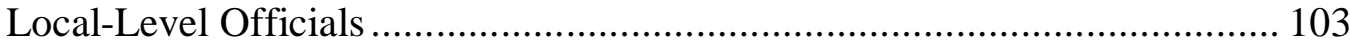

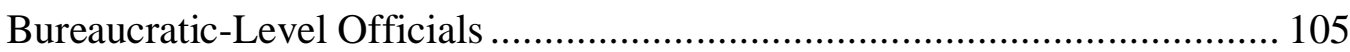

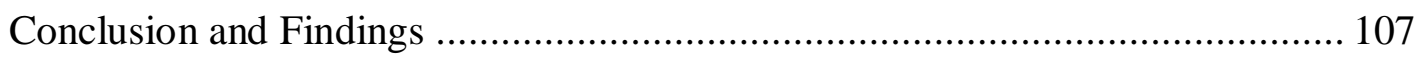

\section{Chapter Five: Quantitative Analysis of National Data}

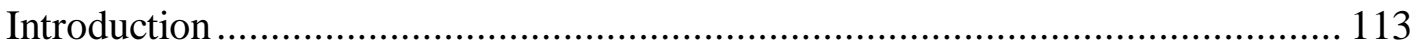

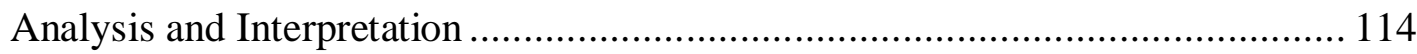

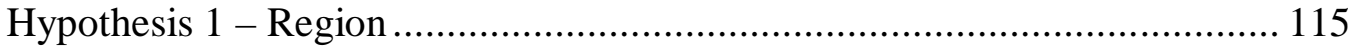

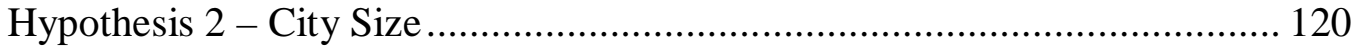


Hypothesis 3 - Form of Government ............................................. 123

Council / Manager............................................................................... 123

Mayor / Council ............................................................................ 125

Commissioner ...................................................................... 126

Hypothesis 4 - How Council is Elected .............................................. 127

Hypothesis 5 - Economics ............................................................ 129

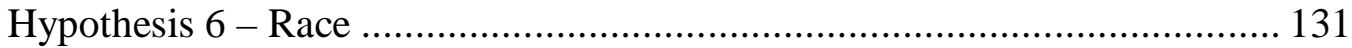

Multiple Relationships ................................................................ 143

\section{Chapter Six: $\quad$ Conclusion and Future Research}

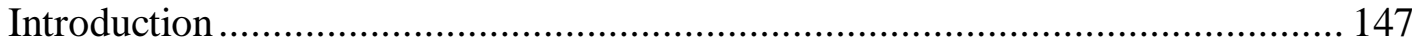

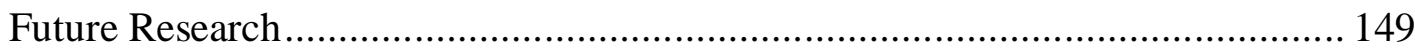

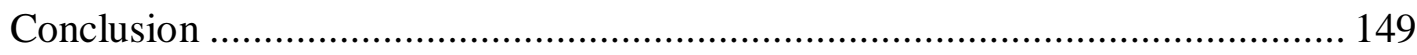

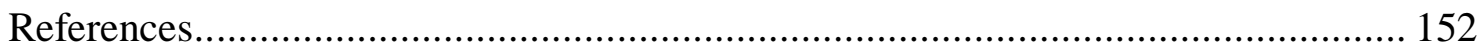

Appendix A: Interview Protocol ............................................................... 161

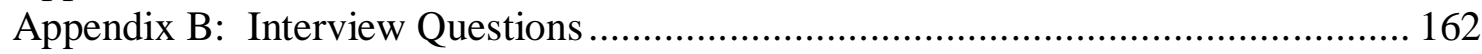

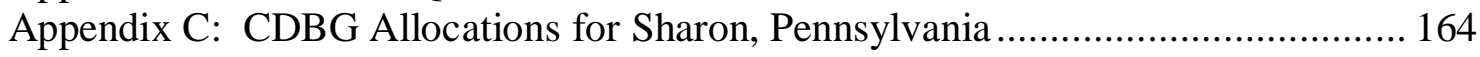

Appendix D: CDBG Allocations for Altoona, Pennsylvania .................................. 165

Appendix E: CDBG Allocations for Pittsburgh, Pennsylvania ............................... 166

Appendix F: CDBG Allocations for Philadelphia, Pennsylvania ........................... 167

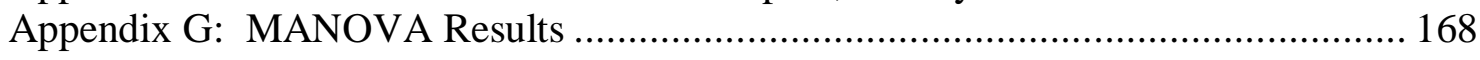

Appendix H: Explanation of Variables .................................................. 175 


\section{List of Charts}

Chart 4.1: CDBG Allocations for Public Improvements during the

Murphy Administration .......................................................... 112

Chart 4.2: CDBG Allocations for Economic Development during the

Goode Administration .............................................................. 112

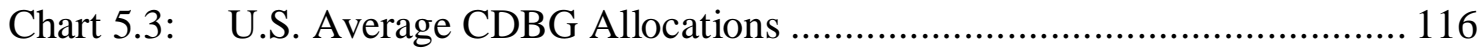

Chart 5.4: Public Improvement Allocations Sorted by City Size ......................... 124 


\section{List of Figures}

Figure 2.1: Symbiotic Approach to Distributive Politics Theory .............................. 35

Figure 4.2: City of Sharon CDBG Eligible Neighborhoods................................ 73

Figure 4.3: City of Altoona CDBG Eligible Neighborhoods ................................ 81

Figure 4.4: City of Pittsburgh CDBG Eligible Neighborhoods............................... 88

Figure 4.5: City of Philadelphia CDBG Eligible Neighborhoods ........................... 97 


\section{List of Tables}

Table 3.1: Grantee Use of CDBG Funds by Category .....................................................65

Table 4.2: Case Study Cities ..................................................................................... 71

Table 4.3: Spending Habits between Mayoral Administrations for Sharon, $\mathrm{Pa}$.................76

Table 4.4: Spending Habits between Mayoral Administrations for Altoona, Pa................85

Table 4.5: Spending Habits between Mayoral Administrations for Pittsburgh, Pa ...........92

Table 4.6: Spending Habits between Mayoral Administrations for Philadelphia, Pa..... 100

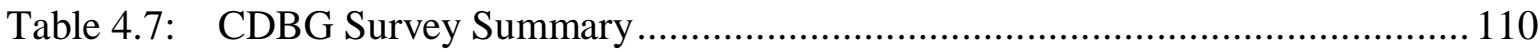

Table 5.8: Comparisons of CDBG Funding Allocations for Regional Influences ......... 134

Table 5.9: Comparisons of CDBG Funding Allocations for Size of City Influences ..... 135

Table 5.10: Comparisons of CDBG Funding Allocations for Form of Government

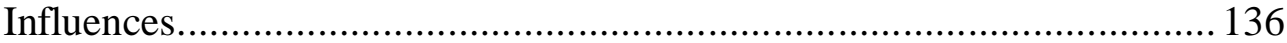

Table 5.11: Comparisons of CDBG Funding Allocations for Council Structure

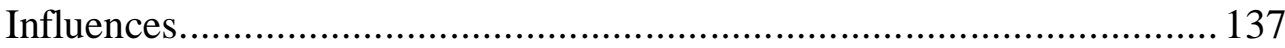

Table 5.12: Comparisons of CDBG Funding Allocations for Per Capita Income

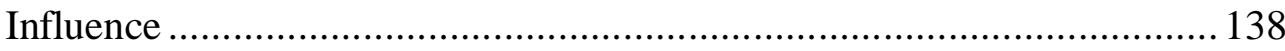

Table 5.13: Comparisons of CDBG Funding Allocations for Poverty Level Influences.. 139

Table 5.14: Comparisons of CDBG Funding Allocations for Unemployment

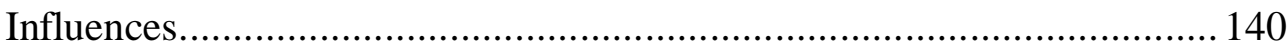

Table 5.15: Comparisons of CDBG Funding Allocations for Housing Values

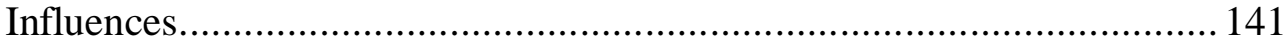

Table 5.16: Comparisons of CDBG Funding Allocations for Racial Influences .............. 142

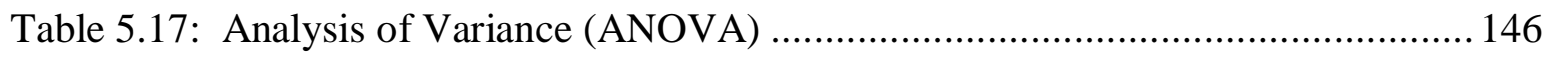

Table 5.18: Multiple Analysis of Variance (MANOVA) ................................................ 146 


\section{Chapter One}

\section{Introduction}

On August 22, 1974, Congress enacted the Housing and Community

Development Act to create a new initiative called the Community Development Block Grant (CDBG) program. This program was designed to consolidate seven existing federal assistance programs -- model cities, urban renewal, rehabilitation loans, public facility loans, water and sewer facilities, open spaces, and neighborhood facilities -- into one comprehensive program. The primary objectives of the newly created CDBG program were to improve overall living conditions and to expand economic opportunities

for low and moderate income neighborhoods by granting entitlement cities the discretion to select and fund projects that would be most beneficial to the cities' low and moderate income residents.

The CDBG program represented a sea change from past federal grant award practices. The devolution of grant dollars directly to the cities, with minimal federal intervention, was unprecedented. As long as the cities were able to meet the guidelines of this new program, the federal government would allow entitlement communities to make their own decisions about where and how they would use federal CDBG dollars. When the CDBG program was created, President Gerald Ford was clear that control would be in local hands: "In a very real sense, this bill will help to return power from the banks of the Potomac to people in their own communities. Decisions will be made at the local level. Action will come at the local level. And responsibility for results will be placed squarely where it belongs - at the local level." (Ford 1974). 
Under the CDBG program, national officials allocate federal dollars to municipalities according to a formula that determines a city's entitlement status. The cities themselves are then supposed to plan, implement and administer those projects most beneficial to the welfare of a city's populace, with the emphasis on providing programs, services and improved infrastructure to underserved areas. But, as my research into local allocation practices will demonstrate, when local officials act as trustees of federal government monies, numerous complex issues surrounding decisionmaking, distribution and accountability arise. Local officials understand that if they fail to implement a federal distributive program in the spirit with which it was intended, then the entitlement community can risk losing the federal appropriation. On the other hand, local officials also must negotiate the pressures of various, powerful internal and external demands. An official might feel pressured by the internal demands of her personal beliefs and values to make good public policy decisions. External forces and factors such as special interest groups, the state of the local and national economy, the agendas of congressional representatives and the scope and slant of media coverage can also exert considerable pressure on a local official's grant-distribution decision-making processes. Whether internal or external in origin, the demands and interests vying for a local official's notice and ongoing consideration significantly complicate the local grant allocation process, a process that, by vesting power at the local level, the CDBG program sought to simplify and improve.

The local-level independence and flexibility allowed by the program often permitted entitlement cities to allocate CDBG dollars in ways that significantly compromised the program's spirit and intent. In some cases, cities allocated federal 
dollars to projects that otherwise would have been funded by their own operating budgets. In other cases, local officials used CDBG monies to further their own political aspirations and leverage, allocating the federal grant monies to local projects that increased these local politicians' own immediate visibility, rather directing the grant dollars to projects that clearly benefited a community's underserved citizens. Over the more than thirty years since the CDBG's first awards were granted, allocation decisions at the local level have increasingly been driven, not by the needs of cities' lower and moderate income citizens, but by a multitude of contextual and social influences ranging from personal self-interest to racial demographics to local and federal political aspirations.

So what caused this apparent disconnect between federal lawmakers' original intentions and local officials' actual practices? Why have Congress's CDBG hopes been dashed at the street level? What role does the fragmentation of government and the importance of representation play in the allocation of CDBG funds? The answers to these questions are difficult to fully determine, but often hinge on a host of contextual factors, including the prevailing economic, political and social environment of the grantreceiving city, the political visibility and approbation so valuable to the local and federal officials, and the complexities of intergovernmental relations. Since political and economic conditions in different parts of the country vary and because governmental structures vary among cities, the allocation processes of cities not only depart from congressional expectations, but also vary city to city.

To illustrate how these contextual factors influence the CDBG allocations of local officials, consider the experiences of two mayors in different parts of the same state: 
Mayor W. Wilson Goode in Philadelphia, Pennsylvania and Mayor Robert Price in Sharon, Pennsylvania. A comparison of how CDBG monies were used by their administrations points to the internal and external pressures that influence both national and local officials' CDBG decisions, and the extent to which these decisions comport with the program's intended spirit.

By all accounts, Philadelphia Mayor W. Wilson Goode was the poster child for federal (CDBG) initiatives. He was responsive to his community's needs, he assembled a competent and professional staff, and the projects and programs he selected were consistent with the national government's program goals and objectives of serving low and moderate-income communities (Kettl 1980, 19). He directed a large proportion of Philadelphia's CDBG monies toward vacant house and rental rehabilitation assistance in targeted neighborhoods. These projects were costly and politically inefficient, in that they benefited only a small fraction of Philadelphia's population: the poorest and least powerful segment of the community. Interestingly, Goode made these spending commitments to benefit the poor and vulnerable, and allocated these funds consistent with primary CDBG objectives, during his second and final term in office.

In contrast, during his first term in office, when he was concerned about seeking reelection and securing votes from a broader cross-section of the population, Mayor Goode allocated nearly $\$ 7,000,000$ of CDBG money for city-wide site improvements. His commitment to rebuilding the City's infrastructure and to increasing economic development opportunities and his allocation of millions of dollars from his CDBG budget for city-wide improvements and initiatives earned him widespread approval. Note that during his reelection bid, Goode spent far less money on the poor neighborhoods the 
CDBG dollars were supposed to benefit, and more on city-wide projects that benefited wealthier, more politically active constituents. In fact, he committed 90 percent more money to city-wide site improvement projects during the four year term preceding his reelection bid than in the four years that followed it (Consolidated Community Development Plan 1984-1991).

Like Mayor Goode, Mayor Robert Price of Sharon, Pennsylvania, was also considered a champion of CDBG program initiatives (Tolbert 2005). He too assembled a competent staff, listened to the needs of his constituency and diligently followed the national government's required program rules and regulations. Unlike Goode, however, Price allocated a consistent and somewhat predictable percentage of his federal CDBG budget to city-wide projects such as improvements to many public facilities. There seemed to be few variations in his funding allocations, and they did not appear to fluctuate during any of his electoral cycles.

So what accounts for the dramatic CDBG allocation shifts seen during Philadelphia Mayor Goode's tenure, and what accounts for the consistency of allocations during Price's many years as Mayor of Sharon? Why do mayors spend federal CDBG dollars the way they do? Do mayors shift priorities from one type of project to another because they believe that some projects have electoral effects? Does the form of government matter (and the concomitant actual power of the mayor) matter? Do communities with large minority populations, relatively high per capita incomes, or low unemployment rates allocate their CDBG dollars differently from communities with large majority populations, high per capita incomes, or low unemployment rates? What factors or influences alter the motivations or decision-making of elected officials? 
As we will see, a combination of behavioral and contextual factors explain the allocation decisions made by local-level elected officials in distributing CDBG monies.

\section{Questions of the Study}

The decision-making process of elected officials is a central concern of those who study how policies are developed and implemented. The motivation of individual players, coupled with the political, economic and social characteristics of the organizations those individuals control, can play a salient role in the policy-making process. The distributive politics model illustrates and explains this decision-making process. In conjunction with a demand-side explanation, this model suggests that the behaviors and decisions of elected officials are explained by their desire to get reelected, by their need to do what is right, and by their quest for power (Mayhew 1979, Savage 1999). This model focuses on the perceptions of elected federal officials to explain how and why government benefits are allocated (Rich 1989). The distributive politics model maintains that these particular motivations are the primary determining factors in officials' decision-making processes.

Although helpful in explaining the decision-making process of local officials, the distributive politics model is not sufficiently nuanced to explain decisions, such as the allocation of CDBG monies. To better understand the behaviors of elected officials at the local level, it is imperative to understand the demand-side explanation of federal aid allocation and by expanding the traditional distributive politics model. The demand-side explanation suggests that not all recipients are equally capable of applying for and obtaining federal grant dollars (Stein 1981). The monetary and human costs of accepting 
a federal grant, such as matching requirements and reporting data, can be an exhaustive and expensive undertaking.

Through an expanded distributive politics model -- one that takes into account the motivation, form of government, size of city, geographical region, per capita income, race and poverty level of the jurisdiction -- it is possible to better explain the allocation decisions made by local elected officials, particularly mayors. An expanded model will contribute to the understanding of intergovernmental relations by offering a more comprehensive approach that considers a variety of contextual factors ignored by the traditional distributive politics model.

This study will test the demand-side explanation of federal grant dollars and an expanded distributive politics model by examining the federally funded CDBG program. The federal CDBG program serves as an excellent vehicle for testing an expanded distributive politics model for two reasons. First, as long as a city meets the population requirement, it will be eligible for federal CDBG monies with very few qualifications or requirements. Basically, the federal government devolves CDBG funds to state and local governments irrespective of economic health, region or politics. Because of the general availability of CDBG monies and the enormous flexibility cities enjoy in distributing these funds, this program provides an excellent opportunity to study how and why government benefits are allocated. Second, the federal government maintains detailed data on the CDBG program, which permits careful analysis of the role that the contextual factors play in the allocation of federal dollars.

The CDBG program represents a real commitment to the cities and neighborhoods by the federal government and enjoys bi-partisan support from Congress; 
both Democrats and Republicans. More importantly, the whole concept of CDBG represented a shift or devolution of control from the federal government to the cities. Previously, categorical grants were the most common ways that the federal government disbursed monies to the local governments on a project-by-project basis. Categorical grants gave the federal bureaucracy much more power in the approval process and ensured that local governments used federal dollars that were consistent with the national governments priorities at the time (Friedland and Wong 1983). When the federal government decided to shift from categorical to block grants, the rigid guidelines imposed on the localities were loosened and the project-by-project approval process dissipated. As long as the vague CDBG guidelines were met, cities can implement the projects and programs of their choice with little accountability. The reasoning behind the flexibility of the CDBG program is that the decision makers at the local level are inherently more knowledgeable and responsive to their community's needs (Pratt Institute Center for Community and Environmental Development 2001) than the national government.

According to HUD, CDBG monies can be used for a variety of projects to improve housing, public buildings, green spaces, transportation and jobs. Projects ranging from street resurfacing to playground rehabilitation are eligible under this program. It is not uncommon for an ice skating rink or a firehouse to be remodeled using CDBG monies. Although the program is targeted towards low and moderate-income neighborhoods, the program guidelines are vague and ambiguous. As a result, a large percentage of CDBG funds can be spent anywhere within an entire community providing that the programs targeted sector benefits as well. The CDBG program devolves benefit 
dollars directly to local governments to allocate to their constituents, often with very few and vague guidelines. As a result, $\mathrm{CDBG}$ recipient jurisdictions enjoy immense flexibility in the disbursement of these federal benefit dollars.

The key question I am asking is whether the inclusion of contextual factors, that are ignored by the traditional distributive politics model, result in easier and more reliable predictors about how public benefits are likely to be allocated? Specifically, I examine the choices made by local officials' regarding distributive programs and how they impact recipient jurisdictions and their constituents. To deal with this issue, I will offer a demand-side explanation in the distribution of federal CDBG monies and an expanded distributive politics model to articulate and to answer the following research questions: What influences and motivations drive an official's decision-making process in the allocation of CDBG dollars? Does form of government and size of city help explain how CDBG monies are allocated? Do wealthier cities allocate CDBG dollars differently than poorer cities? Does geographical region influence funding decisions? Do allocation decisions vary during Republican or Democratic administrations? Does incumbency matter? What role does a professional CDBG staff play in the allocation of CDBG federal aid monies? Do stakeholders really care if CDBG monies are allocated equitably? These questions will be answered through a case study of four Pennsylvania cities and through a statistical analysis of the actual CDBG allocations reported by the U.S. Department of Housing for every large and small entitlement city in the fifty United States and the District of Columbia. 


\section{Contributions of this Research}

This research introduces a more sophisticated distributive politics framework, one that considers a demand-side explanation, to help define the motivations and behaviors of local elected officials. This framework will demonstrate that mayors allocate public dollars based on the political, economic and social environment around them. Expanding the traditional distributive politics model to include a thorough understanding of the saliency and role of contextual factors will result in easier and more reliable predictions about how public benefits are likely to be allocated.

These contextual factors may help the political scientist develop a matrix or schema that can accurately reflect and predict a pattern of behavior and decisions. These behaviors, for example, may stem from the way a mayor sees her role in the community, how she perceives the economic well-being of her community, how she assesses the needs and wants of her political counterparts, city size, and the form of government she serves. Ultimately, these factors will prove instrumental in predicting the way mayors or other elected officials at the local level distribute government benefits.

\section{Organization of Dissertation}

The chapters that follow support my argument that an expanded distributed politics model by focusing on the demand-side considerations of grant allocations (Stein 1981), which considers a variety of contextual factors, such as city size, form of government and race, better explains the behaviors and allocation decision of local elected leaders. This model is tested through the use of case studies and personal interviews and through the quantitative examination of the empirical data of all CDBG 
entitlement cities. Chapter 2 presents the distributive politics model and the demand-side explanation in the allocation of federal dollars, which provides the theoretical basis from which I expand my arguments. Chapter 2 also focuses on the motivations and behaviors of local elected officials in the decision-making process and proposes an expanded distributive politics model by introducing a symbiotic approach that explains the decision-making relationships among the national, local and bureaucratic stakeholders. Chapter 3 provides a detailed overview of the Community Development Block Grant (CDBG) program by discussing the program's history, regulations, and eligibility requirements. This chapter examines the devolution process of distributive benefits from the federal government to the cities.

Chapter 4 tests the efficacy of the symbiotic model, through the case study approach, by examining the ways cities and their mayors allocate CDBG funds. Chapter 5 analyzes the CDBG allocations for every (758) CDBG eligible community in the United States and the District of Columbia for the year 2001. This analysis will examine the impact of several variables on the dependent variable. By examining the strength of bivariate and multivariate relationships (through ANOVA and MANOVA), it is possible to test the robustness of these relationships when controlled for other variables. Chapter 6 summarizes the study's main findings and conclusions and places them in context of the larger literature on distributive politics theory. This chapter also discusses the need for future research and concludes with a summary of the lessons-learned from this study. 


\section{Chapter 2}

\section{Distributive Politics}

\section{Introduction}

When asked his opinion of the national government's practice of distributing federal dollars to the cities, Texas Senator Phil Gramm summed up his position this way: "if the federal government decides to build a cheese factory on the moon, [I] would naturally be opposed to such a project, but if built, [I] would want a Texas firm to do the engineering [and] I would want to use milk from Texas cows" (Barrett 1997, 6). Put another way, if federal money is to be given to the cities and states, Senator Gramm is most concerned that his constituents from Texas benefit, either directly or indirectly, from these federal dollars. It is this type of attitude -- federal monies are available, an elected official wants those dollars for his locality -- that serves as the cornerstone of distributive politics theory.

According to the distributive politics model, legislators and local elected officials allocate monies (1) to curry favor with constituents in order to get reelected; (2) to create good public policy; and (3) to bolster their reputation and position among political colleagues (Savage 1999). When elected officials allocate monies to curry favors with constituents, they are making decisions based on politics (sometimes referred to as porkbarrel politics). When they allocate monies to create good public policy, they are making decisions in light of their psychological, cultural and/or ideological orientations. When they allocate monies to bolster their professional reputations, they are making decisions that serve their personal beliefs and values. 
Bikers and Stein (1994) suggest that transaction costs explain the tradeoffs that occurs in an official's decision to allocate distributive benefits. Transaction cost's consists of the decision to offer a benefit (both personal and professional) and the opportunity costs of a decision. Unfortunately, imperfect or incomplete information and personal beliefs systems can and do impact the legitimacy of weighing the transaction costs of a decision. The implications of a particular decision or allocation will vary according to the individual decision maker.

Traditionally, the distributive politics model focuses on decision-makers at the national level, such as the President and Congress, and ignores the power and role of the local participants such as the mayors and city council members. Such a top-down and centralized approach focuses on the perceptions of elected federal officials to explain how and why government benefits are allocated in particular ways (Rich 1989). My research, which will apply the distributive politics theory to decision-makers at the local (municipal) level, will examine each of the three distribution motivations in greater detail and will demonstrate that these factors alone do not adequately explain allocation decisions made by local officials.

Before addressing the inadequacies of the existing theory, one must first understand how the traditional assumptions used to describe top-down federal award distributions apply in the context of local officials allocating federal dollars. First, pork barrel politics -- the allocation of federal dollars to gain political influence among constituents -- is the most commonly applied assumption of the distributive politics model. Political science scholars (Dilger 1989, Rich 1989) posit that elected officials distribute federal dollars to their constituencies in order to enhance their own personal 
visibility and support. With pork barrel politics, public tax dollars and appropriations are used to finance programs and projects in a specific locale or community for the sole purpose of gaining voter support and ultimately winning reelection (Evans 2004, Bickers and Stein 1996). Although most people view pork barrel politics as a system by which particular locales receive money to build a new bridge or dam, to initiate a job training program, or to purchase a new fire truck, legislators sometimes use less concrete enticements, such as tax policies and loopholes, to attract and secure voter favor in their districts (Sakamoto 2001). Just as federal lawmakers distribute resources to gain political support, local officials allocate the federal dollars they receive for the same purposes.

Second, in addition to currying favor with voters, elected officials allocate monies in an effort to create good public policy. This judgment about what constitutes "good" public policy is a reflection of the official's psychological, cultural and ideological orientation (Golden 2000). The psychological perspective suggests that human behavior is driven by emotions. The sociological perspective recognizes that "no person is an island," and that contextual elements such as groups, peers, and professional associations can influence and shape an official's behavior. The ideological or cultural perspective contends that an individual's behavior reflects his or her beliefs, values or social needs, all of which reflect an individual's upbringing and orientation.

Motivated by a desire to develop good public policy, an elected official will sometimes make decisions that she considers are in the best interests of the country and her constituency. Many times these policy decisions are made contrary to the special interests or wishes of her constituency. Realizing the potential consequences of an unpopular decision, these elected officials are most concerned with doing what they 
consider "right." When officials behave according to their beliefs and values, they are sometimes referred to as "saints," because the official is putting her fundamental beliefs/values ahead of short-term reelection or other political concerns. Typical saint behavior occurs when elected officials decline the opportunity to accept pork for their recipient jurisdiction (Savage 1991).

A distribution of federal dollars to bolster an elected official's reputation and status with voters is the third way by which elected officials make allocation decisions. Elected officials will sometimes take a position that is unpopular with their own constituency to accumulate and enhance their political capital for future issues that are important to them. By supporting an unpopular position, elected officials at both the national and local levels may bolster their reputation and position among their political colleagues who may ultimately help them develop the political support for future endeavors

\section{Demand-Side Explanation}

The prevailing theory in the allocation of federal grant dollars suggests that all recipient government agencies are equally desirous of federal aid dollars and that the distribution of these monies has more to do with the available dollars on the supply-side, than it does with the recipients' capacity to request and administer federal funds on the demand-side (Stein 1981). Unfortunately, this supply-side theory does not take into account the needs and motivations of the requesting agencies. As a result, researchers have begun to look at the demand-side perspective of federal allocations, one that addresses the recipients' concerns in order to enhance the traditional understanding of federal grant allocations. 
The demand-side theory suggests that there are other variables, both social and financial, that explain why recipient jurisdictions either apply for or refrain from seeking federal aid. From a social perspective, the government agency may not have the appropriate staff or resources to adequately administer, implement or evaluate the grant. This lack of expertise might influence a community's desire or ability to pursue a federal grant. From a financial perspective, the direct and indirect costs associated with administering a grant may be too costly for some localities to absorb. These costs, such as required monetary matches or the need to develop systems that track and audit data, sometimes requires a substantial financial and human investment. Put another way, communities will sometimes refrain from applying for federal aid since they cannot afford the financial and reporting expenses associated with the grant.

Interestingly, it is the smaller cities, especially distressed and economically vulnerable areas, that are less inclined to pursue federal monies because of smaller staffs and limited resources. When a smaller city lacks the capacity to administer a federal grant, an imbalance between those communities that need the allocations but fail to get them and those less needy communities that do receive grants becomes even greater. Recognizing that potential inequities exist between cities that have the capacity to administer and implement a grant and those that do not, the federal government has changed the nature of many of its grant-in-aid programs. The original Model Cities program was a categorical grant program; participating cities had to apply for funding for individual projects. In the 1970s, the program was changed from a categorical grant program to a block grant program, which provides cities with greater autonomy and 
flexibility in project selections. After all, who knows the needs of the city better than the cities themselves (Dilger 1989).

Unfortunately, this sea change did not have the desired affects - alleviating inequities in the distribution of grant dollars (Stein 1981). Instead, as the CDBG program demonstrates, the actual number of cities applying for block grants actually decreased from the program's early years. Between 1976 and 2001, the number of participating entitlement cities dropped from 1,250 (HUD 2nd Annual Report) to less than 820 ("CDBG Matrix Website" 2005), a decrease of more than 34 percent. This reduction suggests that the block grant solution to increase city participation was not a panacea and that the federal government might need to reconsider the demand-side concerns and obstacles before making federal funding available to the cities. These concerns are better understood with a thorough explanation of the political economy and the role it plays in the allocation of federal benefits.

\section{Political Economy}

The political-business cycle also plays a role in the distribution of federal dollars by states and localities. Just as federal politicians will sometimes manipulate the economy prior to an election in order to raise their visibility and gain electoral support (Tufte 1978), mayors and other local officials may manipulate the distribution of federal monies before an election for the same reasons. For example, within the politicalbusiness cycle, a mayor seeking reelection may find it useful, immediately preceding the election, to shift federal dollars from low-visibility projects that are not likely to yield a significant political pay-off (such as winterization of homes for the poor) to higher visibility projects that may yield greater electoral support (such as a popular street 
resurfacing program in an affluent neighborhood). The beneficiaries of the allocated monies and consequent services are influenced to vote for her.

Cameron (1978) explains the growth of the public economy as political in nature: the power of electoral competition is a very powerful influence of public spending. According to Cameron, examining the relationship between politics and the public economy will "imply that the contenders for political office alter their programs in order to enhance their electoral appeal" (Cameron 1978, 1246). A politically motivated official will make the project alterations necessary to secure more funding and more services for her own district. Commonly referred to as "pork barrel" politics, elected leaders spend public taxpayer dollars to increase their personal visibility and popularity within their districts or communities.

To understand the effects of pork barrel politics on policy, it is also important to consider the internal or domestic explanatory variables such as the power of special interest groups. Such groups tend to be highly organized, exert political clout, and have greater access to elected officials, allowing these interest groups considerable influence over pork barrel allocations. Unfortunately, the motives of these special interest groups are not always reflective of general societal needs and attitudes. Instead, these potentially very influential groups represent the special interests they work for, even if those interests are not shared by the general electorate. Interest group pressure -- and the bigger the membership and financial resources, the more powerful the group -- leads to unfair tax advantages for some and pork barrel projects that can ultimately, and negatively, impact an entire state's fiscal health. For local governments, the pressures of interest groups can be very powerful for both city-council member and the mayor. For council members, 
especially those members elected by-district, it is imperative to have support for those special interests that reside in their districts. For mayor's and council members elected at-large, it is important to have the financial and political backing from a group that can generate large amounts of votes and publicity. This sentiment was conveyed most directly by one Pittsburgh council member when asked about the importance of interest groups for his district: "Even if I give \$1,000 to a group, it still communicates a sense of support and commitment to that organization" (Udin 2005).

\section{Motivation of Elected Officials}

The decision-making process of elected officials is a central concern of those who study policies and how policies are developed and implemented. The motivations of individual players and their contemporaries, coupled with the political, economic and social characteristics of the organizations they control, play a salient role in the policymaking process. These decision-making processes may seem straightforward, even simple, but to get to the root of these issues, one needs to study and apply the internal and external influences of decision-making that are prominent in the political science literature and apply them to the behaviors of local officials in the allocation of federal benefits.

\section{Self-Interest Theory}

Self-interest theory considers the value of a person's culture and motivation, identifying preferences via an integral understanding of three areas of an official's background: psychological, sociological and ideological. The psychological perspective 
suggests that behavior is driven by emotions, and that an understanding of how particular emotions influence various behaviors is essential to understanding processes of decisionmaking. The sociological perspective suggests that a person's behavior is significantly influenced by groups, peers, and professional associations. The ideological or cultural perspective posits that behavior is a reflection of the beliefs and values of an individual and that these beliefs and values are shaped during a person's upbringing. These background-influenced preferences share varying traits, ranging from the "ideal" to the “quest for power” (Browning \& Jacob 1964).

Not everyone believes that self-interest is the determining factor in a person's behavior. Sabatier and Jenkins-Smith (1999) contend that bureaucrats operate under two types of belief systems, deep core and policy core, neither of which derives primarily from self-interest. These and similar concepts can be applied to a city's mayor and elected officials. A deep core belief system encompasses those beliefs that are deeply ingrained and often difficult to change. Policy core beliefs are more amenable to change over time, if the actors can rationalize the change (Sabatier and Jenkins-Smith 1999, 122). Sabatier and Jenkins-Smith suggest that bureaucrats, including operators, are not driven by self-interest, but rather by commitment to a cause.

\section{Decision and Rational Choice}

By studying decision-making and rational choice theories, it is possible to explain how and why elected local officials, namely mayors and city-council members, distribute CDBG allocations. Decision theory suggests that an individual unilaterally makes decisions without considering the strategic interactions of other interested parties. In other words, the decision-maker makes choices based on current circumstances and the 
probability of future outcomes, without significant consideration of how other interested parties might be involved in or might react to the individual's decision (Humes and Gates, 2000). These choices are typically influenced and shaped by the individual's own ideological and cultural preferences. With decision theory, the only factor that can influence a choice other than the individual herself is an event that is beyond her control. So, for example, a city's mayor can decide to fund a particular project with federal dollars, but if the federal government decides not to allocate any dollars to that city, then the mayor must act on an "event" that is not within her control—-the event of not having federal dollars for the project.

According to rational choice theory, decision-makers are presumed to make wellreasoned choices. If choices are reasonable, the behavior of the decision-maker can make choices with sufficient accuracy to clarify and predict the strategies and consequences of her actions (cite).

Unfortunately, it is not always possible to determine if a decision is "logical" or "reasonable." What is reasonable for one person is not necessarily reasonable for another. Viewpoints and attitudes tend to be subjective and contingent upon a person's orientation and individual belief system. What is more problematic is that these viewpoints are sometimes reinforced by a person's personal or professional associations. When an individual surrounds himself with like-thinkers, his decision-making process is not likely to take into account individuals who hold differing viewpoints or offer competing advice. If a policy-making individual surrounds himself with only those who share his views, "logic" and "reason" can come to mean the beliefs, values and motivations of only that select group. 


\section{Internal Influences}

Steinmo (1992) believes that culture is an important determinant of decisionmaking, but that the context of a particular time is the most influential factor in establishing a definition of relevant "culture," Steinmo (1992) believes that a person's world view is shaped by a person's most recently significant life experiences, and not necessarily by those lessons learned in early childhood. For example, events like 9/11 or Hurricane Katrina can and do have a substantial impact on officials' policy-making processes. Analysts such as Steinmo argue that culture and a person's attitudes change according to the experiences and events in a person's life, rather than being unwaveringly dependent on lessons taught early on by parents and family.

When an official makes a decision that is based on her own sense of what is appropriate and best, but that decision is contrary to the values or desires of a particular sector of the citizenry, a divided public can result and the elected official is faced with the need to balance the interests of various groups and what she believes is appropriate. Whenever a democracy possesses a rich mixture of diverse and opposing viewpoints, the development of decisions amicable to all -- including to the elected officials who believe in the social significance of doing what they, themselves, view as "right thing" -- is difficult to achieve.

\section{External Influences}

The external influences on a mayor's decision-making processes are many: bureaucracies, constituents, media, interest groups, and action-channels all can affect a mayor's actions and decisions. Regardless of the decision to be made, it is almost certain 
that some external person or group will attempt to shape an outcome to his, her or its advantage. In other words, the relationships that are forged between the external influences and the mayors will help determine the behaviors and actions of a mayor's decision-making process.

\section{Bureaucracy}

Two important elements of a mayor's power are his appointment of important players to key positions and his direct or indirect control of the city budget and "purse strings.” A mayor can directly order budget cuts and he can reassign departmental responsibilities, which allows him to effectively both alter departmental budgets and to bestow or rescind powerful departmental positions. With such budgetary and bureaucratic powers in his hand, a mayor can exert substantial control over the behaviors and policies of a city's operating departments and the distribution of federal dollars -- ultimately impacting the decision-making process.

Another way mayors gain support for their decision and program allocations is through agent buy-in. This is frequently done with both monetary and non-monetary rewards. Like any elected officials, mayors tend to be more successful in controlling an organization if they can gain an agent's trust and support. Since agents become powerful specialists in knowing and running their organizations, and, therefore in implementing their organization's policy, their buy-in and support is imperative for the principal that seeks to control an organization and its actions. This buy-in is especially salient for mayors in their implementation of CDBG strategies and goals. By having a loyal organization that understands and supports a program's rules and regulations, and that 
has established solid bonds with agencies such as HUD, a mayor can increase the likelihood that his goals and objectives will be met. In other words, the shared values of the organization's actors can play a large role in determining the outcomes of a mayor's policy goals and objectives.

Regardless of the policy program, the elected official must understand the orientation and values of policy stakeholders in differing contexts. Notwithstanding the policy track, policies evolve and result from the beliefs and value systems of the community at a particular place and time. Whether a policy is influenced by peer support systems, deep core beliefs, special interest groups, politicians, or partisan politics, a policy maker must be cognizant of both the internal and external variables that influence policy.

Each time a new mayor assumes office, the elected official must make a decision about whether she can work with existing operators or should recruit new operators. Before a decision can be made, principals must identify those employees who are loyal or will become loyal to the organization. Otherwise, the behavior or actions of ambivalent or disloyal operators can sabotage or threaten an official's objectives. Assessing the way an operator interprets policy and behaves or will behave, however, can be difficult at best. The official must understand that she is dealing with a person's culture and belief system and that people tend to be resistant to change. Elected officials must also realize that they are dealing with organizational constraints such as civil service rules and regulations that can impact their ability to manage or shape the organization. However, through pecuniary and nonpecuniary rewards, and through an understanding of factors that affect a willingness (or unwillingness) to alter behavior, a principal can be successful 
in achieving a significant level of cooperation and compliance within a city's bureaucracy (Brehm and Gates 1997). The ability to understand the organizational rules and regulations, as well as the operator's behaviors, is salient for the elected officials so they can achieve the goals that are important to them. In the case of CDBG allocations, these goals include getting bureaucrats to fund "pet" projects and receiving credit from their constituency.

\section{Constituents}

Like all elected officials, a city's mayor and its council members understand that their constituents are the ultimate judge of their behavior and that these constituents participate in the political process in many ways. They participate through silence, they participate through groups, and they participate by running for elected office themselves. People who feel strongly about an issue can participate in the political process through interest groups, referenda and direct intervention. Elected officials understand that a constituent's decision to pursue a particular direction or action in the political process will have a profound impact on the way other constituents perceive and consequently involve themselves in the policy process.

In order to understand why a person or constituent participates the way she does, it is important to understand a person's belief systems, cultural influences, biases and attitudes. While personality characteristics are important determinants in understanding how a person participates in the political process, there are other determinative factors such as issue saliency, class divisions, state of the economy and the leadership qualities of competent and skillful bureaucrats. These considerations play an important role in 
determining who becomes involved in policy-making activities, and in how a person would choose to participate in the political and policy process.

A person's class background or social origins are essential elements in her decision to participate in the political process. These decisions are also influenced by a person's conscious or unconscious engagement with sociological and ideological perspectives. Jones (2001) argues that the sociological perspective recognizes that "no person is an island," and that groups, peers, and professional associations can influence and shape behavior (Jones 2001, 197). It follows, then, that a person's decision to participate in policy-making is at least somewhat dependent on the groups with which she identifies and associates. An ideological or cultural perspective contends that a person's choices are a reflection of her beliefs, and that these beliefs are formed during an individual's upbringing and cultural orientation. Thus, a person's decision about the nature of her participation in policy-making processes is influenced by a lifetime of experiencing the beliefs and actions of her family and cultural community.

Exercising the right to vote can be considered participation through silence. A person who votes may not be publicly vocal in her beliefs or may not directly participate in political or policy-making processes; rather she "silently" casts her vote, in this way acting on her values and making her beliefs "heard." In extreme cases, people will silently vote "with their feet"; a voter may be so concerned with local policies and elected leaders that she will physically relocate to another state or locality in "silent" protest of local policies and officials.

When a person participates through a group, she provides financial assistance to or joins a special interest group or organization that supports the person or policy she 
believes in or that works against what she considers to be an undesirable person or policy. Rather than "taking matters into her own hands," a person can support or join an interest group that has sufficient resources and members to sway the opinion of a political candidate or policy-maker. The collective voice of such a group sends a powerful message to lawmakers and politicians alike; thus political participation via contributing to or belonging to groups can have a significant effect on policy.

Referenda and direct intervention are other ways that the citizenry can participate in the political process. These tools allow an individual to question and change an existing policy that she perceives as being unfair. By seeking a change via referendum, an individual can participate in government in a powerful and meaningful way.

According to Kinder and Kiewiet's (1981) article on sociotropic politics, individuals participate in the political process based on how they are doing economically. This self-interest perspective is based on the overall state of the economy, from both a national and personal perspective of the economy as well as the overall prosperity of their family. In other words, individual's measure economic performance based on their personal situation coupled with national economic climate. Kinder and Kiewiet believe that individual's pursue this self-serving behavior since it is the most effective way that voter's can serve their best interests (Kinder and Kiewiet, 1981).

\section{Media}

Mayors are influenced by the media and the awareness levels raised by media practices and outlets. Media coverage has considerable power to raise the general public's awareness of particular issues at particular times. The media decides which stories to run, which stories to make a big deal about, and which stories to dwell upon 
(Powlick and Katz 1998). In other words, the media can be an extremely powerful external force in activating public opinion and shaping the policy conclusions that are reached by the general public and the mayors (Hermann, Tetlock and Visser 1999). As Baker and O'Neal (2001) point out, the media's power and influence cannot be discounted and can sometimes mislead the public to inaccurate conclusions. Since the press does not always have access to the same information that a mayor or elected officials do, the media might portray an issue or behavior in misleading and inaccurate ways. As a result, a mayor or other public official is sometimes forced to deal with the added burden of responding to a manipulated or factually misinformed public.

Conversely, the media can have a positive effect on a constituent's perception of an official, an issue or policy decision by bringing these issues to the public's attention.

With the advent of twenty-four hour news coverage, the Internet and other features of the information age, a mayor's decision-making processes and actions are available for scrutiny as never before. The results of such information availability can allow for undue media influence on politics, but such ease of access also allows for potentially increased citizen participation, "silent," or otherwise, in the political and policy-making processes.

Overall, the power of the media can have both positive and negative consequences for a mayor. On the plus side, the media can foster support for a mayor's policy decisions. On the negative side, the media can shape public attitudes that are hostile to the mayor's policy outcomes and goals. Whatever the repercussions, the media serves as a powerful tool that, by providing information in particular ways to the general public, can influence the decision-making choices of the mayor. 


\section{Interest Groups}

Interest group influence is yet another external influence that shapes the behavior of a mayor. Since some groups have vast financial resources or staffs that can gather important data or statistics, their power can, consequently, be substantial. By contributing large amounts of money or support to a legislator, a special interest group can have a profound impact on how that legislator makes and implements a policy decision.

Unfortunately, some stakeholders exert more influence than others. The politically powerful and financially secure interest groups, for example, tend to wield more influence in the policy-making process since their presence and visibility is high. Although there are several kinds of interest groups in the American political system (such as economic, social policy, public interest, labor unions, and ideologically based groups), interest groups have the power to influence public policy in many ways. When groups give money to a particular candidate, they hope to elect a person that is sympathetic to their cause. Interest groups, by contributing money or supporting a candidate, hope to gain better access to the candidates and organize lobbying efforts to persuade elected officials to support or oppose those issues that are important to them. As a result, mayors must be cognizant of these influences and powers.

\section{Action-Channels}

Action-channels "are decision-making processes which describe the participation of actors and their influences" (Krasner 1972). Action-channels describe the influences that drive an actor's decisions. For instance, understanding that major players within an 
organization, such as trusted advisors have the "ear" of the mayor allows the actionchannel to play a pivotal role in influencing an actor's decisions. In other words, an action-channel is an exchange between a bureaucrat, organization, or private person. This exchange can have a profound impact on a policy-making decision.

In the allocation of CDBG dollars, the action-channels could be affluent constituents demanding that federal benefits be used to further enhance their own neighborhoods. Knowing that these constituents are likely to offer financial and political support for future elections, mayors will be more inclined to pay close attention to the alleged needs of these constituents.

\section{Subsystems}

As the internal and external influences have shown, it is not enough to simply explain that a particular CDBG allocation decision was made. Rather we need to understand how and why a particular decision was made. Through the study of policy subsystems, legislators, administrative agencies and interest groups work behind the scenes to secure the adoption, protection and expansion of distributive programs and projects (Bickers and Stein, p. 589).

\section{Symbiotic Approach to the Distributive Politics Model}

\section{Symbiotic Approach}

There has been much criticism about pork barrel spending. Many people believe that federal tax dollars should be earmarked for national priorities such as Social Security or AIDS research. Locale-specific improvements, such as a bridge reconstruction project in West Virginia, offer little benefit to taxpayers in Iowa. Whether or not it is ethical and 
legitimate to use federal tax dollars for project-specific applications has been highly debated. Since elections turn on serving the needs and wants of the electorate, elected officials at the federal and local levels can be put to a difficult choice: allocate federal money toward legitimate federal and local social needs or allocate money to projects that increase the officials' visibility and favor among a particular group of voters. These choices are better explained through the application of a symbiotic approach - one that encourages officials and bureaucrats at the national and local level to satisfy each others needs.

According to Rich (1989), the distribution of federal monies is a two-way street in that the federal legislators give local bureaucrats flexibility in spending, and the local bureaucrats make certain that the federal legislators receive credit for enabling local projects. In this scenario, both the legislators and bureaucrats are benefiting from federal grant money -- local bureaucrats implement more projects and federal legislators claim credit for 'pushing' a grant award through the bureaucracy. In other words, legislators and national government leaders are content to allow recipient jurisdictions and their elected officials to pick and choose those individual projects they wish to fund as long as these legislators and national government leaders can claim credit for the many diverse projects funded with federal government dollars.

Rich's two-way street analogy can be extended to include the bureaucrats and elected officials at both the national and local levels. In this symbiotic scenario, the distribution of federal benefits is contingent upon a delicate balance among policy makers and elected officials at the national and local levels. At the national level, the elected decision-makers are the legislators. These principals help lobby for funding, help 
determine eligibility formulas and expedite award decisions. The bureaucratic officials (e.g., HUD) at the national level are charged with the responsibility of program implementation and oversight. At the local level, the elected decision-makers are the mayors and city-council members. Although these elected officials have geographically differing motivations, these actors have an interest in allocating or reallocating a portion of the total federal entitlement dollars to their "pet projects." At the bureaucratic level, the primary decision-makers are the bureaucrats or program administrators who administer and implement the federal allocations. These bureaucrats are more concerned with keeping their principals satisfied than with challenging the principals about where and how federal money should be spent, although those in bureaucratic positions often try to do what they perceive to be right (Golden 2000, 21) and to do the best that they can do (Lipsky 1980, 81). By playing the role of conciliator among their principals, bureaucrats "cope with their impossible jobs quite ingeniously and imaginatively" (Hargrove and Glidewell 1990, 4), while trying to maintain program autonomy, compliance and personal job security.

"When a program depends on so many actors, there are numerous possibilities for disagreement and delay" (Pressman and Wildavsky 1973, 102), resulting in disagreement and/or conflict in the administration of the national program. As Figure 1 indicates, the elected principals at the national-level will expedite award dollars through the federal bureaucracy in exchange for acknowledgement from the elected local-level officials. In turn, the elected local-level officials will provide program autonomy at the bureaucraticlevel providing they find a way to fund their "pet projects" with the federal dollars. The local-level officials at the bureaucratic level are eager to provide professional program 
management as long as the national-level bureaucrats relax the oversight process.

Finally, the national-level bureaucrats will strive to comply with the program's rules and regulations in the hopes that the elected national-level officials provide them with some autonomy in the administration of the program.

The distributive nature of this symbiotic approach "can be conceived of as a system in which each element is dependent on the other" (Pressman and Wildavsky 1973, xv). Only when all four levels (national-bureaucratic, national-elected, local-bureaucratic, and local-elected) are satisfied that their needs are being met can the elected officials and bureaucrats work in harmony. In short, a sense of trust and confidence in one another occurs when each level of elected official and bureaucrat does what the other desires. This symbiotic or mutually beneficial approach to distributive politics suggests that each programming level feeds off the other so that the distribution of federal monies can run smoothly.

\section{An Economic Model of Supply and Demand}

The symbiotic model in Figure 2.1 has many characteristics of an economic model with a supply and demand perspective. On the supply side, federal CDBG dollars are provided to entitlement cities in the form of grants. The federal legislature appropriates the monies with stipulated general guidelines and requirements and the entitlement cities determine how and for what purposes these grant dollars will be used. Despite the limitations placed on these federal dollars, eligible localities enjoy a high degree of flexibility and freedoms in allocating these monies. 
Another supply side determinant involves the level of professionalism involved in administering and implementing federal grants. Not all entitlement cities maintain the same resources, potential or expertise for grant management. This lack of parity creates vast inequities in obtaining grants, allowing some cities to seek grant dollars that others may not have the staff or expertise to pursue. Cities with a large tax base, are more inclined to hire professionally educated staffers that can assist in the grant procurement process. Such large tax bases and the resulting staffing opportunities are typically related to the size and wealth of a city.

The amount of discretion an entitlement community exerts in the grant allocation process is another supply side consideration. Because of the physical distance from the federal policy makers who set the general CDBG guidelines, recipient jurisdictions maintain a level of "freedoms" to develop specific projects that may or may not be in the intended spirit of the grant. Localities will use this "physical distance" consideration as a means of supporting projects that are deemed, by local politicians and administrators, to be most important to the recipient jurisdiction. If a city's grant administrators are proficient at reporting to and complying with the federal government, they are less inclined to be questioned on their spending activities. Entitlement cities that have a history of questionable reporting activities will, however, be monitored more closely.

From a demand side perspective, the federal government imposes certain expectations on recipient jurisdictions to which those jurisdictions are expected to adhere -- namely the ability to support and follow the rules and regulations of the federal grant. In essence, these expectations require "a relationship of mutual trust and obligation" 
Figure 2.1

Symbiotic Approach

to

Distributive Politics Theory

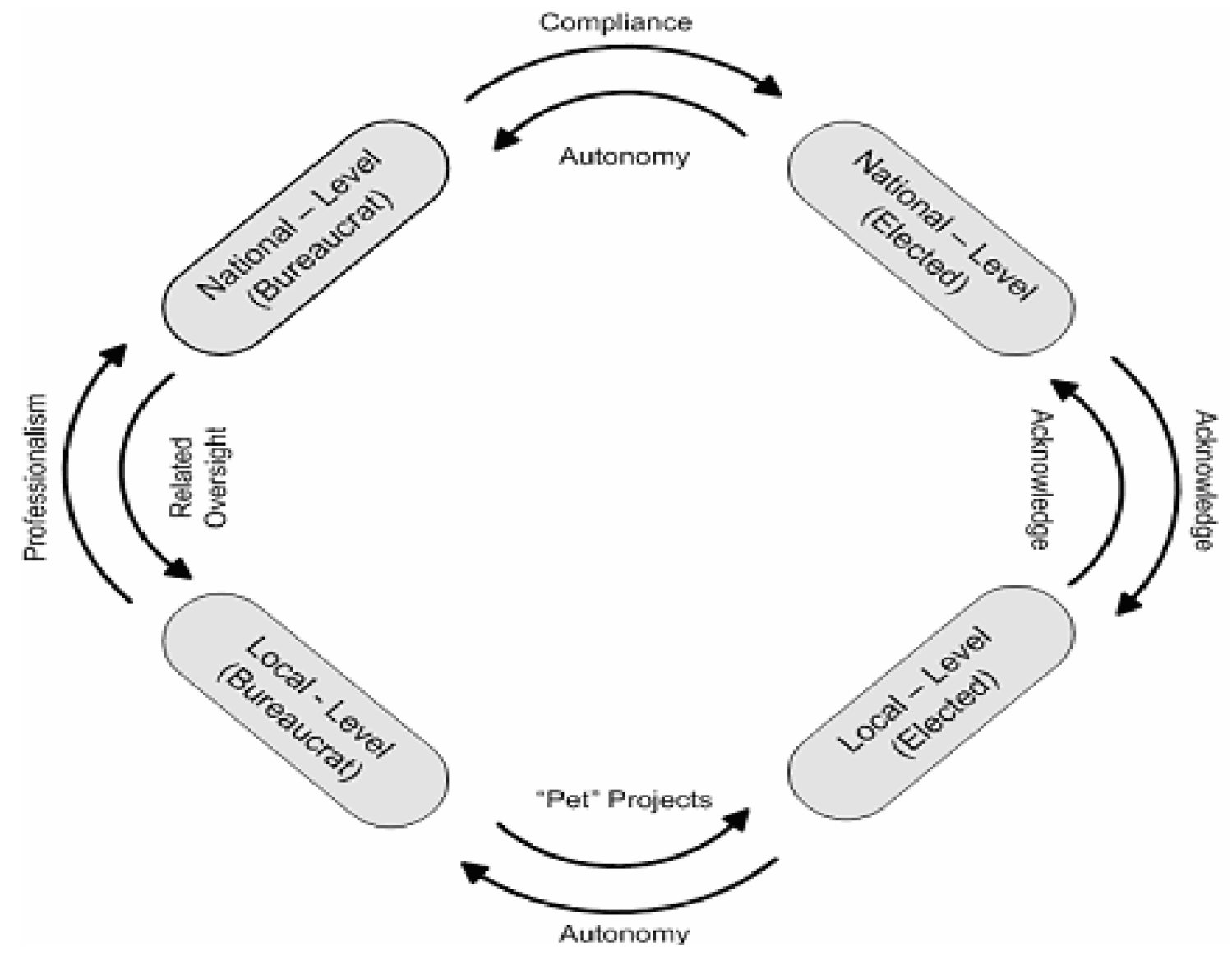


(Pitkin 1967, 129) and that local officials will distribute their appropriations in the spirit in which they were intended.

National legislators, namely members of Congress, maintain an expectation that they will be acknowledged or "receive credit" for their efforts to secure grant monies for their local constituents. Typically, elected officials at the local levels are more than happy to comply with this tacit expectation, providing that the national legislators do actually come through with CDBG monies for the localities. In fact, both federal and local elected officials frequently strive to be acknowledged for these federal outlays, but for different reasons: federal legislators want to gain national exposure for the projects they support; local politicians hope to garner ongoing voter approval and support for proposed and completed local improvement projects.

Being responsive to local interests and to the electorate is another demand side issue associated with federal CDBG allocations. Since elected officials at the national and local levels are continuously concerned with reelection (Mayhew 1979), they are extremely alert to the types of projects they might fund and extremely aware of the publicity that these projects generate. Demand side analysis shows, then, that the desire to make “good policy” stems from not only from politicians' and legislators' personal values and belief systems, but also from their political ambitions.

In sum, the relationship between the supply-demand model and the symbiotic model share many commonalities: flexibility, acknowledgement, and responsiveness. Grant dollars are allocated to the localities and the allocation decisions are made according to the capacity of that city to administer the grant effectively and efficiently. It is this lack of capacity, unfortunately, that differentiates the supply-demand model from 
the symbiotic model. With the symbiotic model, each entity is dependent upon the other for the successes and failures of a program. With the supply and demand model, the assumption that entities are dependent upon one another is not relevant. Therefore, the supply and demand model does not consider an organizations lack of professionalism or capacity administer a grant.

\section{National-Level Officials}

National legislators are rewarded, not punished, for allocating pork to cities (Kelly 1993). These rewards translate into high visibility among their legislative colleagues, in the media and among the general public. The distribution of federal benefits gives legislators a nonpartisan way to gain electoral support from their districts (Mayhew 1979). Distributive politics permits national legislators to pursue their selfinterested electoral goals with the tacit blessing of other legislators, regardless of benefit or differences (Bickers and Stein 1996). This school of thought holds that if any one member receives federal pork, then a majority of the members must receive pork too (Evans 1994).

Often referred to as universalism, legislators distribute benefits for purposes of securing credit and positive attention for themselves, without caring about who receives the federal monies they have facilitated and without ongoing concern for how these funds are used (Balla et al. 2002). The logic behind this broad-based support is that, as long as no one objects to the entire package, everyone benefits from his share of the "pie." These interactions of who gets what, when and how are central to the study of politics and decision-making. 
Even if federal pork is unevenly dispensed, legislators are not inclined to oppose its distribution since most localities receive some pork. Legislators believe that the goodwill realized by distributing federal benefits to specific localities not directly associated with them will yield residual effects that may be even more important to the legislators' visibility and reputation (Fenno 1978), is better to support and receive some distribution rather than opposing all pork benefits and risk the possibility of receiving no distribution (Evans 1994). One notable exception to this laissez-faire attitude is the infamous 'bridge to nowhere' controversy in Ketchikan, Alaska. This \$200 million dollar, federally funded double span bridge, rising more than 200 feet above ocean level, will be built to serve a small island with an average population of 50 residents. Despite Republican Don Young's argument that this project will create significant economic development and employment opportunities for the region, there has been extensive criticism of this 'pork' project from the legislators and electorate alike.

Weingast offers an example of how federal monies used for one locale can be of benefit to other constituencies and areas (Weingast 1994). Weingast explains that a $\$ 10$ million dollar dam project can assist multiple communities. The construction and site can help one city, while the agricultural benefits and environmental interests are beneficial to another locale. Likewise, a highway project in Pennsylvania will indirectly assist the trucking industry in West Virginia by providing better roads and easier access to certain destinations. Because these benefits affect multiple districts or communities, and since the monies to pay for these benefits are provided by national, rather than local, taxes, there tends to be minimal opposition at both the federal and local levels. 
Unfortunately, not all pork can be divided or distributed in ways that benefit communities and constituencies outside an immediate recipient area. As a result, there is a concern that federal allocations will be distributed to high profile areas or highly competitive districts where legitimate challengers could pose a threat. Therefore, strategic allocation decisions must be made to determine which communities are to receive the lion's share of federal benefits and which communities receive the indirect benefits of the distribution.

Because distributive benefits are so closely tied to a local official's electoral interests, legislators tend to allocate federal dollars to localities for projects that are doable within an electoral cycle. Legislators intentionally fund projects for the shortterm so that they can claim credit every benefit every time money is awarded. In other words, a $\$ 40$ million dollar bridge project can foster a huge amount of support and visibility, but once the publicity and "hoopla" is over, the legislator will begin searching for and facilitating the next pork project for which he can claim credit.

Beside the electoral concerns, a federal legislator will frequently commit federal monies to smaller projects in case the need arises for shifting support from one local project or official to another. In the event the national legislator decides to change her support, the legislator has federal pork dollars available to fund other projects. In short, a legislator does not want to commit to a large allocation unless she is confident that the recipient jurisdiction and local elected official will significantly contribute to her winning reelection (Bickers and Stein 1996).

National legislators often allocate federal grants to reward local officials for their past support. This support is necessary to achieve recognition and publicity for the 
national legislator's hard work on behalf of a local populace and to further a legislator's personal agenda or the agenda of the President. When federal monies or pork are allocated to the localities for the projects and programs that directly benefit local officials, local officials are less inclined to resist those programs that are most important to the national legislators.

Federal legislators also have the capacity and power to expedite reward requests, and are likely to do so when such expedition coincides with a local official's election process. Using their extensive personal and professional contacts and their ability to efficiently navigate federal bureaucracies, national leaders will sometimes accelerate or delay federal grant announcement so that their political colleagues at the local level can benefit. Put another way, in exchange for support of a legislator's personal agenda, she may strategically schedule a benefit or "pork" award to assist a local elected official's reelection campaign (Evans 2004).

\section{Local-Level Officials}

For local elected officials, federal benefits represent a means to satisfy campaign promises, achieve visibility, obtain constituent support and get reelected, all without raising local taxes or tapping local coffers. The structure of grants such as the federal Community Development Block Grants (CDBG) allows local officials to apply federal monies to a variety of projects deemed useful by those local elected officials. Projects located in more affluent neighborhoods where voters tend to be politically active are at least as likely to be funded as projects in high-need, low-income neighborhoods. More affluent, active, visible voters may be involved in high-powered interest groups that want infrastructure or other indirect benefits for their neighborhoods. Whatever the reason, 
local officials understand that by satisfying the needs of the special interests and community groups, they can continue to allocate the majority of the federal grant money to those projects that the local officials consider appropriate within the spirit of the federal distribution limits. By studying the politics involved in making decision, it is possible to gain a better understanding of the distribution of power within a locality or organization. A detailed examination of how and why elected local leaders distribute federal dollars and make funding decisions will be discussed in the next chapter.

\section{Bureaucratic-Level Officials (National \& Local)}

At the bureaucratic-level, the bureaucrat is responsible for the administration and implementation of the federal benefits. Specifically, she manages the administration of the federal dollars, including contract management, labor compliance and fiscal operations; develops and implements approved policies, goals and priorities for the allocation of funds; oversees grant sub-recipient application processing and eligibility determinations; and oversees the federal auditing process ("Community Development Program Supervisor Job Description" 1995). As an agent for the mayor and city-council, the bureaucrat must mediate and undertake the very difficult requirements of distributing the federal dollars while balancing the demands of political and elected leaders, supervisors, the citizenry, and the needs and desires of interest groups. In other words, given the scope of the bureaucrat's job and the various offices and people she must satisfy, it becomes nearly impossible for her to successfully act upon all demands and intentions (Hargrove and Glidewell 1990). 
To successfully satisfy the demands of their jobs, the bureaucrats must make decisions that are consistent with their values and beliefs while being sensitive and responsive to the needs of their bosses, while being sensitive to the politics of the organization and decision-making groups of the locality. Having the flexibility to make their own decisions can have an impact on the officials to whom they report. As Lipsky explains, "it is the discretionary role of street-level bureaucrats and their position as de facto policymakers that critically affect managers' dependence upon their subordinates" Lipsky 1980, 24). These de facto policies can and do determine the nature and level of exposure or publicity the national and local-level elected officials obtain.

Monitoring bureaucratic performance through executive oversight is difficult to manage for a host of reasons, ranging from the size of the local agency involved to the quality and professionalism of personnel at the federal oversight agency. In the CDBG context, the federal agency with oversight responsibility is the Department of Housing and Urban Development (HUD). HUD may have difficulty monitoring large cities that receive fifty million entitlement dollars, for example, because of the quantity of programs and projects funded. To thoroughly audit each and every federally-funded project would be too cumbersome and inefficient for the federal auditor. As a result, cities must be trusted to "do the right thing" and spend the federal dollars in accordance with their intended purposes (Kettl 1980).

To maintain control and oversight of local spending, federal officials have come to rely upon "whistle blowers" to keep them informed about a recipient city's activities. Known as "fire alarms," elected officials rely on interest groups, lobbyists and program recipients to keep tabs on agency activities (Mitnick 1984, 15). Elected officials know 
that these "agency watchdogs" will not hesitate to report improprieties to the appropriate body should a perceived conflict occur. In other words, interest groups, active community organizations and citizens alike are used to monitor an agency's activities. This practice allows HUD and local-level officials to concentrate on tasks (such as the administration of the CDBG program or dealing with constituents) more immediately important to their function while keeping their bureaucratic agencies and associated support staff accountable. Without these "fire alarm" safeguards, the officials at the national and local-level would be far less aware of agents' behaviors and would be forced to rely upon the perceptions or preferences of their own support staff for assessment of agencies' integrity and effectiveness.

\section{Elections and Incumbency}

Incumbents for political office at the national and local levels have distinct advantages over their opponents in their ability to manipulate the federal dollars that are made available to them. With the ultimate goal of reelection in mind (Mayhew 1979), distributive benefits are sometimes offered to local officials because of their potential for high visibility and popular projects, and are frequently awarded to entitlement communities just before a local official's reelection bid (Stein 1996). This timing is not coincidental. Election years usually translate into an increase in the distribution of federal dollars or pork that is sometimes used as a tool to help the incumbent candidate at the local level win reelection. This is done by announcing grant awards immediately before an election, speeding up the processing of grant applications and by recognizing the local official for her hard work in securing the federal benefit (Anagnoson 1982). 
Incumbent candidates at both the national and local levels hope that the residual effects of distributed benefits will leave their constituents with an overall positive impression of their hard work and dedication. The goal, according to Tufte (1978), is that the positive feelings of the general public towards the incumbent's distribution of these federal dollars will translate into votes and, ultimately, reelection. Besides the obvious advantages of being an incumbent seeking reelection, such as franking privileges, size of staff and visible community activities, incumbents have the use of federal dollars to boost their image and popularity among their constituencies. The initiation and completion of high-profile projects, financed via federal pork barrel dollars, increase the probability that local officials will be successful in future elections (Bickers and Stein 1996). On the other hand, if a national legislator believes that an incumbent official at the local level is so behind in the polls or is so irreparably involved in controversy that a reelection victory is uncertain, then a reduction of pork may result. Because national legislators want to be associated with successful local candidates and since national legislators want to back local-level officials who will support their goals and objectives, a national legislator may ut her losses if she perceives the incumbent to be losing popularity and appeal among her constituents.

\section{Interest Groups Influences}

The influence of interest groups on the symbiotic model is shaped by the sheer number of special interests. Because of the sheer volume of interest groups, the impact on the symbiotic model can be minimal. Legislators no longer feel obligated to one particular group since they do not represent a large block of support and no longer pose a 
viable threat to a politician's job security. Therefore the consensus among legislators is that they will not be held hostage or intimidated into supporting a particular piece of legislation (Lowery and Gray 1995).

On the other hand, the power of money can play a large role in influencing an official's decisions. An interest group with strong financial resources can lobby independently, and does not need to negotiate with association members or partners, but can deliver its own undiluted message to legislators. Interest groups with fewer resources may be compelled to share the costs of retaining a lobbyist and may have to compromise their positions to achieve a shared lobbying agenda. If competing interest groups share the same lobbyist, then each group's position may become compromised.

The influence or lack of influence of an interest group shapes the preferences of local-level elected officials due to economic, political and social reasons. Economic based on the wealth of the interest group, political due to the clout and influence of a group and social related to a group's inherent value and belief systems.

\section{Expanding the Distributive Politics Model and Demand-Side Explanation}

Although the current literature on the distributive politics model and demand-side explanation in the allocation of federal grant dollars might help explain how and why local officials distribute federal dollars as they do, it fails to address a host of other factors that also influence these decisions. This study will examine a number of these influences including the motivation and behavior of mayors, as well as the contextual factors -- including the size of city, form of government, wealth of city, geographical region, political affiliation of administration and incumbency -- in an effort to better explain allocation decisions made by mayors. In other words, policy makers or scholars 
know a great deal about the "supply-side" of grants as a way of alleviating potential inequities in the allocation process, but know far less about the "demand-side" in the administration, implementation and evaluation of federal aid monies (Stein 1981). These "demand-side" concerns are shaped by the context in which they occur, for both present and future exchanges in the allocation process.

As a case study to illustrate the efficacy of these contextual factors in explaining allocation decisions, this research will examine the CDBG program, a federal program that supports state and municipal programs and projects. The federal CDBG program serves as an excellent vehicle for testing an expanded distributive politics model and demand-side explanation for two reasons. First, as long as a city meets the population requirement, it will be eligible for federal CDBG monies with very few qualifications or

requirements. Basically, the federal government devolves CDBG funds to state and local governments irrespective of a locale's tax basis, geographic region or community politics. Given the general availability of CDBG monies and the enormous flexibility cities enjoy in distributing these funds, this program provides an excellent opportunity to study how and why government benefits are allocated. Second, the federal government maintains detailed data on the CDBG program, which permits careful analysis of the role that the contextual factors play in the allocation of federal dollars.

\section{Conclusion}

To say that decisions are made unilaterally and that the decision-making process is not affected by both internal and external factors would be to underestimate the complexity of decision-making and to dismiss the importance of the many internal and external variables that help predict outcomes. Whatever the apparent strengths or powers 
of elected officials, for these people to be truly effective, there must be a shared understanding between them and all the players who influence them. In other words, special interests, media, and the general public can, in many ways and in many

combinations, play significant roles in the decisions that may, on the surface, appear to be produced by the elected officials themselves.

By examining the how federal dollars are allocated to the localities, specifically the "demand-side" perspective where the social and financial considerations are taken into account, will help explain variation in the way cities distribute CDBG monies. Put another way, this study will identify a linkage between the motivations of mayors, the political implications of decision-making, as well as the social and financial implications of allocating federal aid monies, in an effort to predict how and why CDBG allocations are decided. 


\section{Chapter Three}

\section{The Community Development Block Grant (CDBG) Program}

\section{Introduction}

On August 22, 1974, President Gerald Ford signed into law the Housing and Community Development Act of 1974, which consolidated into one comprehensive program, the Community Development Block Grant Program (CDBG), seven preexisting categorical grants, including urban renewal, model cities, housing code enforcement, neighborhood facilities, water and sewer development, and historical preservation (Dilger 1989). Currently, more than $\$ 5$ billion annually (U.S. Department of Housing and Urban Development 2003) in federal dollars is distributed nationwide through CDBG, with the majority of these dollars allocated through the use of a formula system (Dommel 1980). The program's goals are to expand economic opportunities, improve the overall living conditions and address specific areas of need, particularly for those of low and moderate income ("Code of Federal Regulations" 2003). At the time of its creation, the CDBG program was seen as an important part of a new federalism that was sweeping the nation as various significant powers were shifted from the federal government to the local communities (Rich 1993). The CDBG program continues to evince the federal government's genuine commitment to cities and neighborhoods, and the program enjoys bipartisan support from Congress.

The CDBG program evolved from the Kennedy administration's commitment to the War on Poverty or Model Cities program. The CDBG program was designed to allow decision-makers at the local level, who are inherently more knowledgeable about and responsive to their community's needs than is the national government (Pratt Institute 
Center for Community and Environmental Development 2001), the flexibility to finance projects that are more consistent with the community's needs. This "hands off" approach gave more discretion and power to the local governments in the allocation and spending of federal community improvement dollars (Nathan 1983).

The CDBG program established a shift or devolution of the control of resources from the federal government to the cities' administrators and office-holders. Previously, Congress or federal agencies made categorical grants available to local governments on a project-by-project basis, giving the federal bureaucracy much more power and control in the project approval process and ensuring that local governments used federal dollars consistent with the federal agencies' priorities and directives (Dilger 1989). Under $\mathrm{CDBG}$, the rigid guidelines regarding project type, implementation and assessment imposed by the federal government on localities were loosened, and the project-byproject approval process was no longer required. As long as the CDBG guidelines were met, cities could implement the projects and programs of their choice. The CDBG program, then, allowed those officials who lived in a community to determine the community's most pressing needs. The shift from federal to local decision-making also reflected the belief that local officials could and should be more accountable for the actual uses of federal monies granted to communities. This heightened local accountability brought local officials, in turn, to suggest that since the public held them accountable for their project selections at election time, they should play a larger role in deciding which projects would be implemented (Kettl 1980). 


\section{HUD Regulations}

According to the Department of Housing and Urban Development (HUD), CDBG monies can be used for a variety of projects to improve housing, public buildings, green spaces, transportation and job opportunities. Projects ranging from street resurfacing to playground rehabilitation to workforce training are eligible for federal dollars. Unfortunately, as accountability has shifted to the served localities, guidelines for expenditures and assessment have evolved into vague or ambiguous criteria or standards that allow local officials to increase their own power without necessarily "expanding economic opportunities, improving the overall living conditions and addressing specific areas of need, particularly for those of low and moderate income" (Consolidated Community Development Plan for the City of Pittsburgh 2002). CDBG funds are sometimes spent throughout an entire community, rather than in those areas of greatest immediate need. It is not unheard of for a city to use CDBG monies to construct a marina or tennis courts in an affluent neighborhood (Kettl 1980), while roads, bridges, or substandard public areas, especially in low-income neighborhoods, remain unimproved.

Because the program guidelines are so flexible, program administrators who report to, for instance, the mayor of a municipality have immense freedom to fund whichever projects they want that will reflect well on the mayor. These grants allow elected local leaders, such as mayors, to boast about community improvements that did not require any local tax dollars. The flexibility that allows CDBG monies to be well used by knowledgeable officials for genuine and immediate local needs can also allow for problematic appropriation of funds by officials who want to secure power via their freedom to address the desires of various influential constituencies. Therefore, it is 
important to question the distributive policies of the CDBG program at the local level to see if the program goals, as defined by HUD, are being met consistently over time, both legally and in spirit.

According to CDBG regulations promulgated by HUD, if an affluent neighborhood borders a low to moderate-income community, then the poorer community can benefit from an improvement in the affluent neighborhood (Code of Federal Regulations 2003). The rationale is that the residents of the poorer community can take advantage of the improvement in the affluent neighborhood. Under these circumstances, an expenditure in an affluent neighborhood may well be considered permissible under CDBG guidelines. The final result of these improvements is that the affluent community is pleased to be getting a glitzy new facility and the poorer community is happy to have access to such a facility within walking distance. It could be argued, though, that if the CDBG regulations were written more tightly, then the glitzy new facility would have been located in the low-to-moderate-income neighborhood. The improvement would then have been in a neighborhood with more direct need, and the more affluent neighborhood's constituents could easily partake of the improvement by walking to it from their own neighborhood. As CDBG guidelines currently exist, however, a poorer community can, without its own direct, in-neighborhood benefit, serve as a catalyst or justification for the improvement to an already well served, affluent neighborhood.

Given that such funding situations exist, there has been much criticism regarding the inequitable distribution of CDBG funds and the siphoning of monies intended for the poorer neighborhoods. "Watchdog" groups believe that giving the cities the discretion to administer and implement CDBG monies can lead to questionable project decisions. 
"Opponents have argued that, in many localities, the strong hand of federal authority in the administration of the categorical programs was the only thing that kept these funds targeted to the needs of low-income and minority communities" (Pratt Institute Center for Community and Environmental Development 2001). Opponents of CDBG believe that the devolution of the monies to the local level invites abuse and misuse of the monies (Kettl 1980). Further, opponents believe that the intended recipients of these monies do not have the political influence needed to ensure that the monies are spent consistent with the intended purposes of the federal grant dollars (Rich 1993). Although difficult to test because of the subjective nature of this assertion, it is possible to look at the individual projects funded in a locality and correlate it with the percentage of people living in poverty, per capita income and unemployment rates for a particular city. If more CDBG dollars are being allocated to city-wide projects as opposed to targeted, specific projects in low and moderate income neighborhoods, than it is reasonable to conclude that poorer people in poorer neighborhoods do not exert the same political influence as more affluent people in wealthier neighborhoods.

\section{Program Eligibility}

The federal government is charged with the responsibility of determining how CDBG benefits are to be awarded, how they will be distributed and who does the distributing. Decisions regarding grant management and administration, program accountability, and which body of government should determine how benefits are distributed can be difficult. As with any federal grant-in-aid program, there are four generally agreed upon principles that need to be addressed when designing a program: 
(1) fairness to ensure that monies are allocated appropriately, (2) cost to ensure that program goals are affordable and attainable, (3) necessity to ensure that a true crisis exists and (4) capacity to ensure that the government has the ability to execute a benefit program efficiently and effectively (Rich 1993).

To deal with these principles effectively, the federal government initiated a formula method of distributing CDBG benefit dollars to the cities. The formula for determining the eligibility of a local community is based on three factors using the most recent census data. The formula weighs the "size of the population (weighted at .25), number of persons in poverty (weighted at .50), and the number of overcrowded housing units (weighted at .25)" (NCDA Washington Report 2002). By providing these weights, the formula determines how much money each individual locality receives (Nathan et al. 1995). In other words, funding differences are strictly tied to the demographic of a community and does not change according to a cities electoral, political or economic circumstances.

By using census data, HUD can make the necessary calculations to determine eligibility. This formula is designed to distribute monies to cities and communities based on their needs, not on partisan politics. For a city or community to receive CDBG funds, the CDBG program regulations mandate that 70 percent of any entitlement community's funds directly benefit the target population of low and moderate-income residents ("Code of Federal Regulations" 2003). According to HUD, low and moderate-income communities are defined as communities whose members earn less than 80 percent of the average income for the particular city. HUD does not compare the average income to other cities, since the inter-city differences can be significant. 
The CDBG regulations promulgated by HUD permit 30 percent of the CDBG monies to be spent outside low and moderate-income neighborhoods as long as the target population will benefit from the expenditure, at least indirectly. Neighborhoods are defined as geographically localized community census track within a larger city ("Code of Federal Regulations" 2003). As noted earlier, this 30 percent provision allows for CDBG monies to be spent in affluent neighborhoods, though, as also noted previously, the rationale and effect of such an allowance continues to be seriously questioned.

Although there is some support from neighborhood organizations, public interest and civil rights groups regarding the distribution of CDBG monies outside low and moderate-income neighborhoods, there has been much criticism regarding the inequitable distribution of CDBG funds and the siphoning of monies designated for the poorer neighborhoods (Dommel 1980). Because of this, many people believe that giving the cities the discretion to administer and implement CDBG monies can lead to questionable project decisions. "Opponents argued that, in many localities, the strong hand of federal authority in the administration of the categorical programs was the only thing that kept these funds targeted to the needs of low-income and minority communities" (Pratt Institute Center for Community and Environmental Development 2001). Opponents believe that the devolution of the monies to the local level invites abuse and misuse of the monies. Further, opponents believe that the intended recipients of these monies do not have the political influence needed to ensure that the monies are spent in compliance with federal mandates (Kettl 1980). 


\section{Devolution from Federal Government to the Cities}

The CDBG program provides for the devolution of funds from the federal government to the local governments. This transfer of funds gives the cities, and the elected officials that have decision-making authority, huge discretion and power over how these monies are allocated and distributed (Nathan et al. 1977). As a result of this transfer of power to the cities, city planners and administrative personnel have been able to play a greater role in the distribution of these federal grant dollars. This power transfer has led to the creation of professional bureaucrats who are skilled in the art of grantsmanship. These individuals are experts in understanding a grant's rules and regulations as well as in the reporting of grant-related activities. As localities became eligible for and began to receive large shares of federal dollars, these professional grant specialists became increasingly powerful and important (Nathan 1983).

Fortunately, HUD structured the CDBG program to offset the possibility of absolute power of certain individuals within the entitlement community by including citizen participation. Although HUD has given its grant recipients some loosely written rules in choosing projects and disbursing funds, there is a protocol that all recipient localities must follow before it can formally select the projects and programs that are funded by CDBG monies. Each year, a draft plan listing the proposed CDBG funded projects and improvements are compiled for distribution to the community for public review. After a set number of days, the public is invited to submit oral and written comments to the Community Development program supervisor expressing opposition to or support for the projects. Once all these comments have been received and reviewed, a public hearing is scheduled to openly discuss the community's recommendations and 
responses to the proposed projects. After the public hearings take place, City Council votes to accept or reject the projects. Council then forwards a recommendation to the mayor for her veto or approval. Although the relationship between mayor and Council is not always harmonious, this system of funding approval does provide some level of

checks and balances. Irrespective of the relationship, final funding decisions lie with the mayor, who has the power to overturn Council recommendations or rejections.

To what extent does citizen participation influence city officials in their decisionmaking processes? The answer to this question is not straightforward since the power of individual neighborhood groups varies. According to Nathan, Dommel, Liebschutz and Morris (1977), senior citizens tend to exert the most influence on community officials, while organized citizen advisory groups, for example, exhibit the least influence. This is because senior citizens vote, active in government and are often more in touch with the needs of the community, while the organized groups such as the American Automobile Association (AAA) or League of Women Voters are more concerned with being heard and promoting their groups image rather than effectuating change.

\section{Advantages of Devolution to the Cities}

Weber and Brace (1999) argue that devolution of governmental authority from the federal government to the cities has its advantages and disadvantages. One of the biggest advantages of devolution is that when it occurs, the size of the national government can be reduced. Devolution of programs to the localities means that the federal government does not have to set up an agency, develop a budget, hire personnel, administer and implement the program. Rather, the local governments receiving the monies are 
responsible for managing the programs, all without the national government's day-to-day involvement. To guarantee that programs are being administered properly and in accordance with the national government's objectives, however, the federal government does need to institute guidelines and auditing mechanisms to oversee the programs' progression, but it is much easier for the federal government to monitor and oversee a program administered elsewhere than to manage and implement a program on its own.

Weber and Brace (1999) also posit that localities are better equipped than the federal government to administer various programs since localities are more efficient at implementation. This efficiency is due to the localities' smaller size and capacity to focus efforts on the goals and objectives of the program. Unlike the federal government, which is probably managing a program from the Washington, D.C. area, a locality that implements a program will have a better "feel" for the needs of those who should benefit from the program.

Local governments have a greater interest than does the federal government in seeing that a government program, such as CDBG, succeeds, since local governments are likely to be more immediately accountable to the local public. If a mistake or mismanagement occurs in a program that is administered by the federal government, it is hard for the constituents of a recipient jurisdiction to hold a bureaucrat from Washington, D.C. responsible for the mishap. If, however, a program mistake or program mismanagement takes place at the local level, then it is easier for the local constituency to require accountability and rectification from the local bureaucrats and elected leaders who run the program. 
Last, but certainly not least, localities that manage and administer their own programs have more flexibility in administering their own program requirements and guidelines. This ability for local management flexibility is important because local officials are likely to know best what local citizens need. By giving local governments more discretion and power in the administration of a program, localities can modify a program's requirements if it is not obtaining the desired outcomes.

\section{Disadvantages of Devolution to the Cities}

Opposition to the devolution of government authority to the cities stems from a basic mistrust of the ideological, political and economic behavior of the state. Concerned that devolution of authority will lead to disingenuous appropriations of the federal benefit, opponents of local grant administration and assessment claim that only the national government can and should maintain control of significant federal community improvement monies.

Giving localities the ability to manage and administer federal programs, like CDBG, can influence the electorate's perspective on local politicians. If a program is highly successful, then the local politicians can claim credit for its success and use it to their political advantage. In other words, the devolution of power to the localities can give local politicians greater visibility and recognition for doing a good job, all with monies provided by the national government. Not only, then, can federal monies be potentially misused by visibility-seeking local officials, but, the national leaders who lobby for a particular program may receive negative publicity from an ill-gotten program.

Another disadvantage of devolution of authority to the local level is the potential for a misapplication of funds. If a locality sets a program's guidelines to benefit sectors 
of the citizenry other than those for which the money, at the federal level, was intended, then those federal funds are being misapplied. Despite the fact that auditing procedures may exist to control such problems, when a locality has enormous latitude in administering a program, there may be little that the national government can do to control exactly how funds are used. As a result, a program's federal dollars are sometimes accounted for by the locality in technically legitimate ways, even when those funds have not been applied according to the intended spirit of the program.

\section{The Spirit of Cooperation}

Elazar (1993) has said that our society is not just about the federal government telling the states and localities what to do. Rather, we have a cooperative relationship among federal and state and local governments. This cooperative relationship allows both the states and localities and the national government to achieve their goals. In Elazar's opinion, the allocation of money and of authority is not about devolution; rather it is about cooperation.

This cooperative viewpoint can be extended to the entitlement cities that receive federal grant dollars. Although there are very significant advantages to having the localities assume more authority and responsibility, the reality is such that recipient jurisdictions need to be watched and held accountable for their behaviors. While it is true that devolution allows localities to exert more authority and, because of greater visibility with the electorate, be more accountable, cities cannot always be trusted to spend federal dollars according to the rules and regulations as set forth by national government. Therefore, a sound argument can be made that even as local decision-making has many 
advantages, the national government must always stay involved to oversee and ensure that national interests are being met. Devolution of authority from the federal to the state and/or local levels may have many desirable results, but many public policy analysts posit that limited devolution of authority is the most workable option for consistently and responsibly serving national interests (Dilger 1989).

The most effective use of federal monies is most likely to be maintained when, even with significant devolution (or cooperation), the federal funding agencies construct and impose general rules and guidelines about how federal monies can be spent and determine what ultimate goals and objectives must be reached. In other words, political scientists such as Dilger advocate that the federal government should retain the upper hand, and when push comes to shove, the federal government should act as the senior partner in an otherwise equal relationship. This senior partner status assures the federal government that authority is being used appropriately and that federal priorities are met. This control, though limited, is maintained since the national elected officials are interested in receiving credit for the monies allocated and will always want a role in determining where grant dollars will go. After all, they will want to claim-credit for the projects that get funded.

\section{Why CDBG?}

The CDBG program serves as an exceptional tool to test the distributive politics model and the distribution of public benefits. CDBG benefits are distributed to the cities with few qualifications. In order for a city to receive CDBG funding from the federal government, it must have a minimum population of 50,000 (CDBG Entitlement Program 
Regulations 1996). (Cities with less than 50,000 are sometimes eligible for discretionary funds as approved by HUD.) Other than the formula, which includes poverty rate and housing requirements, a CDBG award does not depend upon a locality's overall financial or economic situation. Although an award amount might vary according to a city's level of poverty and suitable housing, the fact remains that any metropolitan city with a population of at least 50,000 people is eligible to receive some CDBG funding regardless of its financial well-being. In other words, an affluent city in Connecticut with a per capita income of twice the national average can apply for and receive grant dollars as can a West Virginia city with a per capita income well below the national average. Additionally, funding awards are not based on political partisanship. Therefore, a city with a Republican mayor who was a major supporter of a Republican president or Senator or Congressional Representative is not more likely to receive additional CDBG dollars because of this affiliation.

Formula changes, that determine how much money an entitlement city is to receive, can fluctuate from administration to administration. Although the CDBG program enjoys bipartisan support, it is not uncommon to see small and frequent changes in its eligibility formula. As recently as 2005 , for example, formula changes were made that resulted in an overall reduction of money for the localities. The reason for the formula change is unclear, and the Bush administration would not be specific as to the reason, other than to say that it was to increase accountability and responsibility at the local-level.

According to CDBG guidelines, entitlement communities are charged with the responsibility of developing their own programs and funding priorities. They are 
required to have citizen participation in programming selections, to draw down funds appropriately and to follow the proper procedures in the administration and execution of legitimate programs (Rich 1993). Provided that these programs directly or indirectly benefit low and moderate-income residents, a city and its elected officials can allocate monies to a variety of projects, ranging from the construction of public facilities and streets to the purchase and acquisition of real property. In other words, provided that cities administer the CDBG program properly, elected officials at the local levels enjoy immense freedom in spending the entitlement dollars. Because of this flexibility, it is not unusual to see spending in public improvement and economic development programs vary drastically from city to city.

Finally, the availability of accurate and detailed data is yet another reason why the federal CDBG program is an excellent vehicle for testing the effectiveness of the distributive politics model. For the three most recent calendar years, HUD has maintained data on the programs and projects proposed by each entitlement city by category type, including acquisition, administrative and planning, economic development, housing, public improvements, and public services. These categories allow each CDBG entitlement city to report its proposed allocations and projects in an uniform format. This standardized reporting requirement permits an easy comparison of spending habits and program allocations for each CDBG entitlement city. Table 3.1, which provides a more detailed breakdown of the allocation activities reported by HUD, describes the standardized format and program categories for each CDBG entitlement city. Of the six program categories described in Table 3.1, the economic development, housing and public services categories are likely to benefit the poor and disenfranchised. It is these 
categories that provide opportunities for elected officials to manipulate CDBG allocations.

\section{Conclusion}

By studying CDBG, a more sophisticated distributive politics framework that better explains the motivations and behaviors of elected officials will be developed. This framework will demonstrate that decision-makers allocate public dollars based on the political, economic and social environment around them. Expanding the traditional distributive politics model to include a thorough understanding of the saliency and role of contextual factors will result in easier and more reliable predictions about how public benefits are likely to be allocated.

These contextual factors may help the political scientist develop a matrix or schema that can accurately reflect and predict a pattern of behavior and decisions. These behaviors, for example, may stem from the way a mayor sees her role in the community, how she perceives the economic well-being of her community, how she assesses the needs and wants of her political counterparts she serves. Ultimately, these factors will prove instrumental in predicting the way mayors or elected officials distribute CDBG benefits.

The next chapter, through the use of a case study approach, will examine four Pennsylvania cities and their decision-making processes in the allocation of CDBG dollars. Specifically, CDBG allocations for each city will be examined and explained by looking at a mayor's motivations and influences, form of government, partisanship, size 
of city, the strategies in dealing with and appeasing their city-council, coupled with the potential threat of viable challengers to unseat them when reelection time occurs. 


\section{Table 3.1}

\section{Grantee Use of CDBG Funds by Category}

Acquisition - This category allows for the acquisition of real estate for public purposes only. Permissible expenses include the costs associated with relocating an existing business, demolition, and site improvement.

Administrative and Planning - This category allows for the reasonable costs associated with the design, development, implementation and evaluation of overall program management. Permissible expenses include salaries, wages, and related costs associated with the administration of the program. Environmental studies, area neighborhood plans, and budget preparation are allowable costs covered by this category.

Economic Development - This category allows for the direct financial assistance to private, for-profit entities providing that these businesses create or retain jobs and benefit low and moderate-income persons. Permissible expenses include the acquisition, construction and rehabilitation of commercial and industrial buildings. Loans, loan guarantees and equipment purchases are also acceptable.

Housing - This category allows for the construction and rehabilitation of permanent housing of single-family and multi-family homes and shelters. Permissible rehabilitation expenses include paint, smoke detectors, locks, landscaping and water and sewer upgrades.

Public Improvements - This category allows for the rehabilitation of public facilities such as senior, handicapped, youth, neighborhood or childhood centers. Permissible expenses include infrastructure repairs to include streets and sidewalks, as well as tree planting and other landscaping improvements.

Public Services - This category allows for the costs associated with such services as drug and alcohol counseling, daycare, and meals programs. Permissible expenses include the rental of facilities to house these public services, as well as the ongoing operation and maintenance expenses associated with that facility.

Source: http://www.hud.gov/offices/cpd/systems/idis/library/refmanual/ref_man_b.pdf 


\section{Chapter Four}

\section{Case Study}

\section{Introduction}

In Chapter 2, a symbiotic model (see figure 2.1) was introduced to explain the preferences and actions of bureaucratic and elected officials that are responsible for the allocation of CDBG monies. This model graphically displayed a framework where the behavior of each actor was dependent upon the actions of other actors. In other words, only when the national, local and bureaucratic officials satisfy the needs of one another, either by giving credit for a project, relaxing administrative oversight or supporting "pet projects," can the disbursement of federal benefits be allocated efficiently and without controversy. This model reinforced the notion that all interested parties must address and satisfy the needs of others in order to accomplish their own personal agendas.

To test the efficacy of this model, I tested the principles that local-level bureaucrats need to be responsive to the local-level elected officials who in turn need to be responsive to the national-level elected officials. Unfortunately, I was unable to test the responsiveness of the national-level elected officials to the national-level bureaucrats since few national legislators would agree to meet with me.

This symbiotic or circular approach suggests that each level feeds off the other to a smooth distribution of federal monies. These principles were tested by examining four case study cities in the state of Pennsylvania: Sharon, Altoona, Pittsburgh, and Philadelphia (see Table 4.2). Each city was selected because each differs from the others in size, economics, political inclinations and racial composition. City selections within 
Pennsylvania were also based on geographical location, with Sharon to the northwest, Altoona in the central part of the state, Pittsburgh to the west and Philadelphia to the east. Located in the northwestern part of the state and the smallest of the Pennsylvania cities studied was Sharon. With a population of over 16,300 (2000 U.S. Census), Sharon does not meet CDBG minimum population requirements of 50,000 (U.S. Department of Housing and Urban Development 2003), but does qualify for CDBG monies because it is considered a distressed community. Sharon operates under a strong mayoral form of government, and the mayor can be voted into office as many times as the electorate desires. In other words, there are no term limit requirements for the mayor of Sharon. Sharon's City-Council is elected at-large.

The next city examined was Altoona, Pennsylvania. Located in the central part of the state, Altoona has a general population of nearly 50,000 (2000 U.S. Census), eligible to receive CDBG monies since they were eligible under HUD's original model cities program. Similar to Sharon, Altoona has a mayoral form of government with no term limit for its mayors. Unlike Sharon, Altoona operates under a weak mayoral form of government whereby a professional manager runs the day-to-day operations of the city. Altoona's City-Council is elected at-large.

Pittsburgh, the second largest city in Pennsylvania, is located in the southwestern part of the state. With a population of 330,000 (2000 U.S. Census), Pittsburgh easily meets CDBG's population requirements. Pittsburgh operates under a strong mayoral form of government and has no term limit requirements for its mayors. Pittsburgh's CityCouncil is elected by district. 
The largest of the Pennsylvania cities studied was Philadelphia. Located in the eastern part of the state, Philadelphia has a population of 1.5 million (2000 U.S. Census), which makes it, like Pittsburgh, easily eligible for CDBG monies. Philadelphia operates under a strong-mayoral form of government and has term limit of two four year terms for its mayors. Philadelphia's City-Council is elected by both district and at-large.

To understand how and why cities and their mayors allocate CDBG dollars, I visited each city, researched their CDBG archives, and conducted personal interviews with mayors, council-members, program administrators, HUD officials and national legislators. Each visit involved multiple on-site meetings or telephone conversations with various level officials, in order to obtain a better understanding of the decision-making processes and motivations of officials at every level.

During these meetings and conversations, questions were asked regarding each official's overall familiarity with and understanding of the CDBG program, and the role each official played in the project selection and distribution processes. To ensure the accuracy and integrity of the interviews, a set of standardized questions were developed for each official (see appendices A \& B). For the most part, the standardized questions were identical, with the exception of those issue areas that were specific to the individual official. To encourage candid responses, interview questions were written to be nonleading, non-controversial and non-threatening. An analysis of the interview responses will be summarized later in the chapter, but first, an in-depth review of the CDBG funding levels and project histories for each of the four Pennsylvania cities will be examined. 
These case studies will examine a number of such contextual factors -- including the size of city, form of government, wealth of city, geographical region, political affiliation of administration and incumbency -- in an effort to better explain allocation decisions made by local officials. As a case study to illustrate the efficacy of these contextual factors in explaining allocation decisions, I will examine the Community Development Block Grant (CDBG) program, a federal program that supports state and municipal programs and projects, with four Pennsylvania cities that have varying political, economic and social characteristics. By applying these characteristics to the symbiotic model, the outcomes of CDBG allocations will vary by city. These outcomes will be shaped by form of government, term limits, party, racial composition, economic and council type. In addition to the contextual factors and through stakeholder interviews, there will be explanations for how and why CDBG allocation decisions are made. These reasons suggest that housing allocations that favor the poor to infrastructure improvements for the middle class.

\section{Null Hypothesis}

The Null hypothesis suggests that there is no difference or relationship between a variable and its outcome unless tested by some form of statistical analysis, which is either accepted or rejected ("Definitions of Null hypothesis on the Web" 2006). When a Null hypothesis is accepted, the chance that a specific outcome has occurred by chance is probable. When a Null hypothesis is rejected, the probability that a statistical or causal relationship has occurred by chance is not likely; with the conclusion that something else is going on with the data. 
In this chapter, the Null hypothesis suggests that no statistically significant relationship exists between the four Pennsylvania cities studied and the contextual factors that help explain CDBG allocation decision making. In other words, the unique attributes of each case study data has no observable differences in how and why allocation

decisions are made. Unfortunately, the case study data does not lead to a straight-forward conclusion regarding the Null hypothesis. The comments and conclusions from the CDBG decision makers and stakeholders suggest that something is going on in their communities and that specific causal relationships may exist. These causal relationships will become more apparent in the case study analysis of the four Pennsylvania cities that follow.

\section{Sharon, Pennsylvania}

The City of Sharon is situated in northwestern Pennsylvania next to the Ohio border and is located within 75 miles of Cleveland, Erie and Pittsburgh. Its safe neighborhoods and old town charm has allowed it to be ranked among the top ten towns in the United States ("Hometown Index" 2005). Sharon has a population of 16,300 of which 13.6 percent are minority. Sharon’s 2005 operating budget was $\$ 9,247,265$ (US Census 2000).

Sharon operates under a strong mayoral form of government, with all five of its Council members elected at-large. The mayor's job is a full-time position and the mayor's office is responsible for the day-to-day operations of the city. Since 1978, Sharon has had two consecutive Democratic mayors: Richard Price, from 1978 to 2002, and David Ryan, from 2002 to the present. Sharon's current council members (2005) are 
Table 4.2

Case Study Cities

\begin{tabular}{|c|c|c|c|c|}
\hline & *Population & $\begin{array}{c}\text { Form of } \\
\text { Government }\end{array}$ & $\begin{array}{c}\text { Mayoral } \\
\text { Term Limit }\end{array}$ & $\begin{array}{c}\text { Council } \\
\text { Type }\end{array}$ \\
\hline Sharon & 16,328 & Mayor-Council & Unlimited & At Large \\
\hline Altoona & 49,523 & Council-Manager & Unlimited & At Large \\
\hline Pittsburgh & 334,563 & Mayor-Council & Unlimited & +By District \\
\hline Philadelphia & $1,517,550$ & Mayor-Council & 2 terms & $\begin{array}{c}\text { At Large and } \\
\text { By District }\end{array}$ \\
\hline
\end{tabular}


all Democrats. The fact that they are 100 percent Democrat is not surprising since nearly two thirds of Sharon's population voted Democrat in the 2001 mayoral election (Rookey 2005).

\section{Sharon's CDBG Program History}

Since 1983, Sharon has received an average of $\$ 859,000$ CDBG dollars each year and has never received less than $\$ 660,000$ entitlement dollars in any one year (see appendix C). As with other entitlement cities, this consistent source of revenue has allowed the city of Sharon to plan and fund expensive operating and capital line items for the benefit of low and moderate income residents within its borders.

Interestingly, there were very few significant funding changes that occurred in Sharon throughout most of the years the city had applied for and received CDBG monies. Perhaps because the same person held the office of mayor (Price 1978-2002) for much of the time CDBG monies have been available, the fact remains that funding patterns were relatively constant. Just after the first year of the new mayor's 2002 election, however, CDBG allocations started to shift. There are three possible explanations that account for this shift: the new mayor's inexperience, his and his staff's unfamiliarity with CDBG regulations, and self-interest on the part of the new mayor and associated officials. These explanations will be addressed later in this chapter.

As figure 4.2 illustrates, roughly 51 percent of Sharon's 16,500 residents live in CD eligible neighborhoods. This means that one of every two Sharon resident lives in a 
Figure 4.2

City of Sharon CDBG Eligible

Neighborhoods

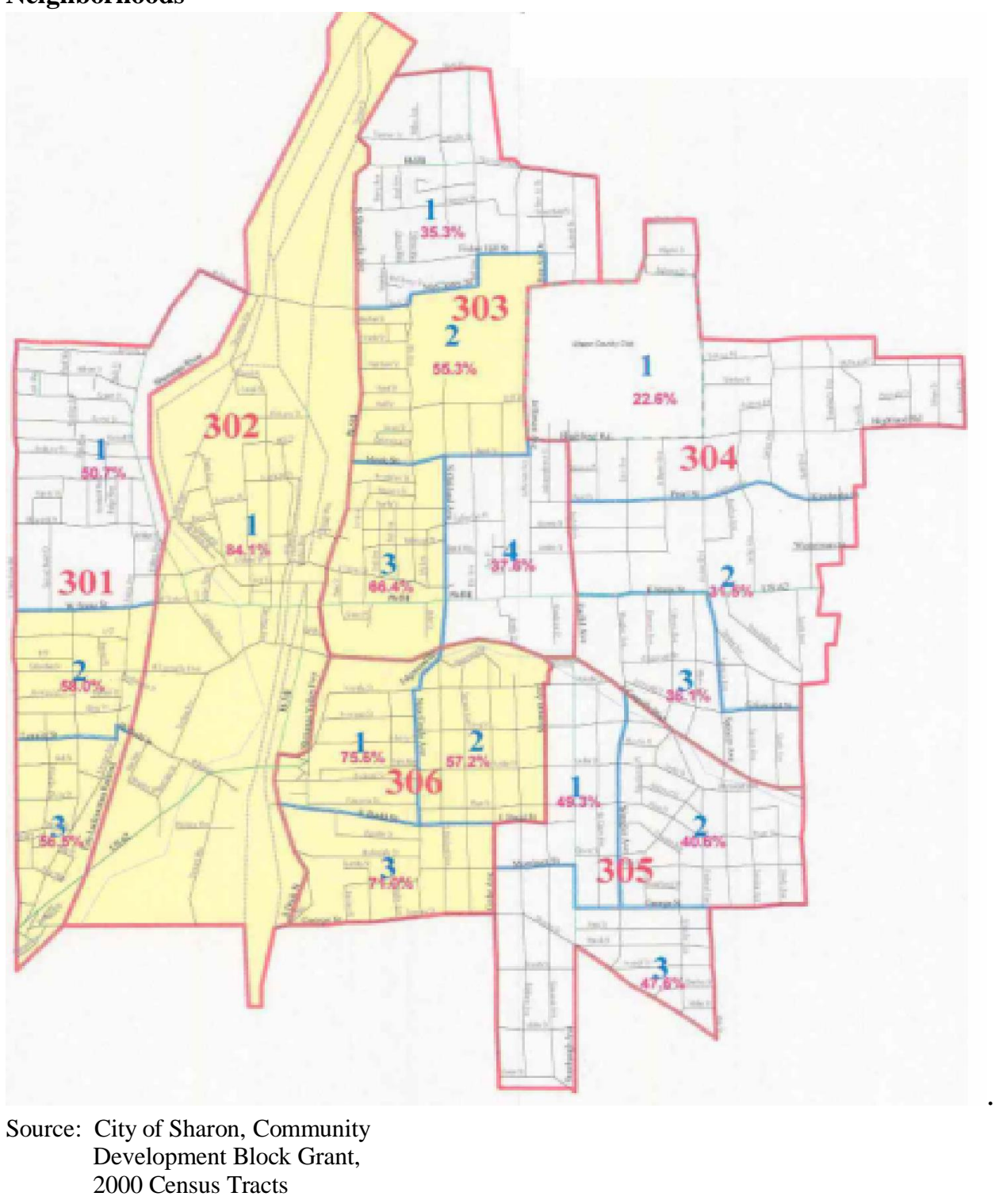


neighborhood that is eligible for federal dollars. Because of this ratio, Sharon program administrators can request and allocate CDBG dollars with ease.

\section{How Sharon's CDBG process works}

Recognizing the value of public participation, some mayors developed innovative approaches to meeting HUD's requirements for community input. Former Sharon Mayor Price, for example, said that he has gone door-to-door in many of his neighborhoods asking residents about the type of projects that would be important to them and asking what could be done to improve their neighborhoods. He said he was often accompanied by a City-Council member to join him in his neighborhood walks. Another tactic used by Price was to go to the neighborhood schools and have the children take information packets to their parents asking for project suggestions. These innovative informationgathering initiatives resulted in greater participation and input, which, in turn not only allowed HUD's community participation regulations to be met, but also allowed Price, for many years, to successfully request and appropriately allocate CDBG monies (Price 2003).

\section{Contrasting CDBG Allocations Under Differing Mayoral Administrations}

According to Table 4.3, the difference between most of the CDBG spending categories is negligible, with the exception of housing and public facility/clearances. During the Price administration, spending patterns for all categories remained constant, with very little variation. It was not until a new mayor and administration was in place that the spending categories began to shift. 


\section{Symbiotic Model Applied to Sharon}

\section{Local-level bureaucrats responsive to local-level elected officials}

During the Price administration, a long-term supervisor was responsible for the day-to-day administration of the CDBG program. This supervisor was experienced in the nuances of the CDBG program, from initial application to final audit. Her institutional knowledge of the city of Sharon and applicable HUD regulations allowed her to make fair and reasonable allocation decisions (Tolbert 2005). As a result, the Community Development office ran efficiently and professionally, and city residents enjoyed a stable and consistent flow of federal monies to CDBG eligible projects, with little variation. Unfortunately, Sharon's CDBG program experience and expertise did not survive a new mayoral administration. Similar to other small cities, where one individual constitutes the entire community development staff, the professionalism and success of an office is often contingent upon one person's skill level. Therefore, when the sitting mayor of 24 years retired and a new mayor (Ryan) was installed, a new program supervisor with little experience in CDBG procedures and regulations was appointed resulting in new CDBG funding priorities.

The shifting of funds from one project to another, however, may have had less to do with an inexperienced staff, and more to do with a new mayor trying to raise his visibility and popularity. Unlike his predecessor, who rarely had any legitimate competition (Price 2004), Mayor Ryan faced a viable challenger after his first term in office. It was during Ryan's administration, which faced being unseated by a viable mayoral challenger that some significant allocation shifts started to occur, leading one to 
Table 4.3 Spending Habits between Mayoral Administrations for Sharon, Pa

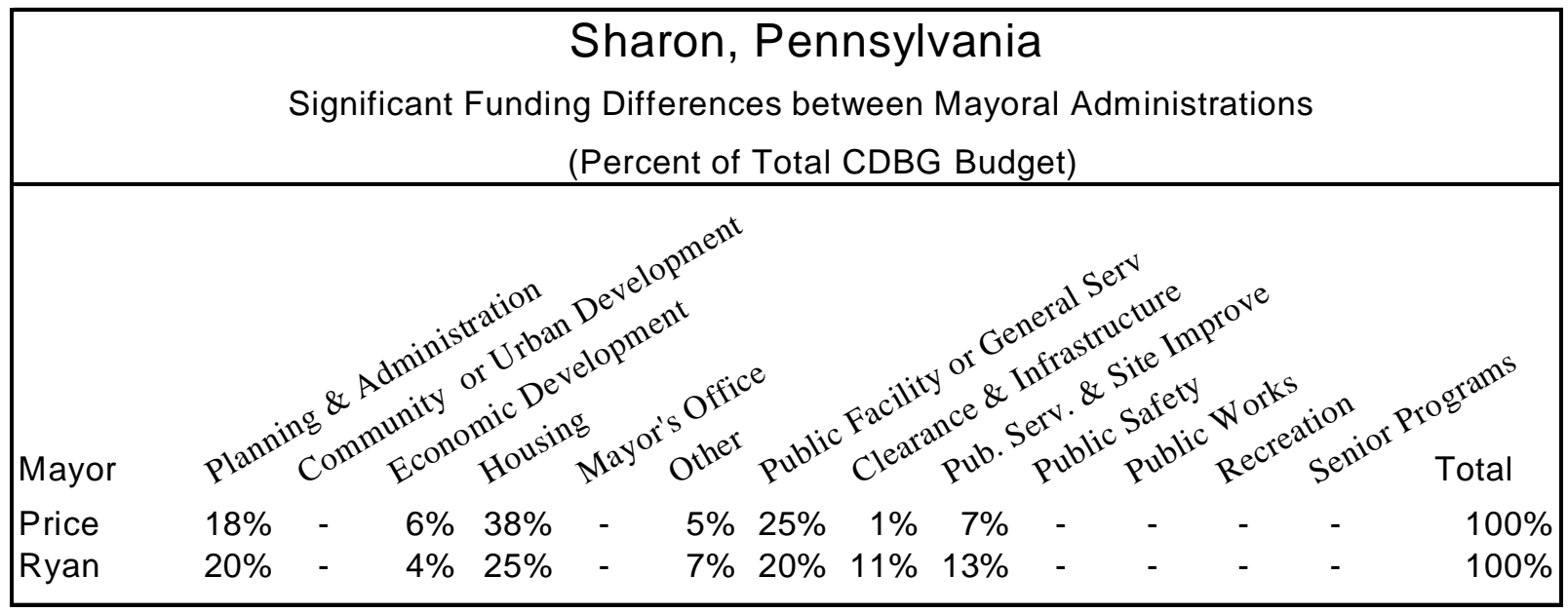


conclude that the pressure of seeking reelection may have had a material impact on CDBG allocations.

During Ryan's four years, the largest shift in funding was in allocation of CDBG monies for housing -- from 38 percent under Price to 25 percent under Ryan. When asked about this allocation differential, Price indicated that he was most concerned with spending CDBG dollars in accordance with their intended purposes and less concerned with trying to spend money in order to please a community or curry favor (Price 2004). Also, clearance and infrastructure increased from 1 percent to 11 percent during the same period. These funding changes -- a significant drop in allocations for improved housing for underserved citizens, with a simultaneous increase in funding for particular infrastructure projects -- seem to indicate that less money was being allocated to lowincome neighborhoods for housing and more money was being spent on high visibility projects such as street resurfacing, demolition of vacant buildings, and tree planting.

Under the Price administration, the CDBG program supervisor enjoyed both job security and autonomy in her position. She continued to support the mayor's wishes by sponsoring projects that were consistent with his local-level priorities and goals, while during the Ryan administration, however, a new CDBG supervisor was appointed who was more willing to fund the projects that were important to his boss (the mayor). Although the supervisors under Price and Ryan did what their bosses wished, the main difference between the two was with the kinds of projects they secured CDBG funding. With Price, it seemed evident that he was more aware of and willing to address the genuine needs of the underserved citizens of Sharon, while Ryan and his CDBG 
supervisor seemed more concerned with providing CDBG funding for projects that were highly visible and important or necessary to Ryan's reelection (Tolbert 2005).

While both administrations may have acted out of some degree of self-interest, it would appear that Price and his supervisor also kept the interests of the underserved citizenry prominent -- which may have been facilitated, somewhat, by the lack of reelection challenge faced by Price, as well as by Price's genuine desire to stay with the spirit of the CDBG program and to serve the underserved.

\section{Local-level elected officials responsive to national-level elected officials}

Mayor Price displayed a willingness and ability to give credit to national-level officials --the federal legislators -- as long as these legislators continued to provide Sharon with federal dollars. Former Sharon Mayor Price offered his opinion of the distribution of federal CDBG monies this way: "I absolutely knew where this money was coming from and had no qualms about giving them [federal government] credit, which they were all too happy to accept" (Price 2004).

\section{Altoona, Pennsylvania}

The City of Altoona is located in central Pennsylvania and sits on the eastern side of the Allegheny Mountains, about a two hour drive from Pittsburgh and the capital, Harrisburg. Known for being a railroad town, Altoona has approximately 50,000 residents with only a 4 percent minority population. Altoona's annual operating budget for 2005 was \$21 million dollars (US Census 2000). 
The city of Altoona operates under a weak mayoral form of government, with a City Manager -- rather than the mayor himself -- running the day-to-day operations of the city. This manager oversees the operation of all city departments, and has the authority to appoint and discharge city employees. Altoona's six council members and mayor are elected at-large. The mayor also serves as a seventh council member, presiding over and participating in all council meetings.

Since 1975, Altoona has had seven mayors; four Democrats and three Republicans. Historically, Altoona's city council consists of both Republican and Democratic representatives. As of 2005, five of the six council members as well as the mayor are Republican while the other council member is a Democrat. Republican voters outnumber Democratic voters in Altoona by nearly a two to one ratio (Crowl 2005).

\section{Altoona's CDBG Program History}

Altoona has received CDBG entitlement dollars since the program's beginnings. During each of these thirty years, Altoona has received an average of $\$ 3.25$ million dollars each year and has never received less than $\$ 1.5$ entitlement dollars in any one year (see appendix D). This consistent source of revenue has allowed Altoona to plan and fund expensive projects that aid low and moderate income residents.

During the program's early years, the bulk of Altoona's CDBG dollars were allocated to neighborhood infrastructure and housing projects citywide, such as street reconstruction and the creation of low and moderate-income housing. As time passed, however, greater shares of CDBG dollars were allocated to economic development and anti-crime initiatives. The economic development allocations were made to entice business and investment in the community to encourage people to work and live in 
Altoona, while anti-crime spending was allocated to enhance Altoona's police force in poorer neighborhoods (Johnson 2005).

As figure 4.3 illustrates, roughly 50 percent of Altoona's 50,000 residents live in CD eligible neighborhoods. This means that one of every two Altoona residents lives in a neighborhood that is eligible for federal dollars. Because of this ratio, program administrators can assign project dollars, under the terms and conditions set forth by HUD, with ease.

\section{How Altoona's CDBG process works}

Although all entitlement cities are expected and required to solicit public input on project selections and allocations, the city of Altoona goes the extra mile in trying to reach its constituency. Each year, Altoona holds a series of public meetings during the project selection process (see appendix 3). These meetings are held at public libraries and senior citizen centers and are advertised in the newspapers as well as on the internet. In addition, those organizations and agencies that received CDBG dollars in prior years are notified of these public meeting via the U.S. mail. Typically, meetings are held at differing locations throughout the city to make access and community input as convenient as possible.

After public input has been solicited, Altoona's community development department finalizes its selections and forwards its CDBG program selections to the mayor and City-Council for their formal approval. In this regard, the elected local officials act as a "rubber stamp" and typically do not have any direct input or influence into the CDBG selection process. According to Mary Johnson, Altoona CDBG program supervisor, "the mayor and council defer to my office's expertise and experience in the 
Figure 4.3

City of Altoona CDBG Eligible

Neighborhoods

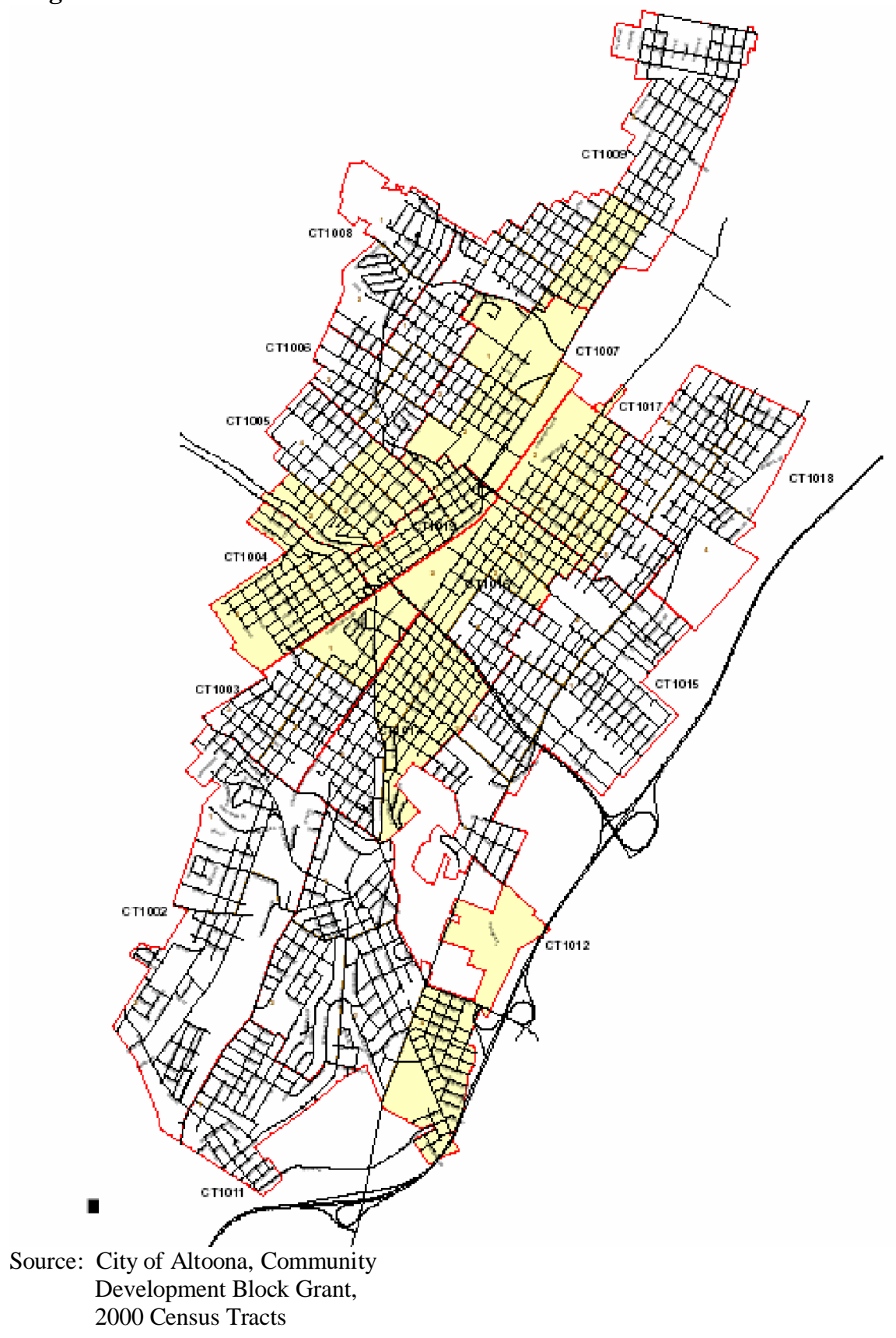


decision-making process. In my experience administering the [CDBG] program, I cannot remember a mayor or councilmember telling me what program to fund or reject" (Johnson 2005).

\section{Contrasting CDBG Allocations Under Differing Mayoral Administrations}

Unlike Pittsburgh and Philadelphia, where Democratic mayors have dominated the mayor's offices historically and from the start of the CDBG program, Altoona has, historically, had both Democratic and Republican mayors. Since the beginning of the federal CDBG program (1975), Altoona has had four Democratic and three Republican mayors (“Altoona's Manager Office" 2005). Despite regular shifts in the mayors' political affiliations, the city of Altoona has not demonstrated noticeable funding differences from one mayoral administration to another.

Of those differences identified (see Table 4.4), such as economic development, program managers simply stated that their office became more aggressive in funding individuals and organizations that had a greater capacity to repay economic development loans. By awarding CDBG dollars more carefully, the economic development dollars were being repaid in a more timely fashion - resulting in more monies being available and reprogrammed for future development projects.

\section{Symbiotic Model Applied to Altoona}

Local-level bureaucrats responsive to local-level elected officials

As long as the program supervisor of Altoona performs her job professionally and equitably, she can feel comfortable that her job is secure. "Of course I try to be sensitive 
to those projects that are important to my bosses, but in all fairness, I am rarely asked to fund something" (Johnson 2005). Of the past and present mayors who understood that CDBG funds came from the federal government, they seem to continue to be reconciled to giving the relevant federal legislators all the necessary credit, providing that federal dollars continue to flow into Altoona.

Irrespective of the fact that Altoona has a history of electing mayors from differing political parties, its CDBG staff has remained relatively constant and nonpolitical. Regardless of a Democratic or Republican administration, or of low unemployment or high unemployment, Altoona's elected officials have not significantly influenced the selection or distribution of CDBG funds. Altoona employs a long term program supervisor, with more than 20 years experience, who appears to be secure in her position and makes CDBG allocation decisions based on need and program guidelines.

One explanation for the program supervisor's longevity and independence is the lack of electoral competition in any of Altoona's mayoral elections. Despite the fact that there has been a new mayor in Altoona much more frequently than there had ever been in its small-city counterpart, Sharon, there has been very little legitimate competition in any of Altoona's mayoral elections in the last 30 years, with the margin of victory for mayoral candidates very one-sided. Without competition, mayors are less motivated to shift or reallocate $\mathrm{CDBG}$ dollars to those programs and projects that can benefit incumbent officials.

\section{Local-level elected officials responsive to national-level elected officials}

Due to an absence of legitimate competition in the mayor's office, or because the mayor's position is basically a part-time job with a full-time city manager running the 
city, the need for giving credit to the national-level legislators is not as prevalent in Altoona as it appears to be in cities in which the mayor faces significant electoral challenge or wields significant city-management power.

Additionally, since the mayor of Altoona is a part-time position and operates under a home rule charter with a full-time city manager, the mayor cannot exert the influence or power as in other cities where the mayor and his or her office directly manage the city and many of its resources. In a city such as Altoona, the power and prestige of the mayor's office is significantly diminished, making the ability to recognize the national legislators for their support less desirable. Another possible reason for the diminished need to recognize national-level support is due to the size of the awards the city has received. Altoona's CDBG awards are relatively small compared with Philadelphia's or Pittsburgh's, monitoring and accountability are less complicated. In other words, it is much easier to audit and track a $\$ 100,000$ housing refurbishment program, than it is to monitor and track a $\$ 20$ million dollar housing refurbishment program. Entitlement cities, such as Altoona, that receive fewer dollars from the federal government seem to be able to maintain a better standard of spending (and accounting for) CDBG dollars well and appropriately than do cities receiving much larger grants. It is simply easier to monitor smaller amounts of grant monies than it is to monitor larger amounts (Rieger 2005).

\section{Pittsburgh, Pennsylvania}

"The City of Pittsburgh is located at the confluence of the Ohio, Monogahela, and Allegheny Rivers" (“Comprehensive Annual Financial Report” 2000) and resides in the southwestern part of the state. Pittsburgh, with a current population of nearly 
Table 4.4 Spending Habits between Mayoral Administrations for Altoona, Pa

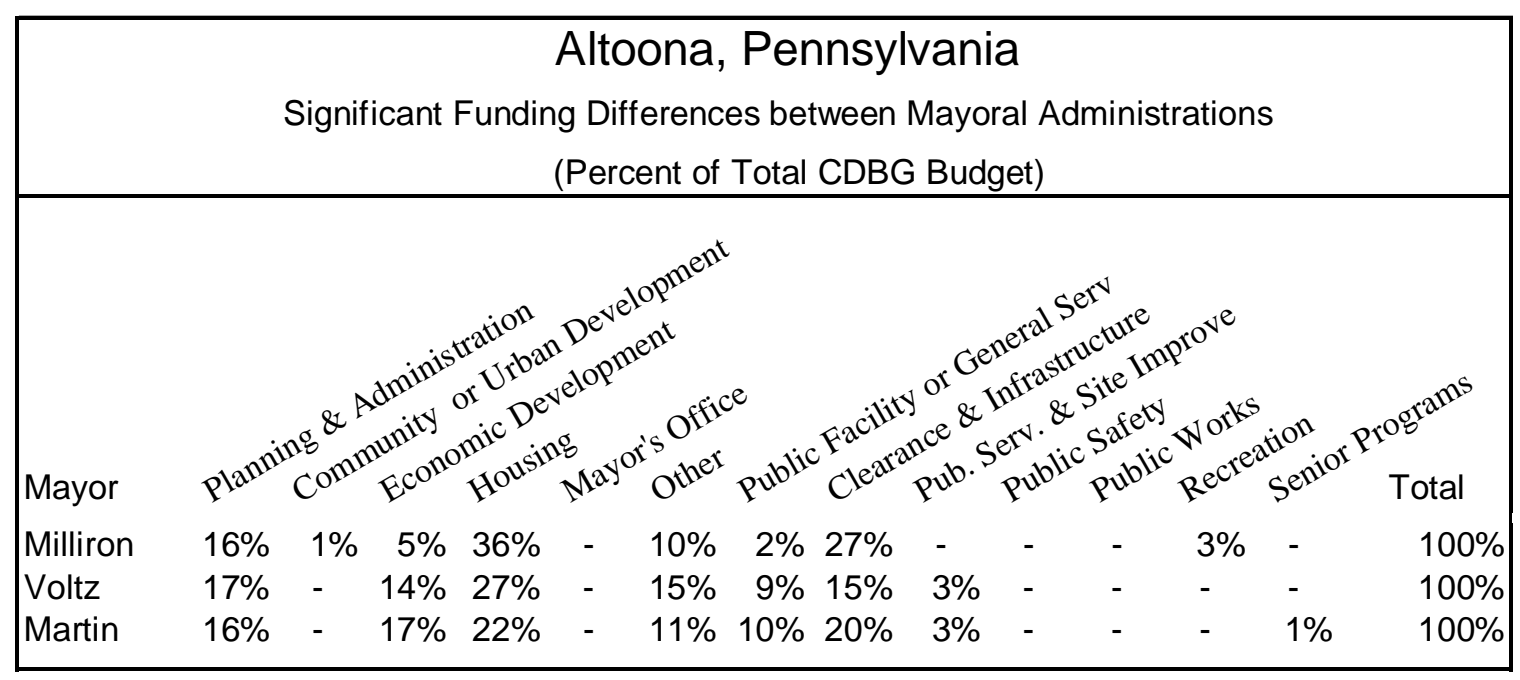


335,000 residents, has an annual operating budget of $\$ 330$ million dollars and is the largest of the region's [north east] 130 municipalities (US Census 2000).

The City of Pittsburgh functions as a strong mayor-council form of government and is made up of three governing bodies: the Mayor's Office, City Controller and City Council. The Mayor's Office is the administrative and servicing branch for the City of Pittsburgh. It includes the operating departments such as Police and Fire, as well and the economic development and maintenance arms such as City Planning and Public Works. The City-Controller's office is the official "watchdog" for the City of Pittsburgh in that it reviews, monitors and reconciles all monies disbursed to ensure that expenditures are in compliance with relevant rules and regulations. Finally, there is City-Council. Council is inherently the most political of the three bodies and functions as a direct link to the public. Council is charged with the responsibility of overseeing and approving any initiatives and actions that may impact its constituents and the City at large. Whenever a new policy initiative is proposed or expenditure request is made, all three bodies need to be involved and consulted with before approval and implementation can take place.

The City of Pittsburgh has five times more registered Democrats than Republicans. In fact, there has not been a Republican mayor in Pittsburgh since 1936 ("All Politics" 2006). This phenomenon is not surprising, however, given that Democrats out number Republicans in Pittsburgh by nearly a 5 to 1 ratio ("Pittsburgh Post-Gazette" 2005).

\section{Pittsburgh's CDBG Program History}

Since the program's beginning in 1975, the federal government has consistently awarded the City of Pittsburgh CDBG dollars each year. Pittsburgh receives an average 
of \$20.4 million dollars per year and has never been awarded less than \$14 million dollars in any one entitlement year (see appendix E). Because of this predictable and reliable source of revenue, entitlement cities like Pittsburgh are able to plan for largescale and long-term capital improvement programs.

Historically, the City of Pittsburgh allocates the majority of its CDBG dollars to housing projects and infrastructure improvements citywide, such as the rehabilitation of homes and businesses or low-interest loans for the purchase and acquisition of housing in low and moderate-income neighborhoods. The next largest allocation of monies goes to economic development projects. These funds are used to assist expanding businesses, for land acquisition for future development projects, and to assist interested manufacturers and industry in relocating to CD eligible neighborhoods. The theory behind funding this type of economic development initiatives is that local jobs will be created, and the neighborhoods will be strengthened by encouraging business or industry to locate in a targeted community.

As figure 4.4 illustrates, nearly fifty three percent (53\%) of the residents of the City of Pittsburgh live in neighborhoods that qualify them for CDBG entitlement dollars. This means that there are nearly 175,000 low to moderate-income residents in the City of

Pittsburgh who can directly benefit from the program. In order for the remaining 155,000 residents to benefit from $\mathrm{CDBG}$ dollars, the program or project selections must have an indirect benefit to the low and moderate-income residents.

\section{How Pittsburgh's CDBG Process Works}

Although HUD has given entitlement cities, including Pittsburgh, some loosely 
Figure 4.4

City of Pittsburgh CDBG Eligible

Neighborhoods

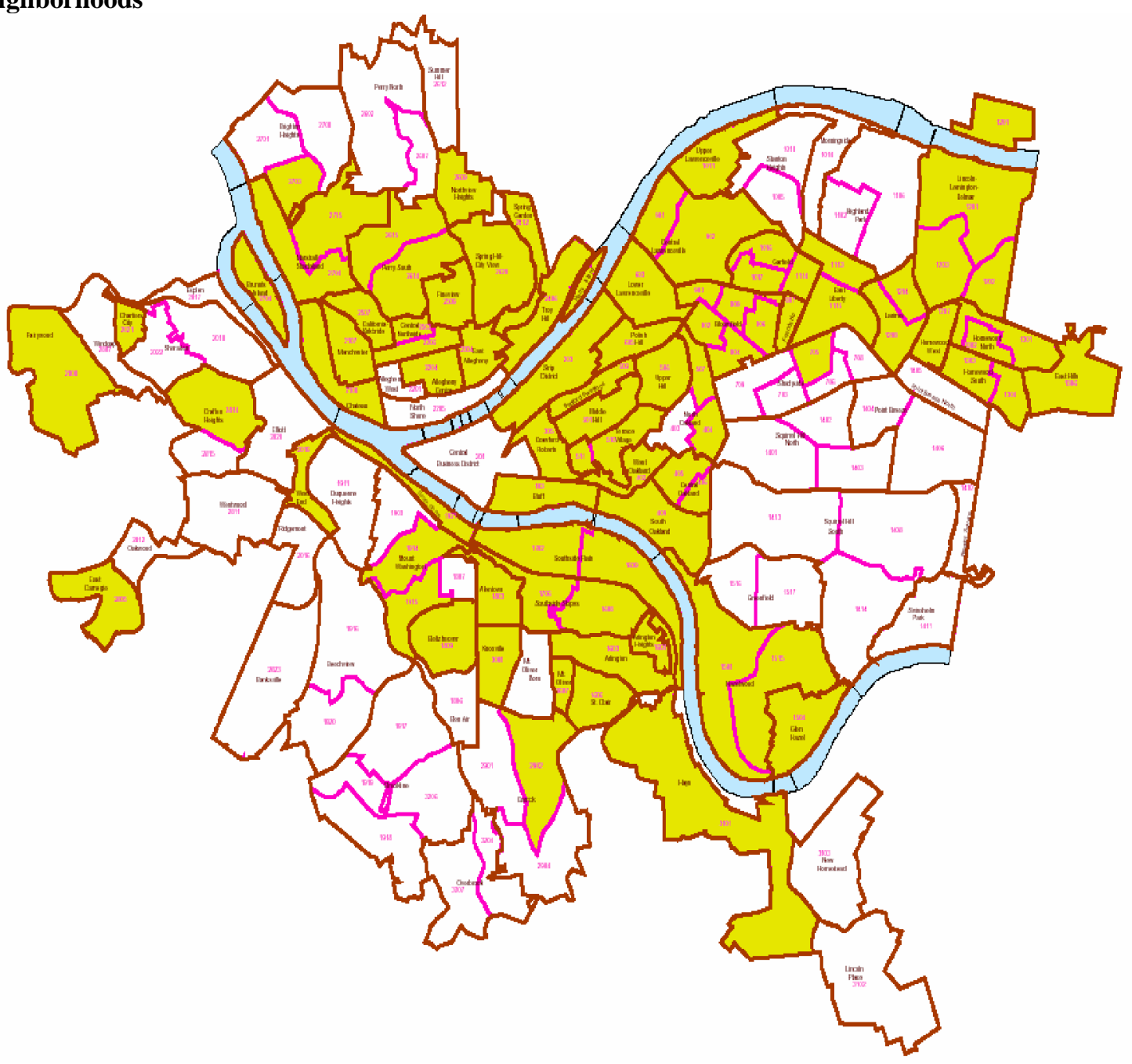

Source: City of Pittsburgh, Community Development Block Grant, 2000 Census Tracts 
written rules in choosing projects and disbursing funds, there is a standard protocol that a city must follow before it can formally select the projects and programs that are funded by CDBG monies. Before the mayor publicizes the approved CDBG funded projects, Pittsburgh holds a series of public hearings to receive input from the community. Each year, a draft plan listing of the proposed projects and improvements are compiled for distribution to the community for public review. After 30 days, the public is invited to submit oral and written comments to the Community Development program supervisor expressing opposition to or support of the projects. Once all these comments have been received and reviewed, a public hearing is scheduled to openly discuss the community's recommendations and responses to the proposed projects. After the public hearings take place, Pittsburgh's City-Council votes to accept or reject the projects. Council then forwards a recommendation to the Mayor for her veto or approval. The final funding decisions ultimately lie with the Mayor, and the rejection, by council, of any project or organization can be overturned by the office of the Mayor.

CDBG grant proposals are submitted to HUD by Office of the Mayor and his program administrators. This proposal contains the names and budgets of the proposed projects and a brief explanation of how they are benefiting the targeted neighborhoods (directly or indirectly). Providing the proposed projects meet the grant's criteria, the Mayor has full authority to recommend and approve any projects she desires. Once HUD approves the grant, the Mayor needs to hold public hearing from within the community to obtain the community's input and recommendations on spending the money. After the hearing, the Mayor forwards the project list before Council for final approval. Realizing that Council members have an allegiance to their own constituencies, the Mayor will try 
to "spread the wealth" and support key projects within each Council district. This behavior usually guarantees prompt passage of the Mayor's CDBG budget. After Council approves the budget, the City Controller monitors the approved projects and programs to make sure that the federal funds are being spent properly. Although the relationship among these three entities is not always harmonious, it does guarantee some level of checks and balances (Bellisario 2005).

\section{Contrasting CDBG Allocations Under Differing Mayoral Administrations}

Since 1975, when the CDBG program was created, the City of Pittsburgh has had three Democratic mayors: Richard Caliguiri, Sophie Masloff, and Tom Murphy [it should be noted that Bob O'Connor took office in January 2006 and making it too early to identify any discernable spending patterns, each of these mayors demonstrated differing strategies and priorities in allocating CDBG monies].

As Table 4.5 indicates, the spending patterns between mayoral administrations seemed most prominent in public works, such as street resurfacing; recreation, such as creation and improvement of parks and playgrounds; housing, such as winterization and rehabilitation of existing structures; public safety, including equipment and facility rehabs; and Mayor's Office initiatives, which might involve the funding of community and neighborhood organizations.

The most discernable difference between mayoral administrations occurs with the election of Mayor Murphy after Sophie Masloff's term in office. Mayor Murphy's priorities for public works' projects and Mayor's Office initiatives are in marked contrast to prioritizing of housing and public safety issues. Mayor Masloff, in fact, allocated almost no dollars from the city's CDBG budget for public works initiatives, instead 
funding public works activities from local tax dollars. Caliguiri, who preceded Masloff, seemed to allocate a disproportionate amount of CDBG dollars to recreational activities. It should be noted, however, that Caliguiri once worked as an administrator for the Department of Parks and Recreation, reflecting a special interest in recreational activities and programming.

\section{Symbiotic Model Applied to Pittsburgh}

\section{Local-level bureaucrats responsive to local-level elected officials}

The city of Pittsburgh provides the strongest documentation that a symbiotic model is a reliable measure of how and why CDBG-funded projects are selected. By providing the Mayor's Office and Council members with funding for their "pet projects," the community development staff is able to keep all their bosses happy and program the other CDBG monies for projects that are consistent with the terms and conditions of the CDBG program.

The City of Pittsburgh has a professional and competent bureaucratic staff that administers its CDBG program and projects efficiently and effectively. For the most part, the program staff makes project recommendations in accordance with all applicable rules and regulations. Unfortunately, though all rules are followed, not all allocations are made in the intended spirit of CDBG program. Much of this deviation from the intended character and achievements of the CDBG program is due to the structure of Pittsburgh's City Council.

In 1990, the City of Pittsburgh switched from a council at-large to a council by district system. For the five year period prior to the council by district system, CDBG spending for major long-term projects (such as a major bridge repair or the rehabilitation 
Table 4.5 Spending Habits between Mayoral Administrations for Pittsburgh, Pa.

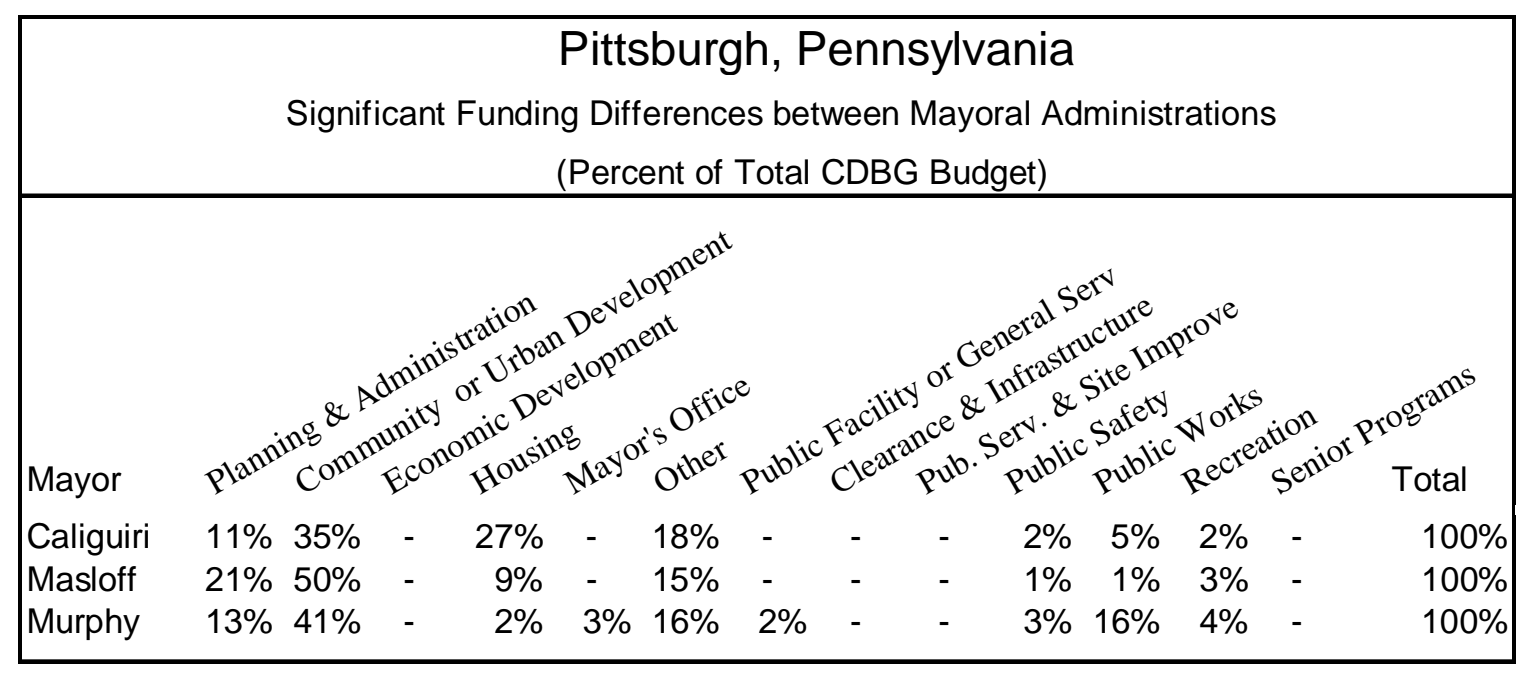


of a recreation center) was nearly 42 percent greater than during the subsequent five years since council by-district was introduced ("CDBG Comprehensive Plan" 1990). The most reasonable explanation for this occurrence is that funding priorities changed once CityCouncil was elected by district. When a Council member represents one portion of the community, he or she is likely to be most motivated to tackle the more narrow and neighborhood-specific projects that will garner direct and immediate political gain, rather than citywide projects that may not be as visibly beneficial to a councilmember's own constituency.

The Mayor's Office contributes to Council's direct participation by giving them absolute control over a small portion of the CDBG monies in a line item called Community Based Organization (CBO). This item is designed to give each of Pittsburgh's nine Council members absolute control of $\$ 100,000$ each to be spent on CDBG eligible projects or programs via special interest groups or organizations in the neighborhoods each council member represents. Council office staff will then work with the Mayor's office staff to make sure that the funding choices are eligible under CDBG requirements. Allocating this money to each Councilmember, effectively frees the mayor to direct the balance and majority of allocations elsewhere. In this case, the $2002 \mathrm{CDBG}$ balance after CDB allocations, was a little more than $\$ 20$ million dollars. In other words, Mayor Murphy obtained or "bought" Council's support for his CDBG budget by giving Council control over $\$ 900,000$-- a comparatively small amount of CDBG dollars.

Should Council object to the Mayor's proposed CDBG budget, the Mayor can threaten to reduce or eliminate Council's $\mathrm{CBO}$ allocations. As a result of $\mathrm{CBO}$ allocations, the passage of Mayor Murphy's proposed 2002 CDBG budget was relatively easy, as has 
been the passage of all Pittsburgh mayors' CDBG proposals accompanied by the $\mathrm{CBO}$ system.

Many of these $\mathrm{CBO}$ dollars have been allocated to Council members so that they can support small groups or organizations in the neighborhoods they represent. By providing these monies, Council members are able to gain the support and visibility of the employees and supporters of the neighborhood groups receiving $\mathrm{CBO}$ funding. The Council member who "secured" the CBO monies will likely be supported by the local grant's beneficiaries at election time (Bellisario 2005). In Pittsburgh, for example, there were nearly 140 groups or organizations that received CDBG monies in 2002, with individual awards ranging from $\$ 1,000$ for the Children of Love Theater to $\$ 250,000$ for the Pittsburgh Community Services Hunger Program (“Consolidated Community Development Plan” 2002).

Local-level elected officials responsive to national-level elected officials

Local-level elected officials will be responsive to national-level officials so that they can expedite awards for the local-level and generate publicity for themselves. Typically, this publicity occurs before an upcoming election so that the legislators can claim credit for the award and the mayors can start spending the award money. The timing of CDBG awards is not coincidental and is always on the minds of both the federal and local-level officials (Tolbert, HUD). 


\section{Philadelphia, Pennsylvania}

With a 2006 operating budget of $\$ 3.48$ billion dollars (Philadelphia budget office $12 / 6 / 05)$ and a population of 1.5 million residents, the City of Philadelphia is the fifth most populated city in the United States ("Top 50 cities in the U.S." 2006). More than 55 percent of Philadelphia's population is minorities (US Census 2000).

Similar to its big city counterpart to the west, Philadelphia operates under a strong form of government with its mayor responsible for the administration and operations of its day-to-day business affairs. Unlike Pittsburgh, where a mayor can be elected for unlimited terms, Philadelphia mayors can only hold office for two terms.

There are twice as many registered Democrats as Republicans in the City of Philadelphia. Given this ratio, it is not surprising that Philadelphia has not elected a Republican mayor since the 1940's (“The Philadelphia Inquirer” 2005).

Similarly, the majority of Philadelphia's Council members are disproportionately Democratic; 14 of its current 17 elected members are Democrats ("Chief Clerk of City Council Office" 2006). Of Philadelphia's 17 elected council members, 10 are elected bydistrict with the remaining elected at-large.

\section{Philadelphia's CDBG Program History}

Between 1983 and 1998, Philadelphia received CDBG entitlement dollars each and every year (see appendix F). During this time, Philadelphia received an average of $\$ 73,341,813$ million dollars each year and has never received less than $\$ 45$ million dollars in any one calendar year ("Comprehensive plans" 1983 - 1998). This infusion of 
revenue has given Philadelphia enormous opportunities to improve and modernize the quality of life for many of its low-income neighborhoods throughout the city.

During the early years of the block grants, the majority of CDBG entitlement dollars were allocated to housing-related activities such as weatherization and rehabilitation assistance programs citywide ("Consolidated plans" 1983-1998). Over the years and varying administrations, however, CDBG allocations shifted from housingrelated activities to community development initiatives ranging from loans and grants to facade improvements for small businesses. This shift in allocations represents a sea change from the W. Wilson Goode administration (1984-1992) to the Ed Rendell Administration (1992-2000) and from individual residents to the small businesses within the community.

As figure 4.5 illustrates, roughly 75 percent of Philadelphia's 1.5 million residents live in CD eligible neighborhoods. Because of this ratio, program supervisors enjoy immense flexibility in the distribution of CDBG entitlement dollars.

\section{How Philadelphia's CDBG process works}

Under the terms and conditions set forth by HUD, Philadelphia is required to advertise and hold public meeting so that the public can help determine how and where CDBG allocations are distributed. To maximize its efforts in reaching as many citizens as possible, Philadelphia advertises CDBG meetings at public libraries, newspapers, and on-line, as well as through direct mailing to community activists and organizations. Once these meetings are held, Philadelphia's City-Council holds public hearings on the feasibility of each project. 


\section{Figure 4.5}

\section{City of Philadelphia CDBG Eligible}

\section{Neighborhoods}

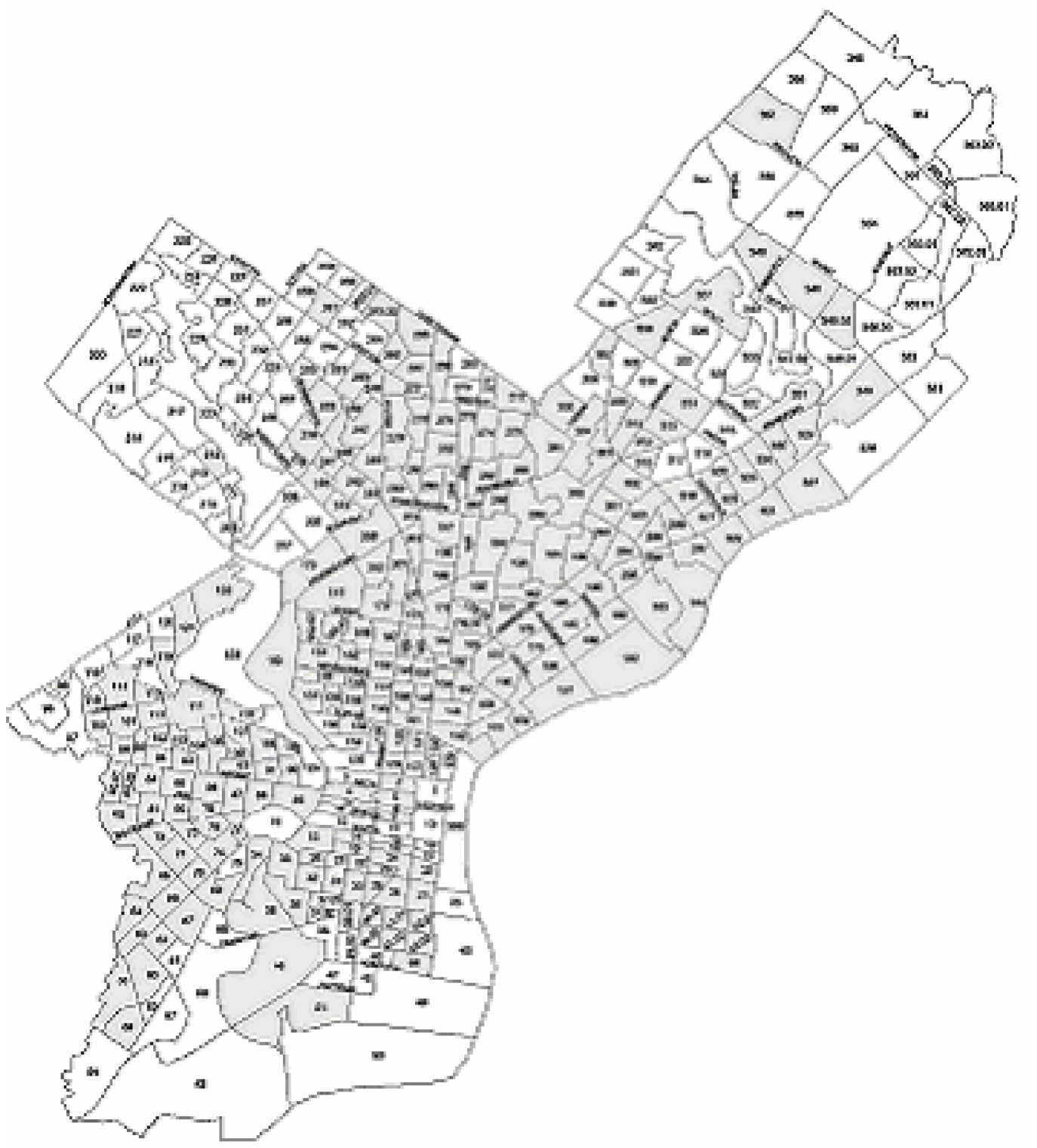

Source: City of Philadelphia, Community Development Block Grant, 2000 Census Tracts 
The inherent structure of Philadelphia's City-Council and the way members are elected plays a pivotal role in the selection of CDBG federal allocations. The public hearings and council meetings are "where by-district [Council members] reviews the project selections to make sure their constituencies and self-interests are being represented" (Jastrzab 2005). Council members take advantage of these public meetings to raise their visibility and popularity among their constituents.

There are seventeen council members on Philadelphia's City-Council: ten elected by-district and the remaining seven at-large. Those members elected by-district are more inclined to push for projects that benefit their individual constituencies. Conversely, members elected at-large are most concerned with citywide, larger scale projects that cross neighborhoods. As a result, a struggle exists within Council between those members desiring projects for their own districts and those members who are more concerned with citywide projects.

\section{Contrasting CDBG Allocations Under Differing Mayoral Administrations}

During the early 1980's, most of Philadelphia's federal CDBG monies were allocated toward housing and public improvement projects. In fact, nearly $\$ 10$ million dollars was appropriated for site improvements during the early eighties, compared with $\$ 2.4$ million dollars in the following decade. What accounts for this phenomenon is not entirely clear, but what is apparent is that monies for community development initiatives were made much more available during the 1990's.

As Table 4.6 indicates, the difference in spending patterns between the Goode and Rendell administrations seems most prominent in housing, community development and economic development initiatives. Housing allocations dealt with weatherization and 
rehabilitation issues, community development involved small business loans and improvements, while economic development dealt with development projects that benefited the entire community. Such funding allocations clearly identify a mayor's interests and priorities. According to Table 4.6, Rendell seemed to care more about community development initiatives -- allocations for such initiatives increased sevenfold during Rendell's years in office. The reasons for this large differential is unclear except for the fact that Rendell may have been trying to raise his overall visibility, not just in Philadelphia, but within the region and state, as he was preparing to seek the gubernatorial nomination.

\section{Symbiotic Model Applied to Philadelphia}

\section{Local-level bureaucrats responsive to local-level elected officials}

For the most part, Philadelphia maintains a professional and experienced CDBG program staff. On the surface, elected politicians in Philadelphia do not appear to play as large a role in influencing CDBG allocations as do Pittsburgh's CBO allocations of $\$ 100,000$ for each council member. "Certainly a [Philadelphia] council member that represents a particular district will push for those projects that can help him, but the allocation recommendations are typically controlled by the Planning Department” (Jastrzab 2005).

Funding shifts in various CDBG eligible activities suggest that program supervisors are sensitive to the needs of their mayors and council. This sensitivity suggests that some type of tacit agreement exists between bureaucrats and local-level officials and that bureaucrats' job security is somehow tied into doing what their bosses want. 
Table 4.6 Spending Habits between Mayoral Administrations for Philadelphia, Pa.

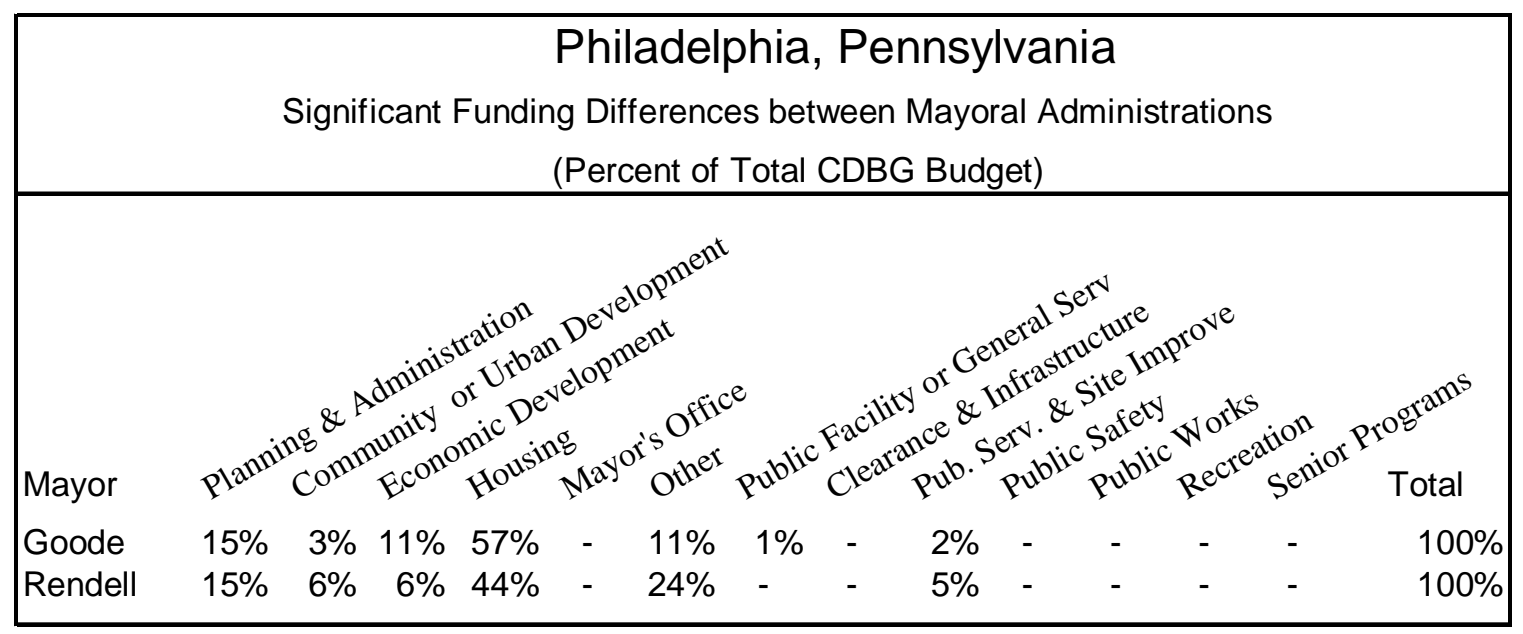




\section{Local-level elected officials responsive to national-level elected officials}

What can be seen in Philadelphia, suggests that formula adjustments or expedited awards do take place during election time or to elevate the visibility of a council member (Tolbert 2005). These awards are timed to give both the national legislator and the mayor credit for the CDBG. Put another way, the local-level officials are happy to give the national legislators credit for the grant, providing they can access the money to fund projects throughout the city, including those "pet projects" that are important to them (Tolbert 2005).

The size of the award is another determinant in apportioning - -and manipulating -- CDBG dollars. Looking at Philadelphia's CDBG budget, it is often difficult to determine if "pet projects" are being funded. This is due to the large amount of grant dollars that Philadelphia receives each year. Such large sums of money could facilitate program administrators easily hiding "pet projects" under the guise of the broad categories that are reported to HUD. Given that funding allocations can reach $\$ 30$ million dollars or more for certain activities or categories such as housing or economic development, there is a greater possibility that manipulation of allocations could occur as it is extremely difficult to track, through audits or published budget documents, individual projects that are initiated and carried out within broad categories.

\section{Interviews and Survey Results}

In order to understand the behaviors and decision-making processes at the national, local and bureaucratic levels, interviews were held at each level (see appendix 1). These interviews were conducted in order to understand motivation and how it underlies funding decisions. Unfortunately, a single explanation to under motivation and behavior of actors does not exist. Instead, through the use of interviews and surveys, a 
multitude or explanatory variables explain how and why CDBG allocation decisions are made.

The purpose of these interviews was to evaluate an official's knowledge and understanding of the CDBG program. Participants were asked about their ability to allocate and manipulate CDBG dollars, the impact of citizen participation on allocations, and the influence of politics in their decision-making process. Officials were also asked

about their interest in using CDBG monies to support the "pet projects" that are important to them, and if they believed that the CDBG program was another form of pork-barrel politics.

\section{National-Level Officials}

According to one official from $\mathrm{HUD}$, the CDBG program is an attempt to revitalize America's neighborhoods in a nonpartisan, objective way (Tolbert 2005). Unfortunately, this statement is not entirely accurate. Although it is true that the CDBG program awards monies to entitlement cities regardless of the party in power, it is the process by which awards are distributed that encourages partisan influence. This process can expedite or delay the execution of CDBG funds. An expedited award allows federal dollars to flow into the cities more quickly, while a delayed award can impede the projects and programs that depend upon federal dollars to continue. In other words, by strategically announcing an award prior to or after an election, the national-level official can enhance or diminish his or her reputation and reelection efforts, which, in turn, can materially affect the progress or attenuation of a CDBG funded project. 
In addition to the ability to manipulate the timing of CDBG awards, legislators exert political influence by "tweaking" program formulas (Tolbert 2005). As discussed in chapter 4 , the formula that determines the eligibility of a local community is based on a city's population, persons in poverty and number of overcrowded housing units ("NCDA Washington Report" 2002). A legislator that represents an area that has a higher level of overcrowded housing than of citizens clearly living beneath the poverty line, for example, will try to "tip" or change the formula to the advantage of her constituency. Even a small change in the federal CDBG formula can translate into millions of additional entitlement dollars for a legislator's district.

Not surprisingly, the suggestion that elected legislators manipulate the CDBG formula was met with resistance and cautious acknowledgement - resistance in its implications that federal officials use the CDBG program for personal gain and visibility and cautious acknowledgement that some "tweaking" does occur to bring more monies into specific neighborhoods for specific projects. The elected official asserted that his responsibility is to "grow the pie" and ensure that the federal government continues to fund the block grant program. When asked about his role in selecting and approving individual projects, the national legislator insisted that the distribution of CDBG dollars are determined by city officials and their stakeholders without any pressure or influence from his office (Doyle 2006).

\section{Local-Level Officials}

Of the local-level officials that agreed to be interviewed from Sharon, Altoona, Pittsburgh and Philadelphia, I was surprised by their overall sophistication and understanding of the federally funded CDBG program. Although some younger and 
more inexperienced council members and relatively new mayors did not understand the limitations and guidelines of the program, even the most recently hired or elected officials seemed to grasp its overall potential and implications for their communities -the influx of substantial federal dollars.

Unfortunately, not all council members took full advantage of CDBG monies when offered to them. Former Pittsburgh mayor Sophie Masloff stated that when she was on City-Council, she understood that each member controlled one hundred thousand CDBG dollars, through the CBO line item, to use in their respective neighborhoods and that some of her colleagues would fail to expend their annual allocations (Masloff 2003). As a result, she would sometimes barter for another council member's allocations by trading a legislative vote or favor. Masloff believed she could capitalize on the inexperience and lack of understanding of her council counterparts by redirecting another council member's allocations to the neighborhoods she represented.

Of the mayors and council members that agreed to be interviewed, many acknowledged that the success of the CDBG program was tied to the level of community participation (Price 2003, Murphy 2005). Unfortunately, obtaining public participation is difficult to achieve at best. Although some mayors have taken a proactive approach in trying to reach the communities they represent, most mayors agreed that they did not or do not have the time or the means to coordinate all the initiatives that would ensure maximum community participation. Rather, they suggest that the responsibility of reaching the residents is typically left to their program supervisors or professional staffs (Murphy 2005). 


\section{Bureaucratic-Level Officials}

The duties of a CDBG program supervisor are to "manage the administration of the Community Development Block Grant programs, including contract management, labor compliance and fiscal operations; develop and implement approved policies, goals and priorities for the allocation of funds; oversees grant sub-recipient application processing and eligibility determinations; oversees the federal auditing process" ("Community Development Program Supervisor job description" 1995). These duties clearly indicate the role of the bureaucratic-level official.

Keeping their role in mind, bureaucratic-level leaders were asked about their overall understanding of the CDBG program, the influence of politics on the program, and the amount of program flexibility that they were afforded. Without exception, all CDBG program supervisors felt that their primary responsibilities were to act as an agent for the mayor and City-Council, in order to balance the legal demands and political pressures of the program. Program supervisors believed that much of their liaison work centered on negotiating among the needs, desires and demands of the political and elected leaders, of the citizenry, and of special interest groups. Given the different needs, agendas and desires of each different office, body or group, the job of a CDBG program supervisor was difficult at best and seemingly impossible at times (Hargrove and Glidewell 1990).

Most bureaucratic-level leaders defined their seemingly impossible role as enforcers of the programs rules and regulations, not as the body of government that decides which program gets funded or how much. CDBG program supervisors insisted that funding decisions were left with the local and national leaders and that they had little 
authority over final project selections. Bureaucratic leaders perceived themselves as the professional branch of the CDBG allocation cycle and their sole function was to serve as the resident expert in determining program eligibility and requirements. In other words, of the supervisors/bureaucrats who agreed to be interviewed do not see themselves as facilitating a mayor's or council-member's political agenda/reelection bids; nor do they see themselves as officials who can secure their jobs by advocating for certain CDBG allocations.

All bureaucratic level officials agreed that the direct role and impact of community groups played a lesser role than expected in the allocation of CDBG monies. Although program supervisors are responsible for organizing and scheduling meetings for community input, most program supervisors believe this exercise is basically a waste of time (Johnson 2005). In short, bureaucratic leaders believe that community meetings are a ruse, are held to satisfy HUD requirements, offer little of value, and are largely a waste of time and money.

When asked about changing and improving the CDBG program, most program supervisors expressed frustration of their bosses' level of understanding of the program and the processes that must be following to make a programming change:

Sometimes I get a telephone call from the Mayor's Office telling me to switch funding from one CDBG eligible program to another. Although we are able to reprogram the dollars, they [Mayor's office or City-Council] want immediate access to these monies. What they [Mayor's office or City-Council] don't understand is that it can take months to change. I may need to publicly advertise the change or get council approval. The 
implications of them [Mayor's Office or City-Council] changing their minds creates a lot of work for my office and delays in getting official approval. (Bellisario 2005).

Overall, the bureaucratic-level officials see themselves as the non-political enforcers of the CDBG program. They strive to be the mediator between the local-level officials who decide which projects to fund and the program interpreters who explain HUD rules and regulations. In other words, according to their own assessment of the CDBG process, the bureaucratic-level officials advise their bosses of those projects that are eligible or ineligible to fund. They do not make the allocation decisions.

\section{Conclusion and Findings}

As Table 4.7 indicates, there were noticeable differences between the overall value of community participation among all three levels. Despite the fact that community groups are required (by HUD) to participate in the budgeting and allocation process (U.S. Department of Housing and Urban Development 2003), both the program supervisors at the bureaucratic-level and HUD officials at the national-level believed that the decisionmaking process rarely considers the input of community participation. This perspective is contrary to the mayors' and council members' emphatic claims that community participation is the key to the success of the CDBG program and that the project recommendations that their offices support are a direct result of listening to the community and responding to their needs (Udin 2005).

Of those local-level officials interviewed, the perception of the programs'

purposes was most notable. The program supervisors believe that the CDBG program is 
just another form of pork-barrel politics providing self-interested politician with the programmatic means to manipulate monies (Bellisario 2005). This perspective was very different than the local and national-level officials, who claim to believe that the CDBG dollars was not a pork-barrel program. Interestingly, of the local and national level officials interviewed, most agreed that the CDBG dollars help further their personal "pet projects," that are important to the constituencies they represent, and not necessarily important to their own reelection interests.

Of the program supervisors interviewed, most believed that many of the ultimate allocations were another form of "pork-barrel" politics. The CDBG program supervisor for the City of Pittsburgh suggested that it is not unusual to see monies diverted to more highly visible public improvement projects before an election only to be reverted back to other lower profile projects after an incumbent official secures reelection. For example, in each of Mayor Murphy's reelection bids, some notable spending shifts emerged, namely increased spending for city-wide public improvement projects. In 1994, Mayor Murphy spent a little more than 5 percent of his CDBG budget on public improvement projects. By 1997, that number increased, staggeringly: to 22.58 percent. After Murphy secured reelection, in 1998, public improvement allocations dropped back to 17 percent, only to incrementally increase to more than 25 percent in 2001 (See Chart 4.1). The perception that Mayor Murphy shifted allocations based on reelection considerations was confirmed by Murphy himself when interviewed. When asked about his practice of redirecting monies to public improvement projects prior to election time, the Pittsburgh mayor asserted that "the reality of expenditures is that politics drive $[\mathrm{CDBG}]$ allocations" (Murphy 2005). 
Murphy was not alone in this shifting of CDBG monies prior to election time. In Philadelphia, economic development allocations were significantly higher during Mayor Goode's first term in office compared with his second term in office (see Chart 4.2). Since economic development dollars are often linked to the development of large-scale and highly visible capital improvement projects, CDBG allocations are often higher during a mayor's first term in office. Considering that a 1 percent differential in economic development dollars could translate into millions of dollars, the motivations to manipulate allocations are apparent. In other words, by shifting even a small percentage of monies to high profile projects, a mayor can significantly bolster his or her visibility and popularity among constituents. 
Table: 4.7

CDBG Survey Summary

\begin{tabular}{|c|c|c|c|}
\hline & $\begin{array}{l}\text { Program } \\
\text { Supervisors } \\
\text { (Bureaucratic- } \\
\text { Level) }\end{array}$ & $\begin{array}{c}\text { Mayor's/Council } \\
\text { Members } \\
\text { (Local-Level) }\end{array}$ & $\begin{array}{c}{ }^{*} \text { National } \\
\text { Legislators } \\
\text { (National-Level) }\end{array}$ \\
\hline $\begin{array}{l}\text { Are you familiar with the } \\
\text { CDBG program? }\end{array}$ & Yes & Yes & Yes \\
\hline $\begin{array}{l}\text { Do you select and approve } \\
\text { CDBG projects? }\end{array}$ & No & Yes & Yes \\
\hline $\begin{array}{l}\text { Do you use CDBG funds } \\
\text { for "pet projects?" }\end{array}$ & No & Yes & No \\
\hline $\begin{array}{l}\text { Is CDBG another form of } \\
\text { pork-barrel politics? }\end{array}$ & Yes & No & Yes/No \\
\hline $\begin{array}{l}\text { Do community groups } \\
\text { influence CDBG } \\
\text { allocations? }\end{array}$ & No & Yes & No \\
\hline $\begin{array}{l}\text { Do you feel accountable to } \\
\text { community groups? }\end{array}$ & No & Yes & No \\
\hline $\begin{array}{l}\text { Is the CDBG program free } \\
\text { from political influence? }\end{array}$ & No & No & Yes/No \\
\hline
\end{tabular}


The allocation shifts from CDBG targeted neighborhoods to community-wide activities (economic development and public improvements) that can be seen to occur in direct relation to election cycles, directly reduce the number of targeted programs that are offered in low and moderate-income neighborhoods. This means that job creation programs, rehabilitation of senior citizen centers in low and moderate income communities, and overall neighborhood improvements are not being made in the areas the federal government intended for the money to go. Although it is hard to say with certainty which specific programs or projects are being affected, it is fair to say that substantial sums of monies are being diverted from targeted neighborhood projects to city-wide projects that benefit all communities regardless of their income level.

Although the diverted funds are popular with the higher-income public (and the ability to divert funds is an intriguing option with elected officials), the low and moderate-income constituencies are being harmed by the manipulation of CDBG monies for political visibility and gain.

The next chapter will determine if the lessons learned from Sharon, Altoona, Pittsburgh and Philadelphia, Pennsylvania can be applied at a national level. By quantitatively examining the data and contextual factors of each entitlement community within the United States, I hope to explain that the patterns and hypotheses learned from Pennsylvania are representative of the way elected officials allocate federal community development block grant (CDBG) dollars throughout the entire country. 


\section{Chart 4.1}

CDBG Allocations for Public Improvements during the Murphy Administration

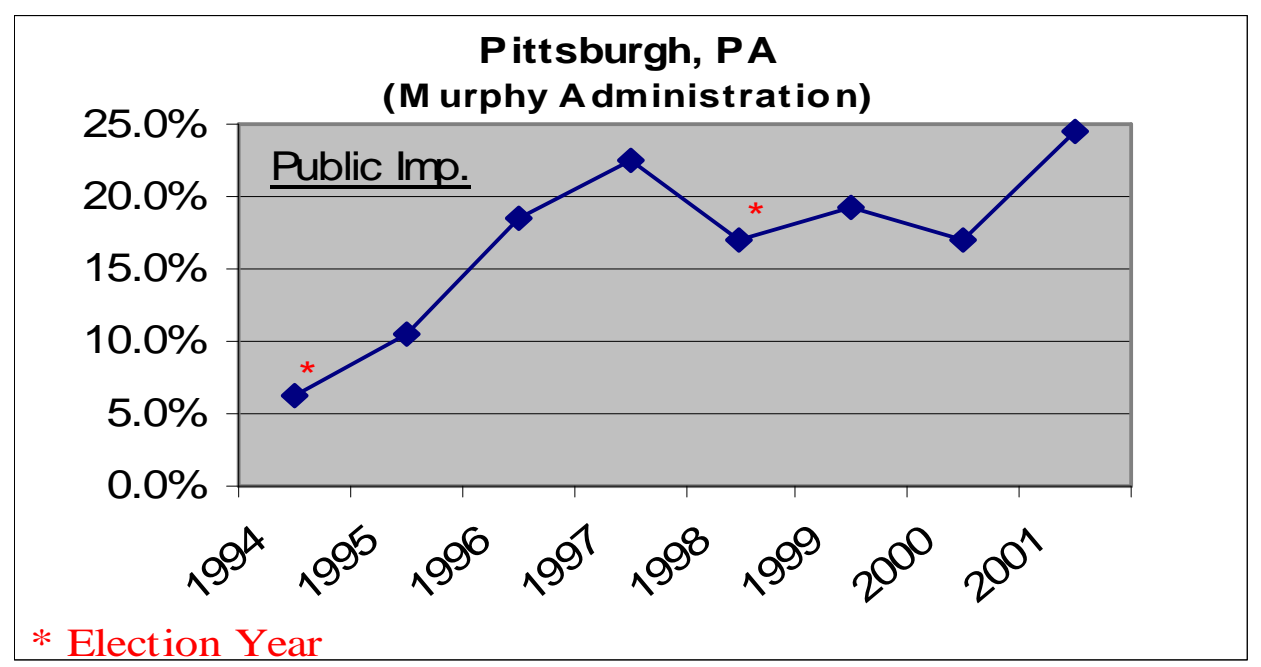

Source: Cost control budgets for City of Pittsburgh Cost Control Budgets for CDBG allocations 1994 - 2001.

\section{Chart 4.2}

CDBG Allocations for Economic Development during the Goode Administration

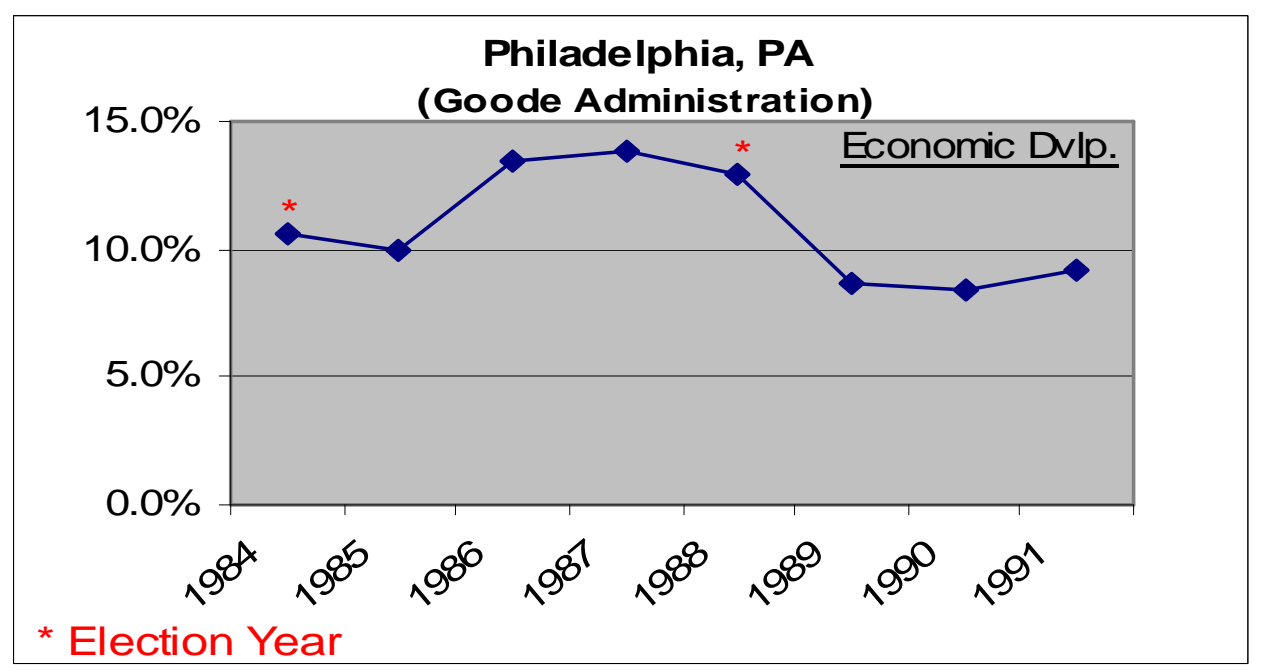

Source: Cost control budgets for City of Philadelphia Cost Control Budgets for CDBG allocations 1984 - 1991. 


\section{Chapter Five}

\section{Quantitative Analysis of National Data}

\section{Introduction}

In chapter four, a case study of four Pennsylvania cities was conducted that examined the ways cities and their mayor's allocated CDBG dollars. These allocations were made by examining the symbiotic model and through the use of stakeholder interviews and surveys. These interviews revealed that big cities allocate federal dollars differently than smaller cities for political, social and economic differences. Additionally, electoral concerns also seemed to play a role in how elected officials disburse CDBG monies.

The results of these interviews are linked to existing research on the distributive politics model. As stated earlier in this study, research on distribution politics must investigate not only the types of projects funded, but also why officials fund projects the way they do. To see if the lessons from the case study data are applicable to the national data, I looked at more than 35 independent variables that tests areas ranging from poverty levels to racial characteristics to city size. These independent variables were correlated with the six standard dependent variables that are reported by HUD (see Table 3.1). By comparing funding allocations for each depended variable, it is possible to identify any political, social or economic indicators of how CDBG monies are distributed.

The purpose of this chapter is to offer a more sophisticated and comprehensive framework, one that contains 2001 data from every CDBG entitlement city in all 50 United States, including the District of Columbia, that received CDBG monies directly from the federal government. The data is not a representative sampling of entitlement 
cites, rather the actual allocations by functional categories that were reported by each recipient jurisdiction. The reported data was obtained from HUD, the 2000 U.S. Census, Municipal Yellow Book, interviews, surveys, and from the internal administrative documents of entitlement communities.

\section{Analysis and Interpretation}

To see if any of the contextual or independent variables were significant, I used analysis of variance (ANOVA) and multiple analysis of variance (MANOVA): ANOVA to test whether three or more groups have overall different means, MANOVA to test if a change in an independent variable impacts the dependent variable. This is an ideal technique for hypothesis testing since it compares the mean allocations for each dependent variable with one another. The major advantage of ANOVA testing is that the results are easier to explain and allows the data to be analyzed as categorical. For example, if we are interested in the relationship between living in the southern part of the United States and the allocation of CDBG dollars for economic development, we would first see if an overall variance in the means' exists for all regions. If we are interested in testing the relationship between multiple independent variables such as form of government and size of city on the allocation of CDBG public improvement dollars, we would employ a MANOVA. By examining the strength of multivariate relationships, it is possible to identify the interactions of the independent variables and its corresponding associations to the dependent variables. In short, this analysis tests each of the independent variables that have a relationship with the dependent variables (see Appendix $\mathrm{H}$ ), to determine if the individual relationships hold true in a multivariate context. At no time were any variables added or removed from this analysis to alter or 
changes any statistical results.

Before we examine the various relationships between the dependent and independent variables, it is helpful to observe the national CDBG allocations for each of the six dependent variables: acquisition, administration and planning, economic development, housing, public improvements and public services (See chart 5.3). These categories will provide a perspective regarding the mean or average amount of federal CDBG dollars being allocated to the cities. To address these relationships, I tested a series of related hypotheses.

\section{Hypothesis 1 - Region}

The first hypothesis pertains to geographical region; I hypothesize that geographical region impacts the funding levels of $C D B G$ projects for both large and small entitlement cities within the United States. This hypothesis suggests that since some areas have stronger economic and employment situations, there are large variations in the allocations of economic development and housing initiatives. This hypothesis can be tested by comparing the CDBG allocations of every CDBG entitlement city in the United States by region, regardless of size, and place it in the appropriate region category.

By studying region, it is possible to explain how and why elected local officials, namely mayors and city-council members, distribute CDBG allocations. Region considers the value of the culture of the population, as well as the economic and political environments of the area. The cultural perspective suggests that behavior is driven by 


\section{Chart 5.3 U.S. Average CDBG Allocations}

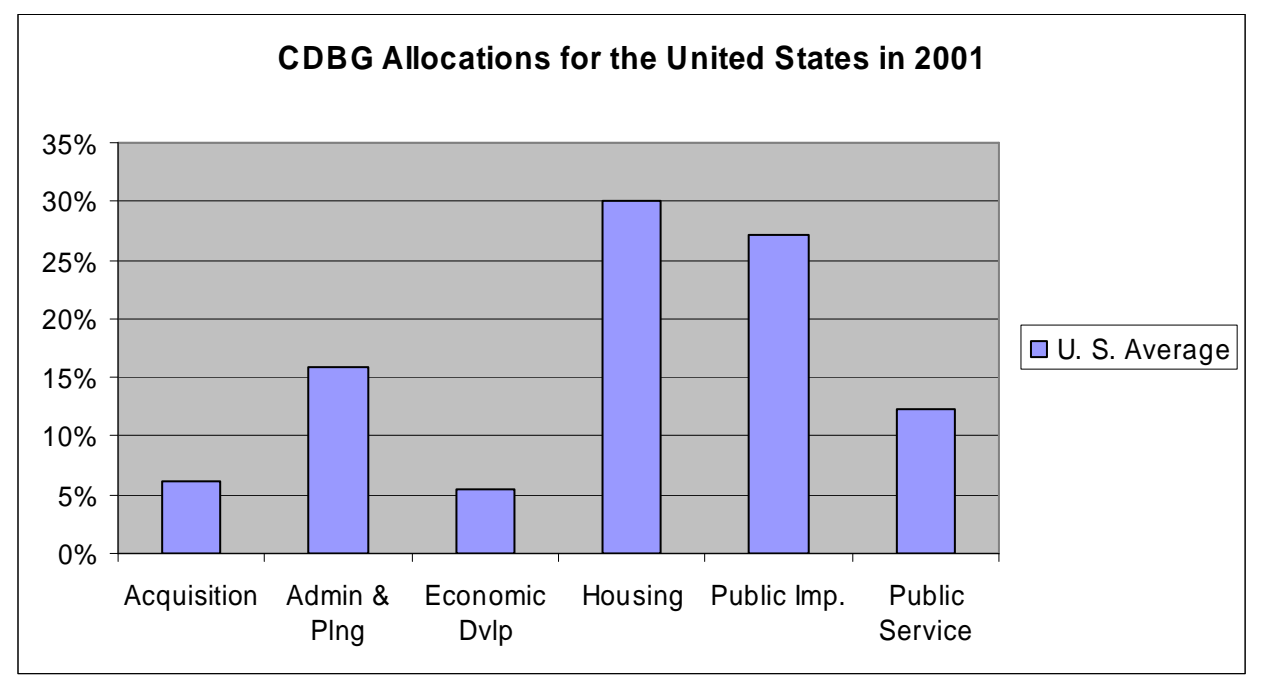


beliefs and examines how these emotions can influence various behaviors. Groups, peers and professional associations can inspire or reinforce these emotionally-informed behaviors causing a decision-maker to act out of various motivations and aspirations ranging from the "ideal" to the "quest for power" (Browning \& Jacob 1964).

An understanding of a region and its population could have an influence on how and why CDBG monies are allocated. The demographics of a city's population, age, and income levels can allow officials to plan for city services that cater to their targeted residents. From an economic and political perspective, a region's tax base, property values, fiscal inequity, racial balance and job opportunities are salient considerations of a particular geographical area. A region that is most concerned with attracting more business and employment opportunities, for example, will have different funding priorities than an area that is interested in rehabilitating its housing stock.

From a demographic perspective, region turned out to be one of the most significant indicators of CDBG allocations. For nearly every coefficient or category in my analysis, region was a key influence in the allocations for economic development, housing, public improvements and public services. These findings were not surprising, however, since these categories considered a city's unique blend of contextual factors coupled with the cultural composition of its community.

Age and condition of a city's infrastructure was another determinant in the distribution of federal CDBG monies. This determinant was especially clear in the older, northeastern cities in the United States where deteriorating roads and crumbling sewer systems seemed to dominate the public improvement categories. The concern over aging infrastructures was made most clear in an interview with Pittsburgh's CDBG program 
supervisor: "Whenever you deal with older streets, you never know what you're going to come across. As a result, the cost to replace and repair can be quite high and we must allocate $[\mathrm{CDBG}]$ monies accordingly" (Bellisario 2005). This sentiment suggests that CDBG program supervisors understand the cities they work for and the financial implications of dealing with crumbling infrastructure through CDBG allocation decisions.

Culture and its relationship to region was another factor that influenced the allocation of CDBG monies. Rooted in a person's past experiences and belief systems, the common cultural characteristics of a community, such as ethnicity or religion, play a salient role in defining an entitlement community's behaviors, attitudes and belief systems. In addition to the impact of cultural identification, the political culture of a particular region, known as sectionalism, and identified by the political ties and electoral behavior of a group of people (Elazar 1993), also impacts how CDBG dollars are spent, distributed and used. If the people of a particular community are weary of stringent federal oversight, for example, they may be reluctant to accept the terms of the national grant. Conversely, a community that is less threatened by the "strong arm" of the federal government may be more inclined to accept the terms and conditions of a distributive grant.

The economics of a particular region also influence the allocation of CDBG monies. A healthy region, with a prosperous community and a growing population, is more inclined to dedicate federal dollars to economic development projects such as new housing developments or industry. A struggling region, on the other hand, will be more 
focused on quality of life issues such as weatherization programs or child care assistance for its community.

My first hypothesis asks whether geographical region impact CDBG allocation levels for both large and small entitlement cities. To establish whether this hypothesis is accurate, I compared the mean funding levels for each of the four geographical regions within the United States: Midwest, Southern, Northeast, and Western. Table 5.8 shows the results of a one-way analysis of variance (ANOVA) test. ANOVA was used to test the overall significance of region for each of the six dependent variables: acquisition, administrative and planning, economic development, housing, public improvements, and public service allocations. The null hypothesis for each of the dependent variables is that the dependent variable does not vary by region at a .05 level of significance. The results of these comparisons show that the housing, public improvement, and public services coefficients are below a .05 level of significance, so we reject the null hypothesis and conclude that some type of relationship does indeed exist for region. For example, the mean CDBG allocation for housing in the Midwest is nearly 39 percent while the western region of the United States can expect only a little more than a 25 percent allocation. It should be noted that the significance of region must be discounted since it often masks other significant variables (such as economic differences, demographics, and political variables) that appears to make region seem more statistically significant than it is. These additional variables will be factored in when the MANOVA analysis is performed on region. 


\section{Hypothesis 2 - City Size}

A second hypothesis pertains to the affects of population and size of city that influences an officials' decision to allocate CDBG dollars. I hypothesize that there are differences between how CDBG dollars are allocated within small and large cities. This hypothesis suggests that there are considerable differences in the way CDBG monies are allocated, because in small entitlement cities, the electoral challenges and need to fund highly visible projects are not as salient as in larger cities. This hypothesis can be tested by comparing CDBG allocations for small, medium and large entitlement cities.

When it comes to CDBG funding decisions, size does matter. Smaller cities do not face the same political and bureaucratic constraints as larger cities since larger cities tend to elect more representatives than their small city counterparts. New York, for example, elects fifty one council members while Cleveland elects only seven council representatives (National League of Cities 2005). The data in this study suggests that, in cities with larger groups of elected officials, the competing demands for CDBG dollars are more numerous and more complicated, creating more difficulties with the efficient allocation of CDBG monies. Smaller cities with fewer elected officials do not face such a complexity of potentially competing interests and can more easily allocate their CDBG dollars.

The competing interest groups of larger cities often come in the form of special interest groups or organizations. In Pittsburgh, for example, there were nearly one hundred forty groups or organizations that received CDBG monies in 2002 with individual awards ranging from $\$ 1,000$ to the Children of Love Theater to $\$ 250,000$ for the Pittsburgh Community Services Hunger Program (City of Pittsburgh Consolidated 
Community Development Plan" 2002). Due to the sheer quantity of competing interest groups and the need to appease as many people as possible, large cities try to spread their CDBG allocation in as many directions as possible while smaller cities will usually allocate money to one or two initiatives or projects.

Interestingly, larger cities have more flexibility in allocating monies to special interest groups or projects since they can "hide" them under large funding umbrellas that make auditing tasks more difficult. Since smaller cities tend to receive smaller grants, it is more difficult for them to hide or reallocate federal monies to special projects without raising flags regarding the appropriateness of their expenditures (Tolbert 2005).

A very strong correlation between public improvement projects and size of city also produced some convincing data regarding the saliency of city size. According to Chart 5.4, very small cities, on average, allocate 30 percent of their CDBG budget to public improvements. As the size of the city increases, the percentage of the CDBG budget allocated to public improvements drops accordingly. Therefore, while a very small city with a population of less than 75,000 , for example, would allocate 30 percent of its CDBG monies to public improvement projects, a much larger city with a population of 500,000 people would allocate, on the average, thirteen percent less of its CDBG money to public improvement projects. These findings are consistent with the notion that smaller cities do not have the resources to fund these public improvement projects without the help of federal grant dollars. Larger cities, on the other hand, that have a larger tax base to pay for public improvement are thus more inclined to use CDBG monies for other initiatives, such as economic development projects. 
The size of a city can have a direct impact upon the level of services and the economic health of a city. A city that has a large population and tax base is likely to possess expensive equipment to perform infrastructure maintenance. A smaller city with a smaller population and less tax revenue is not likely to own such expensive public maintenance equipment. In Pittsburgh, for example, the City owns and operates an asphalt plant that can produce enough asphalt to pave as many roads as it wishes. Because it owns and operates its own asphalt facility, Pittsburgh can produce street resurfacing materials for a fraction of what it will cost a smaller city to purchase such materials (Murphy 2005). In other words, a larger city's tax base and resources may allow for higher levels of services which are unavailable to smaller cities collecting fewer taxes from their smaller populations.

From an economic perspective, cities that have a high proportion of unemployment coupled with a small population are going to have a more difficult time serving the needs of their communities. Conversely, more affluent communities with high tax bases can provide considerable services and amenities to their constituents. The population or size of a city and the concomitant availability of resources can and do significantly affect the CDBG allocation decisions made by federal and local officials.

Similar to region, I also employed an ANOVA test to measure the saliency of this data. According to table 5.9, there is a significant relationship for public improvement allocations and city size for the public allocation coefficients and for very large cities in the public service coefficients. There were not statistically significant relationships among the remaining categories. On can therefore conclude that city size does indeed 
matter in the allocation of public improvement type projects and that public service allocations are significant for very large cities.

\section{Hypothesis 3 - Form of Government}

Another hypothesis pertains to the political relationship between a mayor and its elected council persons or alderman. I hypothesize that in cities that are managed by a council/manager framework, the allocation of CDBG dollars are significantly different than the allocation of CDBG dollars for mayor/council, commissioner, or town manager systems. This hypothesis can be tested by comparing the CDBG allocations of council/manager cities with other forms of government.

The way in which a city exerts its powers over a political community is commonly referred to as form of government ("Form of Government" 2006). There are four four dominant forms of government in the United States: council/manager, mayor/council, commissioner and town manager. Of the $758 \mathrm{CDBG}$ entitlement cities examined in this study, there were 735 (421 council/manager, 299 mayor/council, 15 Commisoner) dominant forms of government. There were 323 cities that did not indicate their political framworks or had government structures that did not fit into a council manager/mayor category ("National League of Cities" 2005).

\section{- Council / Manager}

In the council-manager form of government, a professional city manager is the key administrator responsible for the day-to-day activities of municipal services. In this 
Chart 5.4
Public Improvement Allocations Sorted by City Size

\section{Percentage of CDBG Allocations}

for Public Improvement Projects

(by Size of City)

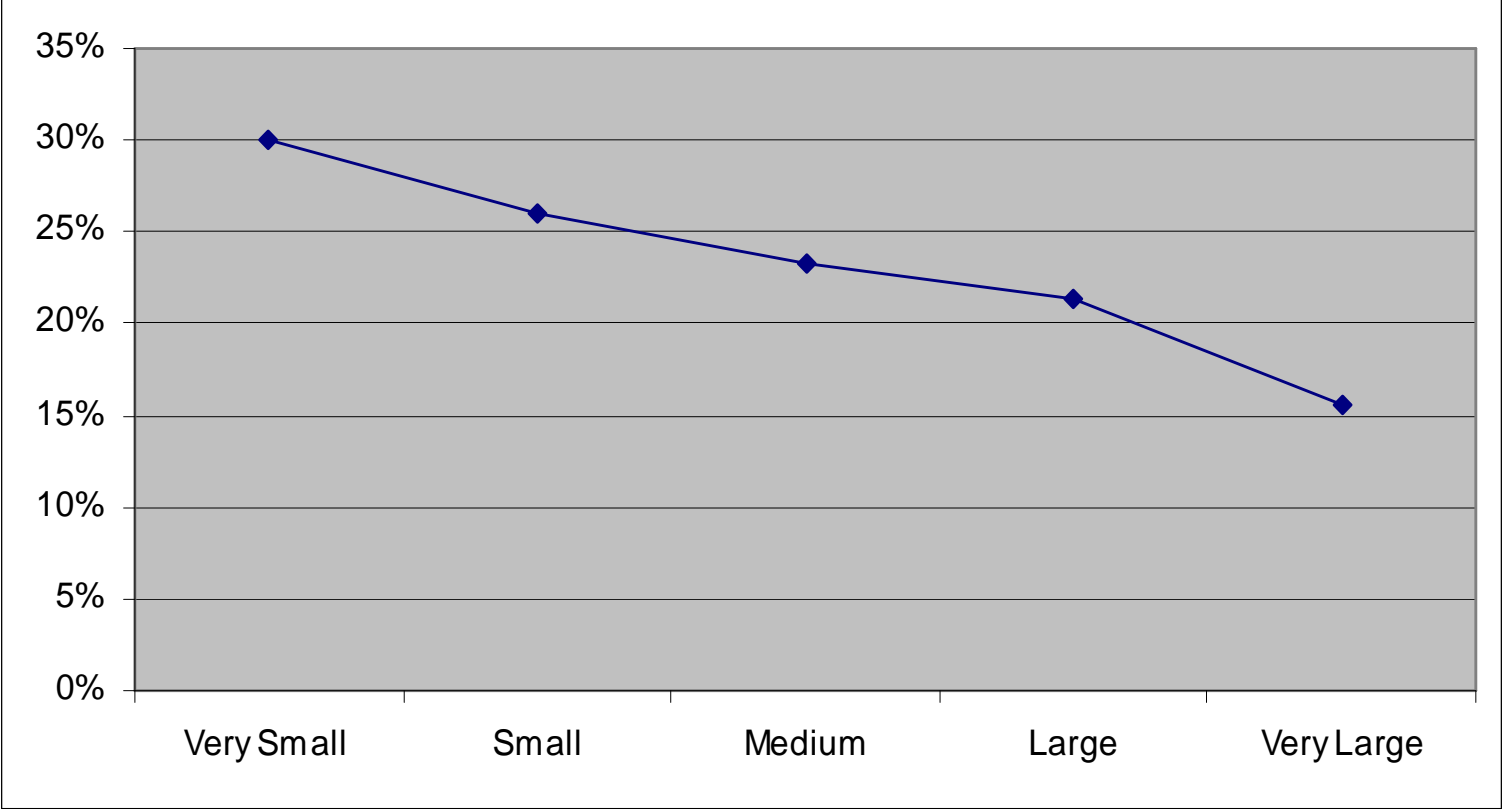


form of government, the city is considered to operate within a weak-mayor environment. In a council-manager framework, the elected officials are the policy makers and leaders of the community and are viewed as the mouthpieces of the community at-large. The appointed manager is charged with the responsibility of carrying out the policies and wishes of the elected officials. The manager is responsible for preparing the operating and capital budgets, hiring and firing staff, serving as the elected body's chief advisor, and executing policy recommendations and initiatives. If the professional manager does not execute the policies and priorities of the elected officials, the elected body has the authority and power to terminate the manager's position.

The mayor typically presides at public meetings, solicits citizen input, and communicates policy recommendations to the city manager. In a weak mayor environment, the mayor is viewed more as a ceremonial and policy figure (who, for example, presides over council, facilitates communications between elected and appointed officials, cuts ribbons and kisses babies), and less as a professional manager who oversees the routine delivery of public services.

\section{- Mayor/Council}

In the mayor-council form of government, the mayor is charged with the responsibility of running the day-to-day operations of city government. In this form of government, the city is considered to operate within a strong-mayor environment. In this scenario, the elected mayor is the policy-maker, administrator and voice of the community and is accountable to both the electorate and city-council. Such accountability is regarded as providing useful checks and balances situation. Council 
serves as the community's legislative body, while the mayor is responsible for the overall administration of the city. In this form of government, council focuses on community goals, large-scale operational and capital improvement projects, zoning, land use and long-term strategic planning goals.

\section{- Commissioner}

In a commissioner form of government, the powers of running city government are shared among a panel of elected officials called commissioners. These commissioners are usually responsible for the development of the budget and ordinances. Typically, commissioners are found in very small communities.

As indicated in table 5.10, an ANOVA was used to test the overall significance of form of government for each of the six dependent variables, with form of government as the factor. The evidence suggests that economic development is below a .05 level of significance. Therefore, we reject the null hypothesis and conclude that some type of significant relationship for the council-manager (weak-mayor) coefficient for the economic development category. All other categories and coefficients did not prove to be significant.

From a political perspective, the only contextual variable that proved statistically significant in the allocation of CDBG dollars was the mayor-council (strong mayor) form of government and this proved significant only for economic development initiatives. This coefficient suggests that economic development allocations increase an average of 2.2 percent (from 4.5 percent to 6.7 percent) when a mayor-council form of government prevails. Why would a strong-mayor factor affect economic development initiatives and 
not the other allocation areas? One possible explanation is that in a strong-mayor environment, where the incumbent mayor is typically interested in seeking reelection and/or raising her visibility, she will try to influence bureaucratic managers or agents to allocate monies for projects that are popular among her constituency.

\section{Hypothesis 4 - How City-Council is Elected}

A fourth hypothesis pertains to the way council members are elected by their constituents. I hypothesize that in large entitlement cities, when city council members are elected by district, more federal dollars are allocated to neighborhood-specific or smaller scale projects, thereby greatly improving each council member's visibility and reelection chances. Conversely, when city council members are elected at-large, CDBG dollars are allocated to citywide projects because the ability to get reelected depends upon satisfying a broader constituency. When council members are elected both at-large and by district, monies are more evenly allocated throughout the community leading to a more balanced distribution of $C D B G$ dollars. These hypotheses can be tested by comparing the CDBG allocations made by large entitlement cities that elect their council members by district, at-large or by a combination of by-district and at-large.

The appointment of most city-council members are made three ways: elected bydistrict, elected at-large, or elected both by-district and at-large. When a council person represents a particular district within a community, the implication of CDBG allocation decisions can very significantly.

When a council person is elected by-district, it is not uncommon for that representative to "push" a project in her district. This strategy stems from a 
representative's desire to claim credit for the project and to be remembered at reelection time. When a council person is elected at-large, the focus is on bigger and longer term projects since the elected member is accountable to the entire electorate as opposed to a particular voting district. Such bigger and longer term projects may include a major bridge repair or the rehabilitation of a centralized recreation center that consumes a large portion of the CDBG budget for that year. Finally, when council members are elected by-district and at-large, it is more likely that a mixture of large scale and smaller, neighborhood specific projects will be funded (Bellisario 2006).

Typically, council members who are elected at-large are more inclined to recommend and approve projects that service the entire community. A council member who is elected by-district, however, are more inclined to push for projects that service those constituents who elected her. Although mayors ultimately control the allocation of CDBG dollars, the need for a mayor to understand a council person's motivations and priorities is imperative before a federal grant is allocated. A council member elected bydistrict will be most concerned with a select group of constituents. On the other hand, a council member who is accountable to an entire community will have very different goals in choosing which projects to fund. As a result, a mayor interested in reelection must appreciate the need to balance her own self-interest with the needs and interests of her fellow elected officials.

Table 5.11 shows the results of the ANOVA to test this hypothesis. At a .05 significance level, there was no evidence to suggest that any of the six dependent variables had a statistical significance for the way council is elected. 


\section{Hypothesis 5 - Economics}

A fifth hypothesis pertains to the affect of wealth of a community and the significance of per capita income, poverty levels, unemployment rates and housing values in determining $\mathrm{CDBG}$ allocations. I hypothesize that wealthier cities allocate $C D B G$ dollars differently than poorer cities do. My hypothesis suggests that wealthier cities direct more money to economic development projects to maintain and enhance overall property values throughout the city and less money to improving substandard housing because there is less of a need to offer financial assistance to low and moderate income residents. This hypothesis can be tested by examining the median housing value, per capita income, unemployment rates and the percentage of city residents living in poverty for each CDBG entitlement city.

From an economic perspective, the most important indicators for CDBG allocations were per capita income and median housing values. These indicators suggest that as per capita income and housing values rise, so do a city's CDBG allocations for acquiring property and investing in a community's housing stock. In other words, cities with high incomes and property values are more inclined to acquire as many blighted properties in their communities as possible for redevelopment purposes. The reasons for this behavior are unclear, but it may be that reversing the decline in one part of a city helps improve the property values throughout the city.

To address this hypothesis, I ran several one-way ANOVA's to test the influence of per capita income, poverty levels, unemployment rates and housing values within the entitlement community. For the per capita income ANOVA in Table 5.12, there was strong evidence that public service allocations are associated at the .01 level for all 
income groups. Similarly, a relationship for economic development at the .05 level indicated that a much higher allocation is made for economic development initiatives when a community's per capita income is less than $\$ 18,000$. For housing, as the per capita income of a community increases, the expected average CDBG allocation will increase by nearly 33 percent. This test statistic proved significant at the .01 level.

For poverty levels, the data was consistent with the per capita income analysis for economic development. According to the ANOVA performed in Table 5.13, when the poverty levels are low (below 8.8 percent of a community), there is less money given to economic develop initiatives than when poverty levels are high. This data suggests that the more the amount of poverty in a community is directly related to the allocation of CDBG dollars for economic development activities.

When unemployment rates are compared, the ANOVA in table 5.14 showed that less money will go to economic development allocations when unemployment is lower compared with higher unemployment rates. This data proved significant at the .05 levels Similarly, housing allocations received significantly more CDBG dollars when unemployment rates ranged between 3.1 and 3.8 percent, than when unemployment rates were 3.9 percent or higher.

For housing values, CDBG allocations proved statistically significant for public services at the .01 level. According to table 5.15, the ANOVA showed that public service allocations averaged 10.69 percent when a house was valued at $\$ 75,000$ or less compared with a 13.62 percent allocation when a house was valued at $\$ 150,000$ or more. This analysis proved significant at a .01 level. 


\section{Hypothesis 6 - Race}

My last hypothesis pertains to the affect of race on the allocations of CDBG allocations. I hypothesize that cities with higher percentages of whites allocate CDBG monies differently than cities with greater percentages of non-white populations? I hypothesize that greater CDBG program allocations are earmarked to housing and public service areas that maintain large minority populations. This hypothesis can be tested by comparing the funding levels of housing and public service categories for minority and non-minority populations.

There has been considerable speculation from sociologists regarding the impact of race and ethnicity on the allocation of CDBG dollars (Kettle 1980). The question becomes: does race and the potentially accompanying prejudice, discrimination or stereotyping matter in how and why federal dollars are distributed. Because of these racial concerns, it is important to see if a relationship exists between funding and racial demographics - are there significant differences between the levels and uses of funding in predominantly white communities and the levels and uses of funding in non-white communities?

My final research hypothesis suggests that cities with higher concentration of white populations allocate CDBG monies differently than non-white communities. From a social perspective, race plays a salient role in the allocation and distribution of CDBG monies for the public improvement and public services categories. For property and economic development initiatives, race is an especially significant allocation determinant for black and Hispanic communities. Since many minority populations have lower per capita incomes and reside in areas where property values are low, it is reasonable to 
conclude that a city's ability to acquire and develop inexpensive property becomes an irresistible temptation for an entitlement community. This perspective raises many questions: Are cities getting/using CDBG monies to acquire land in low income, black and Hispanic neighborhoods with the intention of developing these areas to improve housing and services for that community or for other purposes and beneficiaries? Are cities that apply for CDBG monies claiming that they will use these monies for housing and services in low income/minority areas then using the monies in other areas? Are cities requesting $\mathrm{CDBG}$ monies for low income/minority areas to improve housing and services, then "gentrifying" these areas to the point that the low income, minority residents are "priced out" and must leave?

Race is also a factor among the registered voters of a community. Since voter turnout is traditionally lower in minority communities, and since elected officials are always looking for ways to improve their reelection chances (Mayhew 1979), elected officials are more inclined to be more responsive to, and to target programs for the population that can benefit them directly. In other words, both federal and city officials may be tempted to direct $\mathrm{CDBG}$ monies to projects in neighborhoods that can reciprocate with votes.

The ANOVA showed two distinct results. As indicated in Table 5.9, cities that have a white population less than 59.2 percent are more inclined to allocate greater monies to economic development initiatives than cities with greater white populations. Surprisingly, cities tend to allocate less CDBG monies to housing initiatives when the non-white population is high. As the white population increases, the data shows that housing allocations significantly increase. According to the data, a city that has a white 
population of less than 59.2 percent can expect about 25 percent of its CDBG budget go towards housing initiatives. By the time the white population reaches 85 percent, the average housing allocation is more than 31 percents of a city's CDBG budget. This difference may not seem great, but when a city is allocating tens of millions of dollars towards a particular funding area, a six percent allocation change can represent millions of dollars. 
Table 5.8

Comparisons of CDBG funding allocations for Regional influences

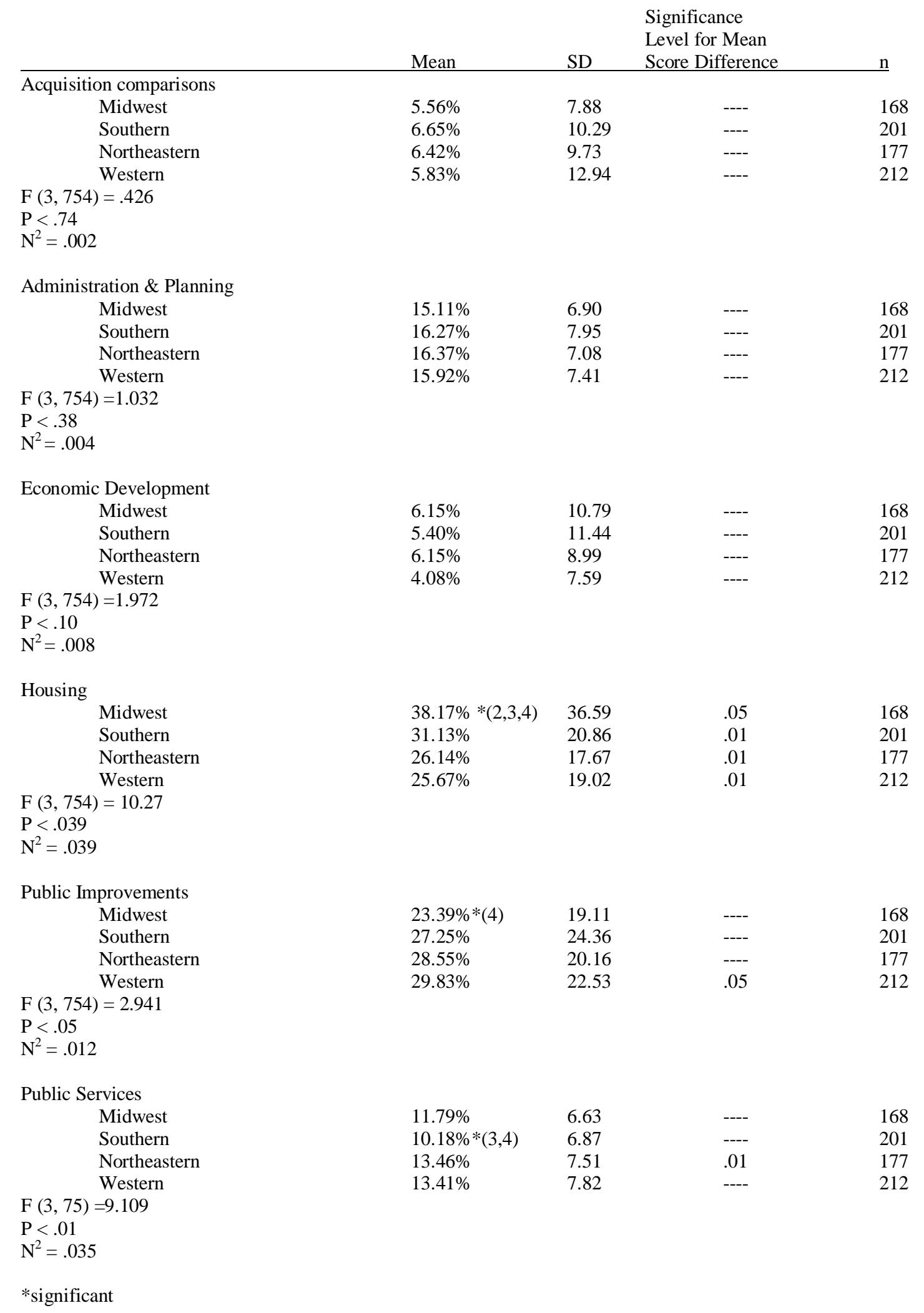


Table 5.9

Comparisons of CDBG funding allocations for size of city influences

\begin{tabular}{|c|c|c|c|c|}
\hline & Mean & $\mathrm{SD}$ & $\begin{array}{l}\text { Significance } \\
\text { Level for Mean } \\
\text { Score Difference }\end{array}$ & $\mathrm{n}$ \\
\hline \multicolumn{5}{|l|}{ Acquisition comparisons } \\
\hline Very Small (under 75k) & $6.01 \%$ & 10.81 & --- & 420 \\
\hline Small $(75 \mathrm{k}-150 \mathrm{k})$ & $5.65 \%$ & 10.69 & --- & 211 \\
\hline Medium $(150 \mathrm{k}-250 \mathrm{k})$ & $7.28 \%$ & 9.32 & --- & 63 \\
\hline Large $(250 \mathrm{k}-500 \mathrm{k})$ & $6.34 \%$ & 8.78 & ---- & 36 \\
\hline Very Large $(5500 \mathrm{k}+)$ & $8.53 \%$ & 9.28 & --- & 28 \\
\hline \multicolumn{5}{|l|}{$F(4,753)=.678$} \\
\hline \multicolumn{5}{|l|}{$P<.61$} \\
\hline \multicolumn{5}{|l|}{$\mathrm{N}^{2}=.004$} \\
\hline \multicolumn{5}{|l|}{ Administration \& Planning } \\
\hline Very Small (under 75k) & $16.10 \%$ & 7.82 & --- & 420 \\
\hline Small $(75 \mathrm{k}-150 \mathrm{k})$ & $15.87 \%$ & 7.64 & ---- & 211 \\
\hline Medium $(150 \mathrm{k}-250 \mathrm{k})$ & $16.01 \%$ & 5.06 & ---- & 63 \\
\hline Large $(250 \mathrm{k}-500 \mathrm{k})$ & $14.88 \%$ & 6.49 & ---- & 36 \\
\hline Very Large $(5500 \mathrm{k}+)$ & $15.30 \%$ & 4.55 & ---- & 28 \\
\hline \multicolumn{5}{|l|}{$\mathrm{F}(4,753)=.291$} \\
\hline \multicolumn{5}{|l|}{$\mathrm{P}<.88$} \\
\hline \multicolumn{5}{|l|}{$\mathrm{N}^{2}=.002$} \\
\hline \multicolumn{5}{|l|}{ Economic Development } \\
\hline Very Small (under 75k) & $5.08 \%$ & 9.75 & ---- & 420 \\
\hline Small $(75 \mathrm{k}-150 \mathrm{k})$ & $5.15 \%$ & 10.75 & --- & 211 \\
\hline Medium $(150 \mathrm{k}-250 \mathrm{k})$ & $5.85 \%$ & 8.69 & --- & 63 \\
\hline Large $(250 \mathrm{k}-500 \mathrm{k})$ & $7.00 \%$ & 7.53 & ---- & 36 \\
\hline Very Large $(5500 \mathrm{k}+)$ & $8.22 \%$ & 7.26 & ---- & 28 \\
\hline \multicolumn{5}{|l|}{$F(4,753)=.994$} \\
\hline \multicolumn{5}{|l|}{$P<.41$} \\
\hline \multicolumn{5}{|l|}{$\mathrm{N}^{2}=.005$} \\
\hline \multicolumn{5}{|l|}{ Housing } \\
\hline Very Small (under 75k) & $29.66 \%$ & 28.53 & --- & 420 \\
\hline Small $(75 \mathrm{k}-150 \mathrm{k})$ & $30.01 \%$ & 20.33 & ---- & 211 \\
\hline Medium $(150 \mathrm{k}-250 \mathrm{k})$ & $30.18 \%$ & 17.81 & ---- & 63 \\
\hline Large $(250 \mathrm{k}-500 \mathrm{k})$ & $32.92 \%$ & 14.64 & ---- & 36 \\
\hline Very Large $(5500 \mathrm{k}+)$ & $30.82 \%$ & 12.84 & --- & 28 \\
\hline \multicolumn{5}{|l|}{$\mathrm{F}(4,753)=.154$} \\
\hline \multicolumn{5}{|l|}{$P<.96$} \\
\hline \multicolumn{5}{|l|}{$\mathrm{N}^{2}=001$} \\
\hline \multicolumn{5}{|l|}{ Public Improvements } \\
\hline Very Small (under 75k) & $30.05 \% *(5)$ & 23.51 & .01 & 420 \\
\hline Small $(75 \mathrm{k}-150 \mathrm{k})$ & $25.95 \%$ & 20.48 & ---- & 211 \\
\hline Medium $(150 \mathrm{k}-250 \mathrm{k})$ & $23.28 \%$ & 18.00 & ---- & 63 \\
\hline Large $(250 \mathrm{k}-500 \mathrm{k})$ & $21.32 \%$ & 14.61 & ---- & 36 \\
\hline Very Large $(5500 \mathrm{k}+)$ & $16.20 \%$ & 15.04 & ---- & 28 \\
\hline \multicolumn{5}{|l|}{$\mathrm{F}(4,753)=4.95$} \\
\hline \multicolumn{5}{|l|}{$P<.01$} \\
\hline $\mathrm{N}^{2}=.026$ & & & & \\
\hline Public Services & & & & \\
\hline Very Small (under 75k) & $11.64 \% *(5)$ & 7.88 & .05 & 420 \\
\hline Small $(75 \mathrm{k}-150 \mathrm{k})$ & $12.75 \%$ & 6.61 & --- & 211 \\
\hline Medium $(150 \mathrm{k}-250 \mathrm{k})$ & $12.32 \%$ & 6.64 & ---- & 63 \\
\hline Large $(250 \mathrm{k}-500 \mathrm{k})$ & $12.70 \%$ & 5.65 & ---- & 36 \\
\hline Very Large $(5500 \mathrm{k}+)$ & 15.73 & 7.26 & --- & 28 \\
\hline$F(4,753)=2.575$ & & & & \\
\hline$P<.05$ & & & & \\
\hline $\mathrm{N}^{2}=.013$ & & & & \\
\hline
\end{tabular}


Table 5.10

Comparisons of CDBG funding allocations for form of government influences

\begin{tabular}{|c|c|c|c|c|}
\hline & Mean & $\mathrm{SD}$ & $\begin{array}{l}\text { Significance } \\
\text { Level for Mean } \\
\text { Score Difference }\end{array}$ & $\mathrm{n}$ \\
\hline \multicolumn{5}{|l|}{ Acquisition comparisons } \\
\hline Council-Manager & $6.16 \%$ & 11.47 & ---- & 421 \\
\hline Mayor-Council & $6.26 \%$ & 9.25 & ---- & 299 \\
\hline Commissioner & $5.56 \%$ & 7.59 & ---- & 15 \\
\hline \multicolumn{5}{|l|}{$\mathrm{F}(2,735)=.436$} \\
\hline \multicolumn{5}{|l|}{$\mathrm{P}<.824$} \\
\hline \multicolumn{5}{|l|}{$\mathrm{N}^{2}=.003$} \\
\hline \multicolumn{5}{|l|}{ Administration \& Planning } \\
\hline Council-Manager & $16.08 \%$ & 8.21 & ---- & 421 \\
\hline Mayor-Council & $15.91 \%$ & 6.16 & ---- & 299 \\
\hline Commissioner & $12.47 \%$ & 4.71 & --- & 15 \\
\hline \multicolumn{5}{|l|}{$F(3,735)=1.157$} \\
\hline \multicolumn{5}{|l|}{$P<.329$} \\
\hline \multicolumn{5}{|l|}{$\mathrm{N}^{2}=.008$} \\
\hline \multicolumn{5}{|l|}{ Economic Development } \\
\hline Council-Manager & $4.55 \% *(3)$ & 9.31 & .05 & 421 \\
\hline Mayor-Council & $6.81 \%$ & 10.63 & ---- & 299 \\
\hline Commissioner & $5.89 \%$ & $9 / 28$ & ---- & 15 \\
\hline \multicolumn{5}{|l|}{$F(2,735)=2.61$} \\
\hline \multicolumn{5}{|l|}{$\begin{array}{l}\mathrm{P}<.05 \\
\mathrm{~N}^{2}=017\end{array}$} \\
\hline $\mathrm{N}^{2}=.017$ & & & & \\
\hline \multicolumn{5}{|l|}{ Housing } \\
\hline Council-Manager & $31.38 \%$ & 28.50 & --- & 421 \\
\hline Mayor-Council & $28.21 \%$ & 18.00 & ---- & 299 \\
\hline Commissioner & $32.11 \%$ & 23.44 & ---- & 15 \\
\hline \multicolumn{5}{|l|}{$F(2,735)=.955$} \\
\hline \multicolumn{5}{|l|}{$\begin{array}{l}P<.444 \\
N^{2}=006\end{array}$} \\
\hline \multicolumn{5}{|l|}{$\mathrm{N}^{2}=.006$} \\
\hline \multicolumn{5}{|l|}{ Public Improvements } \\
\hline Council-Manager & $27.54 \%$ & 22.42 & ---- & 421 \\
\hline Mayor-Council & $26.72 \%$ & 20.23 & --- & 299 \\
\hline Commissioner & $28.59 \%$ & 25.77 & ---- & 15 \\
\hline \multirow{2}{*}{\multicolumn{5}{|c|}{$\mathrm{F}(2,735)=.681$}} \\
\hline \multirow{2}{*}{\multicolumn{5}{|c|}{$\begin{array}{l}\mathrm{P}<.64 \\
\mathrm{~N}^{2}=.005\end{array}$}} \\
\hline & & & & \\
\hline \multicolumn{5}{|l|}{ Public Services } \\
\hline Council-Manager & $11.97 \%$ & 7.58 & --- & 421 \\
\hline Mayor-Council & $12.78 \%$ & 7.20 & ---- & 299 \\
\hline Commissioner & $12.60 \%$ & 5.33 & --- & 15 \\
\hline \multicolumn{5}{|l|}{$F(2,735)=1.531$} \\
\hline $\mathrm{P}<.178$ & & & & \\
\hline $\mathrm{N}^{2}=.01$ & & & & \\
\hline
\end{tabular}


Table 5.11 Comparisons of CDBG funding allocations for council structure influences

\begin{tabular}{|c|c|c|c|c|}
\hline & Mean & SD & $\begin{array}{l}\text { Significance } \\
\text { Level for Mean } \\
\text { Score Difference }\end{array}$ & $\underline{\mathrm{n}}$ \\
\hline \multicolumn{5}{|l|}{ Acquisition comparisons } \\
\hline By-district & $5.43 \%$ & 8.37 & ---- & 221 \\
\hline At-large & $5.99 \%$ & 11.75 & ---- & 357 \\
\hline Both by-district \& at-large & $7.26 \%$ & 10.26 & ---- & 180 \\
\hline \multicolumn{5}{|l|}{$F(2,755)=1.546$} \\
\hline \multicolumn{5}{|l|}{$\mathrm{P}<.214$} \\
\hline \multicolumn{5}{|l|}{$\mathrm{N}^{2}=.004$} \\
\hline \multicolumn{5}{|l|}{ Administration \& Planning } \\
\hline By-district & $15.39 \%$ & 6.65 & ---- & 221 \\
\hline At-large & $16.64 \%$ & 8.46 & ---- & 357 \\
\hline Both by-district \& at-large & $15.25 \%$ & 5.86 & ---- & 180 \\
\hline \multicolumn{5}{|l|}{$F(2,755)=2.99$} \\
\hline \multicolumn{5}{|l|}{$\mathrm{P}<.05$} \\
\hline \multicolumn{5}{|l|}{$\mathrm{N}^{2}=.008$} \\
\hline \multicolumn{5}{|l|}{ Economic Development } \\
\hline By-district & $5.89 \%$ & 10.12 & ---- & 221 \\
\hline At-large & $4.75 \%$ & 9.01 & ---- & 357 \\
\hline Both by-district \& at-large & $5.99 \%$ & 10.83 & ---- & 180 \\
\hline \multicolumn{5}{|l|}{$F(2,752)=1.376$} \\
\hline \multicolumn{5}{|l|}{$\mathrm{P}<.253$} \\
\hline \multicolumn{5}{|l|}{$\mathrm{N}^{2}=.004$} \\
\hline \multicolumn{5}{|l|}{ Housing } \\
\hline By-district & $30.29 \%$ & 18.52 & ---- & 221 \\
\hline At-large & $23.33 \%$ & 20.64 & ---- & 357 \\
\hline Both by-district \& at-large & $32.98 \%$ & 35.88 & ---- & 180 \\
\hline \multicolumn{5}{|l|}{$F(2,752)=2.156$} \\
\hline \multicolumn{5}{|l|}{$P<.117$} \\
\hline \multicolumn{5}{|l|}{$\mathrm{N}^{2}=.006$} \\
\hline \multicolumn{5}{|l|}{ Public Improvements } \\
\hline By-district & $28.07 \%$ & 21.25 & ---- & 221 \\
\hline At-large & $28.31 \%$ & 22.84 & ---- & 357 \\
\hline Both by-district \& at-large & $24.88 \%$ & 20.63 & ---- & 180 \\
\hline \multicolumn{5}{|l|}{$F(2,752)=1.609$} \\
\hline \multicolumn{5}{|l|}{$P<.201$} \\
\hline \multicolumn{5}{|l|}{$\mathrm{N}^{2}=.004$} \\
\hline \multicolumn{5}{|l|}{ Public Services } \\
\hline By-district & $11.95 \%$ & 6.41 & ---- & 221 \\
\hline At-large & $12.54 \%$ & 7.99 & ---- & 357 \\
\hline Both by-district \& at-large & $11.88 \%$ & 7.19 & ---- & 180 \\
\hline$F(2,752)=.674$ & & & & \\
\hline $\mathrm{P}<.51$ & & & & \\
\hline $\mathrm{N}^{2}=.002$ & & & & \\
\hline
\end{tabular}

*Significant 
Table 5.12 Comparisons of CDBG funding allocations for Per Capita Income influences

\begin{tabular}{|c|c|c|c|c|}
\hline & Mean & SD & $\begin{array}{l}\text { Significance } \\
\text { Level for Mean } \\
\text { Score Difference }\end{array}$ & $\mathrm{n}$ \\
\hline \multicolumn{5}{|l|}{ Acquisition comparisons } \\
\hline$\$ 18 \mathrm{k}$ or less & $7.00 \%$ & 10.71 & ---- & 281 \\
\hline$\$ 18,001-\$ 30 \mathrm{k}$ & $5.27 \%$ & 9.24 & ---- & 414 \\
\hline$\$ 30,001$ or more & $7.96 \%$ & 16.00 & ---- & 62 \\
\hline \multicolumn{5}{|l|}{$\mathrm{F}(2,754)=3.295$} \\
\hline \multirow{2}{*}{\multicolumn{5}{|c|}{$\begin{array}{l}\mathrm{P}<.05 \\
\mathrm{~N}^{2}=.009\end{array}$}} \\
\hline & & & & \\
\hline \multicolumn{5}{|l|}{ Administration \& Planning } \\
\hline$\$ 18 \mathrm{k}$ or less & $16.24 \%$ & 6.78 & ---- & 281 \\
\hline$\$ 18,001-\$ 30 \mathrm{k}$ & $15.74 \%$ & 7.24 & ---- & 414 \\
\hline$\$ 30,001$ or more & $15.90 \%$ & 10.80 & ---- & 62 \\
\hline \multicolumn{5}{|l|}{$F(2,754)=.374$} \\
\hline \multicolumn{5}{|l|}{$\begin{array}{l}\mathrm{P}<.68 \\
-68\end{array}$} \\
\hline \multicolumn{5}{|l|}{$\mathrm{N}^{2}=.001$} \\
\hline \multicolumn{5}{|l|}{ Economic Development } \\
\hline$\$ 18 \mathrm{k}$ or less & $6.73 \% *(2)$ & 10.92 & .05 & 281 \\
\hline$\$ 18,001-\$ 30 \mathrm{k}$ & $4.69 \%$ & 8.57 & ---- & 414 \\
\hline$\$ 30,001$ or more & $3.98 \%$ & 11.49 & ---- & 62 \\
\hline \multicolumn{5}{|l|}{$F(2,754)=4.369$} \\
\hline \multicolumn{5}{|l|}{$\begin{array}{l}\mathrm{P}<.01 \\
\mathrm{~N}^{2}=.011\end{array}$} \\
\hline $\mathrm{N}^{2}=.011$ & & & & \\
\hline \multicolumn{5}{|l|}{ Housing } \\
\hline$\$ 18 \mathrm{k}$ or less & $25.83 \% *(2)$ & 30.20 & .01 & 281 \\
\hline$\$ 18,001-\$ 30 \mathrm{k}$ & $33.51 \%$ & 19.77 & --- & 414 \\
\hline$\$ 30,001$ or more & $25.80 \%$ & 22.87 & ---- & 62 \\
\hline \multirow{2}{*}{\multicolumn{5}{|c|}{$\mathrm{F}(2,754)=9.319$}} \\
\hline & & & & $\begin{array}{l}\mathrm{P}<.01 \\
\mathrm{~N}^{2}=.024\end{array}$ \\
\hline $\mathrm{N}^{2}=.024$ & & & & \\
\hline \multicolumn{5}{|l|}{ Public Improvements } \\
\hline$\$ 18 \mathrm{k}$ or less & $28.82 \%$ & 21.34 & ---- & 281 \\
\hline$\$ 18,001-\$ 30 \mathrm{k}$ & $25.98 \%$ & 21.54 & ---- & 414 \\
\hline$\$ 30,001$ or more & $30.35 \%$ & 25.94 & ---- & 62 \\
\hline \multicolumn{5}{|l|}{$F(2,754)=2.032$} \\
\hline \multicolumn{5}{|l|}{$\mathrm{P}<.132$} \\
\hline \multicolumn{5}{|l|}{$\mathrm{N}^{2}=.005$} \\
\hline \multicolumn{5}{|l|}{ Public Services } \\
\hline$\$ 18 \mathrm{k}$ or less & $11.81 \% *(3)$ & 7.12 & .01 & 281 \\
\hline$\$ 18,001-\$ 30 \mathrm{k}$ & $12.07 \% *(3)$ & 6.70 & .01 & 414 \\
\hline$\$ 30,001$ or more & $14.99 \% *(2,3)$ & 11.32 & .01 & 62 \\
\hline $\mathrm{F}(2,754)=4.955$ & & & & \\
\hline $\mathrm{P}<.01$ & & & & \\
\hline $\mathrm{N}^{2}=.013$ & & & & \\
\hline
\end{tabular}

*Significant 
Table 5.13 Comparisons of CDBG funding allocations for Poverty level influences

\begin{tabular}{|c|c|c|c|c|}
\hline & Mean & SD & $\begin{array}{l}\text { Significance } \\
\text { Level for Mean } \\
\text { Score Difference }\end{array}$ & $\underline{\mathrm{n}}$ \\
\hline \multicolumn{5}{|l|}{ Acquisition comparisons } \\
\hline $8.8 \%$ or less & $4.42 \% *(3)$ & 10.67 & .05 & 198 \\
\hline $8.9 \%$ to $14.1 \%$ & $6.49 \%$ & 11.08 & ---- & 181 \\
\hline $14.2 \%$ or more & $6.85 \%$ & 10.09 & ---- & 379 \\
\hline \multicolumn{5}{|l|}{$F(2,755)=3.646$} \\
\hline \multicolumn{5}{|l|}{$\mathrm{P}<.05$} \\
\hline \multicolumn{5}{|l|}{$\mathrm{N}^{2}=.01$} \\
\hline \multicolumn{5}{|l|}{ Administration \& Planning } \\
\hline $8.8 \%$ or less & $16.33 \%$ & 9.04 & ---- & 198 \\
\hline $8.9 \%$ to $14.1 \%$ & $15.81 \%$ & 7.73 & ---- & 181 \\
\hline $14.2 \%$ or more & $15.81 \%$ & 6.45 & ---- & 379 \\
\hline \multicolumn{5}{|l|}{$\mathrm{F}(2,755)=.354$} \\
\hline \multicolumn{5}{|l|}{$P<.702$} \\
\hline \multicolumn{5}{|l|}{$\mathrm{N}^{2}=.001$} \\
\hline \multicolumn{5}{|l|}{ Economic Development } \\
\hline $8.8 \%$ or less & $3.51 \% *(3)$ & 9.15 & .01 & 198 \\
\hline $8.9 \%$ to $14.1 \%$ & $4.85 \%$ & 8.73 & ---- & 181 \\
\hline $14.2 \%$ or more & $6.61 \%$ & 10.43 & ---- & 379 \\
\hline \multicolumn{5}{|l|}{$F(2,755)=6.953$} \\
\hline \multicolumn{5}{|l|}{$\mathrm{P}<.01$} \\
\hline \multicolumn{5}{|l|}{$\mathrm{N}^{2}=.018$} \\
\hline \multicolumn{5}{|l|}{ Housing } \\
\hline $8.8 \%$ or less & $31.44 \%$ & 22.43 & ---- & 198 \\
\hline $8.9 \%$ to $14.1 \%$ & $31.04 \%$ & 19.12 & ---- & 181 \\
\hline $14.2 \%$ or more & $28.75 \%$ & 27.89 & ---- & 379 \\
\hline \multicolumn{5}{|l|}{$F(2,755)=.985$} \\
\hline \multicolumn{5}{|l|}{$P<.374$} \\
\hline \multicolumn{5}{|l|}{$\mathrm{N}^{2}=.003$} \\
\hline \multicolumn{5}{|l|}{ Public Improvements } \\
\hline $8.8 \%$ or less & $29.30 \%$ & 24.02 & ---- & 198 \\
\hline $8.9 \%$ to $14.1 \%$ & $26.73 \%$ & 21.48 & ---- & 181 \\
\hline $14.2 \%$ or more & $26.77 \%$ & 20.89 & ---- & 379 \\
\hline \multicolumn{5}{|l|}{$F(2,755)=.988$} \\
\hline \multicolumn{5}{|l|}{$\mathrm{P}<.373$} \\
\hline \multicolumn{5}{|l|}{$\mathrm{N}^{2}=.003$} \\
\hline \multicolumn{5}{|l|}{ Public Services } \\
\hline $8.8 \%$ or less & $12.57 \%$ & 7.74 & ---- & 198 \\
\hline $8.9 \%$ to $14.1 \%$ & $12.57 \%$ & 7.66 & ---- & 181 \\
\hline $14.2 \%$ or more & $11.85 \%$ & 7.02 & --- & 379 \\
\hline \multicolumn{5}{|l|}{$F(2,755)=.91$} \\
\hline$P<.403$ & & & & \\
\hline $\mathrm{N}^{2}=.002$ & & & & \\
\hline
\end{tabular}

*Significant 
Table 5.14 Comparisons of CDBG funding allocations for Unemployment influences

\begin{tabular}{|c|c|c|c|c|}
\hline & Mean & SD & $\begin{array}{l}\text { Significance } \\
\text { Level for Mean } \\
\text { Score Difference }\end{array}$ & $\underline{n}$ \\
\hline \multicolumn{5}{|l|}{ Acquisition comparisons } \\
\hline $3 \%$ or less & $5.13 \%$ & 10.96 & ---- & 197 \\
\hline $3.1 \%$ to $3.8 \%$ & $6.47 \%$ & 11.49 & ---- & 184 \\
\hline $3.9 \%$ or more & $6.49 \%$ & 9.76 & ---- & 377 \\
\hline \multicolumn{5}{|l|}{$F(2,755)=1.206$} \\
\hline \multicolumn{5}{|l|}{$\mathrm{P}<.3$} \\
\hline \multicolumn{5}{|l|}{$\mathrm{N}^{2}=.003$} \\
\hline \multicolumn{5}{|l|}{ Administration \& Planning } \\
\hline $3 \%$ or less & $15.86 \%$ & 8.72 & ---- & 197 \\
\hline $3.1 \%$ to $3.8 \%$ & $16.12 \%$ & 6.93 & ---- & 184 \\
\hline $3.9 \%$ or more & $15.90 \%$ & 6.91 & ---- & 377 \\
\hline \multicolumn{5}{|l|}{$F(2,755)=.073$} \\
\hline \multicolumn{5}{|l|}{$P<.929$} \\
\hline \multicolumn{5}{|l|}{$\mathrm{N}^{2}=.000$} \\
\hline \multicolumn{5}{|l|}{ Economic Development } \\
\hline $3 \%$ or less & $3.99 \% *(3)$ & 9.36 & .05 & 197 \\
\hline $3.1 \%$ to $3.8 \%$ & $5.51 \%$ & 9.41 & ---- & 184 \\
\hline $3.9 \%$ or more & $6.04 \%$ & 10.15 & ---- & 377 \\
\hline \multicolumn{5}{|l|}{$F(2,755)=2.83$} \\
\hline \multicolumn{5}{|l|}{$\mathrm{P}<.1$} \\
\hline \multicolumn{5}{|l|}{$\mathrm{N}^{2}=.007$} \\
\hline \multicolumn{5}{|l|}{ Housing } \\
\hline $3 \%$ or less & $30.74 \%$ & 22.54 & ---- & 197 \\
\hline $3.1 \%$ to $3.8 \%$ & $33.34 \% *(3)$ & 35.68 & .05 & 184 \\
\hline $3.9 \%$ or more & $27.99 \%$ & 18.15 & ---- & 377 \\
\hline \multicolumn{5}{|l|}{$F(2,755)=3.043$} \\
\hline \multicolumn{5}{|l|}{$\mathrm{P}<.0 .5$} \\
\hline \multicolumn{5}{|l|}{$\mathrm{N}^{2}=.008$} \\
\hline \multicolumn{5}{|l|}{ Public Improvements } \\
\hline $3 \%$ or less & $29.49 \%$ & 24.73 & ---- & 197 \\
\hline $3.1 \%$ to $3.8 \%$ & $25.74 \%$ & 20.33 & ---- & 184 \\
\hline $3.9 \%$ or more & $27.16 \%$ & 21.00 & ---- & 377 \\
\hline \multicolumn{5}{|l|}{$F(2,755)=1.447$} \\
\hline \multicolumn{5}{|l|}{$\mathrm{P}<.236$} \\
\hline \multicolumn{5}{|l|}{$\mathrm{N}^{2}=.004$} \\
\hline \multicolumn{5}{|l|}{ Public Services } \\
\hline $3 \%$ or less & $12.87 \%$ & 8.86 & ---- & 197 \\
\hline $3.1 \%$ to $3.8 \%$ & $12.09 \%$ & 6.83 & ---- & 184 \\
\hline $3.9 \%$ or more & $11.93 \%$ & 6.74 & ---- & 377 \\
\hline \multicolumn{5}{|l|}{$F(2,755)=1.093$} \\
\hline \multicolumn{5}{|l|}{$\mathrm{P}<.336$} \\
\hline $\mathrm{N}^{2}=.003$ & & & & \\
\hline
\end{tabular}


Table 5.15 Comparisons of CDBG funding allocations for Housing Values influences

\begin{tabular}{|c|c|c|c|c|}
\hline & Mean & SD & $\begin{array}{l}\text { Significance } \\
\text { Level for Mean } \\
\text { Score Difference }\end{array}$ & $\underline{\mathrm{n}}$ \\
\hline \multicolumn{5}{|l|}{ Acquisition comparisons } \\
\hline$\$ 75 \mathrm{k}$ or less & $7.65 \%$ & 8.18 & ---- & 134 \\
\hline$\$ 75,001$ to $\$ 150 \mathrm{k}$ & $6.11 \%$ & 10.41 & ---- & 412 \\
\hline$\$ 150,001$ or more & $5.20 \%$ & 11.88 & ---- & 212 \\
\hline \multicolumn{5}{|l|}{$F(2,755)=2.232$} \\
\hline \multicolumn{5}{|l|}{$\mathrm{P}<.11$} \\
\hline \multicolumn{5}{|l|}{$\mathrm{N}^{2}=.006$} \\
\hline \multicolumn{5}{|l|}{ Administration \& Planning } \\
\hline$\$ 75 \mathrm{k}$ or less & $15.87 \%$ & 5.87 & ---- & 134 \\
\hline$\$ 75,001$ to $\$ 150 \mathrm{k}$ & $15.93 \%$ & 7.39 & ---- & 412 \\
\hline$\$ 150,001$ or more & $16.01 \%$ & 8.32 & ---- & 212 \\
\hline \multicolumn{5}{|l|}{$F(2,755)=.016$} \\
\hline \multicolumn{5}{|l|}{$P<.984$} \\
\hline \multicolumn{5}{|l|}{$\mathrm{N}^{2}=.000$} \\
\hline \multicolumn{5}{|l|}{ Economic Development } \\
\hline$\$ 75 \mathrm{k}$ or less & $5.72 \%$ & 9.17 & ---- & 134 \\
\hline$\$ 75,001$ to $\$ 150 \mathrm{k}$ & $5.63 \%$ & 9.82 & ---- & 412 \\
\hline$\$ 150,001$ or more & $4.67 \%$ & 10.13 & ---- & 212 \\
\hline \multicolumn{5}{|l|}{$F(2,755)=.766$} \\
\hline \multicolumn{5}{|l|}{$\mathrm{P}<.465$} \\
\hline \multicolumn{5}{|l|}{$\mathrm{N}^{2}=.002$} \\
\hline \multicolumn{5}{|l|}{ Housing } \\
\hline$\$ 75 \mathrm{k}$ or less & $32.65 \%$ & 39.39 & ---- & 134 \\
\hline$\$ 75,001$ to $\$ 150 \mathrm{k}$ & $30.17 \%$ & 19.99 & ---- & 412 \\
\hline$\$ 150,001$ or more & $27.99 \%$ & 20.39 & ---- & 212 \\
\hline \multicolumn{5}{|l|}{$F(2,755)=1.486$} \\
\hline \multicolumn{5}{|l|}{$\mathrm{P}<.227$} \\
\hline \multicolumn{5}{|l|}{$\mathrm{N}^{2}=.004$} \\
\hline \multicolumn{5}{|l|}{ Public Improvements } \\
\hline$\$ 75 \mathrm{k}$ or less & $25.97 \%$ & 19.40 & ---- & 134 \\
\hline$\$ 75,001$ to $\$ 150 \mathrm{k}$ & $27.49 \%$ & 22.22 & ---- & 412 \\
\hline$\$ 150,001$ or more & $28.22 \%$ & 22.76 & ---- & 212 \\
\hline \multicolumn{5}{|l|}{$F(2,755)=.434$} \\
\hline \multicolumn{5}{|l|}{$\mathrm{P}<.648$} \\
\hline \multicolumn{5}{|l|}{$\mathrm{N}^{2}=.001$} \\
\hline \multicolumn{5}{|l|}{ Public Services } \\
\hline$\$ 75 \mathrm{k}$ or less & $10.69 \% *(3)$ & 6.09 & .01 & 134 \\
\hline$\$ 75,001$ to $\$ 150 \mathrm{k}$ & $11.98 \%$ & 7.32 & ---- & 412 \\
\hline$\$ 150,001$ or more & $13.62 \%$ & 7.996 & --- & 212 \\
\hline \multicolumn{5}{|l|}{$F(2,755)=7.025$} \\
\hline $\mathrm{P}<.01$ & & & & \\
\hline $\mathrm{N}^{2}=.018$ & & & & \\
\hline
\end{tabular}

*Significant 
Table 5.16

Comparisons of CDBG funding allocations for Racial influence

\begin{tabular}{|c|c|c|c|c|}
\hline & Mean & SD & $\begin{array}{l}\text { Significance } \\
\text { Level for Mean } \\
\text { Score Difference }\end{array}$ & $\mathrm{n}$ \\
\hline \multicolumn{5}{|l|}{ Acquisition comparisons } \\
\hline $59.2 \%$ or less white & $7.39 \%$ & 11.81 & ---- & 185 \\
\hline $59.3 \%$ to $85.5 \%$ white & $5.96 \%$ & 10.40 & ---- & 388 \\
\hline $85.6 \%$ or more white & $5.20 \%$ & 9.24 & ---- & 185 \\
\hline \multicolumn{5}{|l|}{$F(2,755)=2.123$} \\
\hline \multicolumn{5}{|l|}{$\begin{array}{l}\mathrm{P}<.05 \\
N^{2}=006\end{array}$} \\
\hline $\mathrm{N}^{2}=.006$ & & & & \\
\hline \multicolumn{5}{|l|}{ Administration \& Planning } \\
\hline $59.2 \%$ or less white & 16.08 & 7.53 & ---- & 185 \\
\hline $59.3 \%$ to $85.5 \%$ white & 16.32 & 7.88 & ---- & 388 \\
\hline $85.6 \%$ or more white & 15.01 & 6.12 & ---- & 185 \\
\hline \multicolumn{5}{|l|}{$F(2,755)=2.005$} \\
\hline \multicolumn{5}{|l|}{$\mathrm{P}<.15$} \\
\hline \multicolumn{5}{|l|}{$\mathrm{N}^{2}=.005$} \\
\hline \multicolumn{5}{|l|}{ Economic Development } \\
\hline $59.2 \%$ or less white & $7.06 *(2)$ & 11.60 & .05 & 185 \\
\hline $59.3 \%$ to $85.5 \%$ white & 4.84 & 9.06 & ---- & 388 \\
\hline $85.6 \%$ or more white & 4.81 & 9.12 & ---- & 185 \\
\hline \multicolumn{5}{|l|}{$F(2,755)=3.637$} \\
\hline \multicolumn{5}{|l|}{$P<.05$} \\
\hline \multicolumn{5}{|l|}{$\mathrm{N}^{2}=.01$} \\
\hline \multicolumn{5}{|l|}{ Housing } \\
\hline $59.2 \%$ or less white & $24.80 *(2,3)$ & 15.86 & .01 & 185 \\
\hline $59.3 \%$ to $85.5 \%$ white & 31.83 & 29.18 & ---- & 388 \\
\hline $85.6 \%$ or more white & 31.36 & 20.52 & .05 & 185 \\
\hline \multicolumn{5}{|l|}{$\mathrm{F}(2,755)=5.52$} \\
\hline \multicolumn{5}{|l|}{$\begin{array}{l}\mathrm{P}<.01 \\
\mathrm{~N}^{2}=.014\end{array}$} \\
\hline & & & & \\
\hline \multicolumn{5}{|l|}{ Public Improvements } \\
\hline $59.2 \%$ or less white & 26.80 & 21.25 & ---- & 185 \\
\hline $59.3 \%$ to $85.5 \%$ white & 27.03 & 22.60 & ---- & 388 \\
\hline $85.6 \%$ or more white & 28.85 & 20.93 & ---- & 185 \\
\hline \multicolumn{5}{|l|}{$\mathrm{F}(2,755)=.53$} \\
\hline \multicolumn{5}{|l|}{$P<.01$} \\
\hline \multicolumn{5}{|l|}{$\mathrm{N}^{2}=.001$} \\
\hline \multicolumn{5}{|l|}{ Public Services } \\
\hline $59.2 \%$ or less white & 12.66 & 6.92 & ---- & 185 \\
\hline $59.3 \%$ to $85.5 \%$ white & 12.25 & 7.34 & ---- & 388 \\
\hline $85.6 \%$ or more white & 11.67 & 7.82 & --- & 185 \\
\hline \multicolumn{5}{|l|}{$\mathrm{F}(2,755)=.837$} \\
\hline $\mathrm{P}<.01$ & & & & \\
\hline $\mathrm{N}^{2}=.002$ & & & & \\
\hline
\end{tabular}




\section{Multiple Relationships}

Earlier in this chapter, I introduced an ANOVA test to compare the individual mean allocations of each dependent variable to determine their significance levels. These tests yielded many significance results at the .05 level (see Table 5.17). Unfortunately, these results do not fully explain how and why CDBG allocations are made. Because the decision-making process is so complex, it is important to consider the interactions of all the independent variables on the dependent variable. Since the independent variables may be correlated, it is important to consider the effect that each independent variable has on the others. These correlations will tell us which independent variables have an association with each dependent variable beyond that is already explained by the other variables. Additionally, since the dependent variables are related, an increase in one coefficient is by definition cause for a decrease in at least one of the other dependent variables. Therefore, it is important to consider the impact of each independent variable on the set of dependent variables. The MANOVA model shown here accomplishes both of these things. All the independent variables are included in the model. It is a multivariate model (instead of the bivariate ANOVA models presented earlier) and all the dependent variables are included in the model. The results show the effect of each independent variable controlling for the others and shows the strength of the association each independent variable has with the set of dependent variables and each one separately. Through the use of a MANOVA test (see Table 5.18), it is possible to test the influence of an independent variable by examining them collectively.

After running the MANOVA, there were five independent variables whose results differed from those found in the bivariate ANOVA models: form of government, race, 
housing values, unemployment levels, and per capita income. The change in significance levels between models suggests that there are other explanations, such as demographics or the economy that help to explain CDBG allocation decisions.

The first difference of the MANOVA test suggests that the mean allocations for CDBG housing allocations vary significant when the form of government variable is considered with economic, geographical and political variables. In the case of a strong mayor form of government, for example, it is possible that allocation decisions are driven by reelection concerns and that funding decisions are influenced by a city's political environment, wealth or racial balance.

Race, on the other hand, did not prove to be statistically significant when considered with the other independent variables. These findings are not surprising, however, since other demographic and economic factors such as housing values and per capita income often influence CDBG allocations. Put another way, the decision to fund a particular public service initiative or public improvement project, for example, has more to do with the economic health and well being of a community, rather than its racial makeup.

When housing value was tested without the interactions of other independent variables, the coefficient for public services is statistically significant. When other independent variables are thrown into the mix, however, the significance levels shift from public services allocation to economic development and housing rehabilitation initiatives. Although the reason for this shift is unclear, it seems plausible that the influence of economic data and demographics play a salient role in altering the significance levels for housing values. Since housing values are sometimes associated with the popularity of a 
particular region or availability of jobs or industry, the influence of economic development and the local housing infrastructure becomes salient.

A city's unemployment rate, without the influence of additional independent variables, is significant in the allocation of economic development and housing rehabilitation dollars. When additional independent variables are introduced, however, the significance level for any one funding source disappears. This lack of significance may be due to a city's unique economic and demographical structure. A high growth area, for example, is more likely to keep unemployment rates stagnant since poverty levels are lower and job opportunities are plentiful.

The final difference between the MANOVA and earlier results suggest that per capita income is no longer significantly associated with either economic development or public services when multiple independent variables are introduced. Instead, the association between per capita income and the acquisition and public improvement variables for $\mathrm{CDBG}$ allocations become significant. This change of significance may be associated with the influence of a city's economic and demographical circumstances. In other words, income level coupled with geographical location and overall wealth of the community plays a larger role in determining which public improvements get completed and which land that gets acquired for future development. It should also be noted that housing allocations remained significant for both the individual and multiple variable tests, suggesting that income levels are significant in the allocation of CDBG monies irrespective of the other independent variables. 


\begin{tabular}{|c|c|c|c|c|c|c|c|c|}
\hline \multirow[t]{2}{*}{ Table 5.17} & \multicolumn{8}{|c|}{ Analysis of Variance (ANOVA) } \\
\hline & $\mathrm{P}$ Value & $\begin{array}{c}\text { Eta } \\
\text { Square }\end{array}$ & Acquisition & $\begin{array}{l}\text { Admin.\& } \\
\text { Planning }\end{array}$ & $\begin{array}{c}\text { Economic } \\
\text { Development }\end{array}$ & Housing & $\begin{array}{c}\text { Public } \\
\text { Improvements }\end{array}$ & $\begin{array}{c}\text { Public } \\
\text { Services }\end{array}$ \\
\hline Region & $<.05$ & $<.04$ & & & & $\mathrm{x}$ & $\mathrm{x}$ & $\mathrm{x}$ \\
\hline City size & $<.05$ & $<.03$ & & & & & $\mathrm{x}$ & $\mathrm{x}$ \\
\hline Form of gov't & $<.05$ & .017 & & & $\mathrm{x}$ & & & \\
\hline Council structure & $<.05$ & $<.05$ & & & & & & \\
\hline Race & $<.05$ & $<.014$ & & & $\mathrm{x}$ & $\mathrm{x}$ & & \\
\hline Housing values & $<.01$ & $<.018$ & & & & & & $\mathrm{x}$ \\
\hline Unemployment & $<.10$ & $<.008$ & & & $\mathrm{x}$ & $\mathrm{x}$ & & \\
\hline Per capita income & $<.01$ & $<.024$ & & & $\mathrm{x}$ & $\mathrm{x}$ & & $\mathrm{x}$ \\
\hline Poverty & $<.05$ & $<.018$ & $\mathrm{x}$ & & $\mathrm{x}$ & & & \\
\hline
\end{tabular}

\begin{tabular}{|c|c|c|c|c|c|c|c|c|}
\hline \multirow[t]{2}{*}{ Table 5.18} & \multicolumn{8}{|c|}{$\begin{array}{c}\text { Multiple Analysis of Variance (MANOVA) } \\
\text { Interactions Between Variables }\end{array}$} \\
\hline & P Value* & $\begin{array}{c}\text { Eta } \\
\text { Square }\end{array}$ & Acquisition & $\begin{array}{l}\text { Admin.\& } \\
\text { Planning }\end{array}$ & $\begin{array}{c}\text { Economic } \\
\text { Development }\end{array}$ & Housing & $\begin{array}{l}\text { Public } \\
\text { Improvements }\end{array}$ & $\begin{array}{l}\text { Public } \\
\text { Services }\end{array}$ \\
\hline Region & $<.001$ & .025 & & & & $\mathrm{x}$ & $\mathrm{x}$ & $\mathrm{x}$ \\
\hline City size & .02 & .021 & & & & & $\mathrm{x}$ & $\mathrm{x}$ \\
\hline Form of gov't & .15 & .013 & & & & $\mathrm{x}$ & & \\
\hline Council structure & .32 & .010 & & & & & & \\
\hline Race & .16 & .013 & & & & & & \\
\hline Housing values & .07 & .016 & $\mathrm{x}$ & & $\mathrm{x}$ & $\mathrm{x}$ & & \\
\hline Unemployment & .51 & .003 & & & & & & \\
\hline Per capita income & .02 & .020 & $\mathrm{x}$ & & & $\mathrm{x}$ & $\mathrm{x}$ & \\
\hline Poverty & .04 & .018 & $\mathrm{x}$ & & $\mathrm{x}$ & & & \\
\hline
\end{tabular}




\section{Chapter Six}

\section{Conclusion}

\section{Introduction}

Earlier in this study, I argued that the motivations of elected officials, coupled with the political, economic and social characteristics of a local government, play a salient role in the way CDBG funds are allocated. I demonstrated that the traditional distributive politics model, even when blended with a demand-side explanation, is inadequate as an explanatory tool for how CDBG monies are distributed and used. I suggested that through an expanded distributive politics model -- one that takes into account the motivation, form of government, size of city, geographical region, economic indicators, and racial make-up of a recipient jurisdiction - it is possible to advance a comprehensive explanation for how and why elected officials, namely mayors, allocate federal benefits.

I also introduced a symbiotic model, one that parallels a traditional economic supply and demand model, to help explain the decision-making relationships between the national, local and bureaucratic stakeholders of an entitlement community. This model served as a visual representation of the stakeholders' interactions and suggested that the distribution of federal monies is a two-way street, with bureaucrats and politicians at both the federal and local - levels all acting to secure their own self-interest, while attempting to keep all other interested parties satisfied. This model was then applied to the actual CDBG allocations of four Pennsylvania cities: Altoona, Sharon, Pittsburgh and Philadelphia. Through a case study approach, I was able to explain in depth how and why decision-makers distribute and use CDBG dollars. 
Next, I expanded my four city case study approach to include data from each and every CDBG entitlement community in the United States that has received or continues to receive direct $\mathrm{CDBG}$ funding from the federal government, so that a broader and more comprehensive perspective on the distribution and implementation processes for CDBG monies could be considered. By looking at the contextual factors on a national level, I was able to draw conclusions about which factors significantly affect CDBG allocations.

So how does the devolution of federal dollars to the cities help the poor and disadvantaged? By looking at the case study and national data, despite the fact that monies are sometimes redirected for unintended purposes, the majority of the federal dollars do get redirected to economic development and employment opportunities for the poor. Because CDBG dollars must be spent within several broad spending categories, all designed to benefit low and moderate income people, the bulk of the monies are usually spent in the spirit in which they were intended. So does this form of federalism undercut Washington's good intentions (Pressman and Wildavsky 1973)? The answer to this question is both yes and no: yes in that federal dollars are sometimes redirected to inappropriate and self-serving uses; no in that the overwhelming bulk of the federal dollars to assist the low and moderate income population.

The low and moderate income neighborhoods have seen their roads improved, housing stock updated and their social services increased. In fact, of the CDBG entitlement cities examined for 2001, more than $30 \%$ of a city's CDBG allocations went to housing stock improvements. Because of this study, several interesting questions arose about the benefits and problems associated with allowing cities to allocate federal monies to localities. 


\section{Future Research}

For future research, I expand the overall size of my case study population. For purposes of this study, I researched four Pennsylvania cities to see how CDBG allocation

decisions were made. I scrutinized decades of CDBG budgets in the hopes of identifying funding trends. I also interviewed elected officials and bureaucratic leaders that administer the CDBG program to obtain their insight and understanding of their decisionmaking processes. This level of detail helped me identify distinct funding patterns for large and small cities. In the future, I would like to analyze data from cities nationwide to better understand the way elected officials make CDBG allocation decisions.

In the future, I would be interested to see if the relationship between city size and elected officials' desire to increase their own visibility could be tested, perhaps by conducting in depth interviews of city officials by region. By looking at region along with the economic, demographic, social and political influences of that city, it might be possible to more definitely determine whether or not the desire to fund highly visible projects is limited to larger cities. Similarly, I could look at electoral competitions for both small and large cities to continue to clarify how CDBG funding decisions are correlated with various officials' incumbencies. Such expansions of my study would contribute to detailed explanations of how and why certain contextual factors influence certain projects for certain cities.

\section{Conclusion}

Satisfying campaign promises, obtaining constituent support and gaining reelection are just some of the constant struggles of holding a public office. Performing 
one's job professionally while maintaining constituent support requires both skill and innovation. When presented with an opportunity to deliver on campaign promises while gaining constituent approval by expending federal funds, some politicians who control these funds are tempted to take advantage of this opportunity in ways that might appear self-serving. A mayor's seeming ability to reallocate federal monies at her total discretion offers unique opportunities for the mayors and program administrators across the nation to utilize community-intended funding for purposes that are inconsistent with the program's intent.

But do allocation decisions that not strictly in line with a federal program's intent constitute misappropriation of federal dollars? Or, might such decisions reflect a mayor's sophisticated understanding of how to use available federal monies to truly benefit her own community? Unfortunately, the answer to these questions is not clear. It is clear, though, that CDBG allocations seem to serve the political interests of the elite while exhibiting some residual benefits of the poor. It is these poorest members of the locality that suffer the greatest consequence of misappropriating federal dollars - diverting federal dollars from their intended purposes.

The size of a city and its geographical location also plays a role in determining how federal funds will be spent. Big city mayors seemingly face very different demands than their smaller city counterparts when it comes to the sheer volume of interest groups they must deal with, the strategies in dealing with and appeasing their city-council, the working relationship with their program supervisors or bureaucrats, and the continuous threat of viable challengers to unseat them when reelection time occurs. Whatever the reason, the allocation and distribution of federal grant dollars to specific projects has 
more to do with the contextual factors that influence a local official's decision-making processes than previously thought under the traditional distributive politics model. My current and continuing study of these contextual factors will improve understanding and, potentially, improve predictive and evaluative models for those who engage in and analyze the past and ongoing distribution of many millions of grant dollars. 


\section{References}

“All Politics." Available from

http://www.cnn.com/ALLPOLITICS/1997/gen/resources/ection97/mayors.html;

Internet, accessed 8 November 2005.

“Allegheny county elections director forecasts sparse turnout.” Available from http://www.post-gazette.com/pg/05125/499343.stm; 15 November, 2005.

“American FactFinder.” Available from http://factfinder.census.gov/servlet/saffacts; accessed 15 December 2005.

Anagnoson, Theodore. 1982. "Federal Grant Agencies and Congressional Election Campaigns.” American Journal of Political Science. 26: 547-561.

Andres, Gary J. 1995. "Pork Barrel Spending. On the Wane?" Political Science and Politics. 28:2. June: 207-211.

Baker, William D. and John R. 2001. "Patriotism or Opinion Leadership? The Nature and Origins of the Rally Round the Flag Effect." Journal of Conflict Resolution. 45: 661-687.

Balla, Steven J., Eric D. Lawrence, Forrest Maltzman, and Lee Sigelman. 2002. "Partisanship, Blame Avoidance, and the Distribution of Legislative Pork." American Journal of Political Science. 46:3. July: 515-525.

Barrett, R. Morris 1997. “The Price of Pork.” All Politics. June 9: 1-7.

Bellisario, Rich. Community Development Program Supervisor of the City of Pittsburgh. Interview by author, 8 July 2003. Pittsburgh, Pa.

Bickers, Kenneth N. and Robert M. Stein. 1996. "The Electoral Dynamics of the Federal Pork Barrel." American Journal of Political Science. 40:4. November:1300-1326. 
Brehm, John and Scott Gates. 1997. Working, Shirking, and Sabotage. Ann Arbor: University of Michigan Press.

Browning, Rufus P. and Herbert Jacob. 1964. "Power Motivation and the Political Personality. "Public Opinion Quarterly. 28:1. Spring: pp. 75-90.

Cameron, David R. 1978. "The Expansion of the Public Economy: A Comparative Analysis.” American Political Science Review. 72. December: 1243-1261.

City of Altoona. Consolidated Community Development Plan 1975-2003. Altoona, Pa.

City of Philadelphia. Consolidated Community Development Plan 1975-2003. Philadelphia, Pa.

"City of Philadelphia: Comprehensive Plan.” Available from http:// www.phila.gov/ohcd/complan31/appendix.pdf; Internet; accessed 2 February 2006.

"Code of Federal Regulations." United States Department of Housing and Urban Development 2003. (24, Parts 500-699). Washington, DC: USGPO. 31-171.

“Community Development Block Grant Entitlement Communities Grants," U.S. Department of Housing and Urban Development (HUD). Available from http://www.hud.gov/offices/cpd/communitydevelopment/programs/entitlement/in dex.cfm; Internet; accessed 7 October 2005.

"Community Development Block Grant Entitlement Communities Grants," U.S. Department of Housing and Urban Development (HUD). Available from http://www.hud.gov/offices/cpd/systems/idis/library/refmanual/ref_man_b.pdf; Internet; accessed 30 September 2005.

"Community Development Block Grant Entitlement Program Regulations." Office of Community Planning and Development: 24 CFR 570: March 1996. 
"Community Development in Pittsburgh." City of Pittsburgh A Ten Year Commitment to the Neighborhoods 1975-1984. Pittsburgh, Pa.

“Community Development Program Supervisor Job Description." Department of Personnel and Civil Service Commission, City of Pittsburgh. 1995.

"Consolidated Community Development Plan: City of Pittsburgh Action Plan 2002." Pittsburgh, Pa.

"Consolidated Community Development Plan: City of Pittsburgh Action Plan 2003." Pittsburgh, Pa.

“Consolidated Community Development Plan: City of Pittsburgh 1975-2002." Pittsburgh, Pa.

Crowl, Shirley. Director of Elections for Blair County. Interview by author, 28 November, 2005, Altoona, Pa.

"Definitions of Null hypothesis on the Web" Available from http://www.google.com/search?hl=en\&lr=\&defl=en\&q=define:Null+hypothesis\& $\underline{\mathrm{sa}=X \& 0 i=\text { glossary definition\&ct=title; }}$; accessed 11 July 2006.

Dilger, Robert Jay. 1989. National Intergovernmental Program. NJ: Prentice Hall: 153-170.

Doyle, Mike. Member of U.S. House of Representatives for $14^{\text {th }}$ Congressional District. Interview by author, 17 January 2006. Pittsburgh, Pa.

Dommel, Paul R. 1980. "Social Targeting in Community Development." Political Science Quarterly. 95:3. Autumn: 465-478.

Elazar, Daniel J. 1993. "The Scope of Co-operation." in American Intergovernmental Relations, $3^{\text {rd }}$ Edition, ed. Laurence J. O'Toole, Jr. (Washington, D.C.: Congressional Quarterly, Inc. 2000): 65-73. 
Evans, Diana. 1994. "Policy and Pork: The Use of Pork Barrel Projects to Build Policy Coalitions in the House of Representatives." American Journal of Political Science. 38:4. November: 894-917.

Evans, Diana. 2004. Greasing the Wheels. Cambridge University Press.

Fenno, Richard F., Jr. 1978. Home Style: House Members in Their Districts Cambridge University Press.

Fisher, Rosette C. Executive Director of Community Development. Interview by author, 8 October 2003. Sharon, Pa.

Ford, Gerald R., "Statement on the Housing and Community Development Act of 1974," Public Papers of the President of the United States (Washington, D.C.: Government Printing Office, 1975), p.44.

"Form of Government". Available from http://en.wikipedia.org/wiki/FORMOFGOVERNMENT; Accessed 15 January 2006.

Friedland, Roger and Herbert Wong. 1983. "Congressional Politics, Federal Grants, and Local Needs: Who Gets What and Why." The Municipal Money Chase, Edited by Alberta M. Sbaragia, 213-244.

Golden, Marissa Martino. 2000. What Motivates Bureaucrats? NY: Columbia University Press.

"Grantee Use of CDBG Funds by Matrix Code.” Available from http://www.hud.gov/offices/cpd/communitydevelopment/budget/ disbursementreports/; accessed 3 November 2005.

Hargrove, Erwin and John C. Glidewell, eds. 1990. Impossible Jobs. The University Press of Kansas. 
Herrmann, Richard K., Philip E. Tetlock, and Penny S. Visser, 1999. "Mass Public Decision on Going to War: A Cognitive-Interactionist Framework." American Political Science Review. 93: 553-575.

"Hometown Index." Available from http://www.epodunk.com/top10/home_towns/cities.html; accessed 8 November 2005.

Housing and Urban Redevelopment. Code of Federal Regulations, 24 Parts 500 to 699, Revised April 1, 2003.

Jastrzab, Gary J. Director of Planning and Policy Division. Interview by author, 8 December 2005. Philadelphia, Pa.

Johnson, Mary E. Community Development Block Grant Manager. Interview by author, 17 November 2005. Altoona, Pa.

Jones, Bryan D. 2001. Politics and the Architecture of Choice. Chicago: The University of Chicago Press.

Kelly, Brian. 1993. Adventures in Porkland.: NY: Times Books.

Kettl, Donald F. 1980. Managing Community Development in the New Federalism. NY: Praeger Publishers: 1-142.

Kinder, Donald and Roderick D. Kiewiet. 1981. "Sociotropic Politics - The American Case.” British Journal of Political Science. 11: 129-161.

Krasner, Stephen D. 1972. “Are Bureaucracies Important? (Or Allison Wonderland).” Foreign Policy. 7:159-179.

Lipsky, Michael. 1980. Street-Level Bureaucracy. NY: Russell Sage Foundation. 
Lowery, David and Virginia. 1995. "The Population Ecology of Gucci Gulch, or the Natural Regulation of Interest Group Numbers in the States." American Journal of Political Science (41)1:231-255.

"MANOVA." Available from http://en.wikipedia.org/wiki/MANOVA; Accessed 6 April 2006.

Mayhew, David R. 1979. Congress: The Electoral Connection. New Haven: Yale University Press.

Masloff, Sophie. Former Pittsburgh Mayor. Interview by author, 2 November 1993. Pittsburgh, Pa.

"Mayors of the City of Philadelphia." Available from http://www.phila.gov/phils/mayor1st.html; accessed 6 December 6, 2005.

Millimouno, Faya. National League of Cities. Interview by author, 8 November 2005. Pittsburgh, Pa.

Mitnick, Barry. 1984. "The Bureaucrat as Agent.” APSA Annual Meeting. Moore, Michael K. "Perpetuating the Pork Barrel: Policy Subsystems and American Democracy." Journal of Politics. 59:2. May, 1997.

Municipal Yellow Book: A leadership Directory. Summer 2001, Volume 11, 1. Murphy, Tom. Former Pittsburgh Mayor. Interview by author, 21 November 2005. Pittsburgh, Pa.

Nathan, Richard P. 1983. "State and Local Governments under Federal Grants: Toward a Predictive Theory." Political Science Quarterly. 98:1. Spring: 47-57.

Nathan, Richard P. and Paul R. Dommel. 1978. "Federal-Local Relations Under Block Grants," Political Science Quarterly. 93:3. Fall: 422. 
Nathan, Richard P., Paul R. Dommel, Sarah F. Liebschutz, and Milton D. Morris. 1977. "Monitoring the Block Grant Program for Community Development," Political Science Quarterly. 92:2. Summer: 219-244.

“NDCA Washington Report.” HUD CDBG Allocations with Complete 2000 Census Data. 2002.

National League of Cities 2005. Form of Government for U.S. Cities. Received 8 November 2005 from Faya Millimouno.

Pitkin, Hanna Fenichel 1967. The Concept of Representation: University of California Press.

Powlick, Philip J. and Andrew Z. Katz. 1998. "Defining the American Public Opinion/Foreign Policy Nexus.” Mershon International Studies Review. 42:29-61.

“Pratt Institute Center for Community and Environmental Development" 2001.

Pressman, Jeffrey L. and Aaron B. Wildavsky. 1973. Implementation. Berkeley: University of California Press.

Price, Robert. Former Sharon Mayor. Interview by author, 8 October 2003. Sharon, Pa.

Rich, Michael J. 1989. "Distributive Politics and the Allocation of Federal Grants." The American Political Science Review. 83:1. March: 193-213.

Rich, Michael J. 1993. Federal Policymaking and the Poor. Princeton, NJ: Princeton University Press.

Rieger, Rebecca M. CDP Representative of U.S. Department of Housing and Urban Development. Interview by author, 1 December 2005. Pittsburgh, PA.

Rookey, Tom. Director of Elections for Mercer County, 29 November 2005. Altoona, Pa.

Sabatier, Paul and Hank Jenkins-Smith. 1999. "The Advocacy Coalition Framework." In Sabatier, ed, Theories of the Policy Process. Boulder: Westview Press. 
Sakamoto, Takayuki 2001. "Effects of Government Characteristics on fiscal deficits 18 OECD countries 1961 - 1994.” Comparative Political Studies 34 (2001): 527554.

Savage, James D. 1991. "Saints and Cardinals in Appropriations Committees and the Fight Against Distributive Politics.” Legislative Studies Quarterly. 16:3. August: 329-347.

Savage, James D. 1999. Funding Science in America: in Congress, Universities, and the Politics of the Academic Pork Barrel. Cambridge University Press.

Stein, Robert M. and Kenneth N. Bickers. 1994. "Congressional Elections and the Pork Barrel." The Journal of Politics. 56:2 (May, 1994), 377-399.

Stein, Robert M. and Kenneth N., Bickers. 1995. Perpetuating the Pork Barrel: Cambridge University Press.

Stein, Robert M. 1981. "The Allocation of Federal Aid Monies: The Synthesis of Demand-Side and Supply-Side Explanations.” The American Political Science Review. 75(2), Jun., 1981: 334-343.

Steinmo, Sven 1992. Taxation and Democracy: Swedish, British and American Approaches to Financing the Modern State. Yale University Press.

Tolbert, John E., III. CDBG Manager for U.S. Department of Housing and Urban Development. Interview by author, 1 December 2005. Pittsburgh, PA.

“Top 50 Cities in the U.S. by Population and Rank." Available from http://www.infoplease.com/ipa/A0763098/html; accessed 6 December 2005

Tufte, Edward R. 1978. Political Control of the Economy. Princeton University Press.

Udin, Sala.. Former Pittsburgh City-Council member. Interview by author, 29 November 2005. 
"US Census." Available from http://www.census.gov/; accessed 15 November 2005.

Weber, Ronald E. and Paul Brace. 1999. American State and Local Politics. Chatham House.

Weingast, Barry R. 1994. "Reflections on Distributive Politics and Universalism." Political Research Quarterly. 47:2. June: 319-327. 


\section{Appendix A: Interview Protocol}

Dear Participant:

I am conducting an interview to obtain your insight into the Community Development Block Grant (CDBG) program. The purpose of my study is to understand how public benefits (grant dollars) are allocated to the cities. Specifically, I am interested in the way allocation decisions are made and the role you play in the distribution of federal grant monies.

Your input to this interview is completely voluntary. If you agree to be interviewed, I will be taking notes of our conversation. Your responses will be kept confidential. In the event that I quote you, I will ask for your oral or written permission in advance of publication. Please be advised that you do not have to answer every question and that my class standing or grade will not be affected if you elect not to participate in my study.

Should you have any additional questions or require additional information, you may contact the Chair of my Dissertation Committee: Neil Berch, Ph.D. at (304) 2933811. Thank you.

Sincerely yours,

Howard A. Stern

Doctoral Candidate, WVU

6606 Northumberland Street

Pittsburgh, PA 15217

Email: howard.a.stern@city.pittsburgh.pa.us 


\section{Appendix B: Interview Questions}

Last year, the City of r_ received $\$$ from the federal government to expand the economic opportunities and improve the overall living conditions of individuals living in low and moderate-income neighborhoods.

- Do you know what projects or programs are funded with CDBG dollars OR do you leave these funding decisions to the program administrators?

- Does your office play a role in the selection and approval of programs and projects? If yes, what kind of role?

- Are there any "pet programs" that you encourage or insist to be funded with CDBG dollars?

- Do you acknowledge or give credit to the individual legislatures (or local elected officials) that help secure CDBG funding opportunities for your city?

Did you know that 30 percent of CDBG monies can be used to "indirectly" benefit poor areas? Because of this program flexibility, some legislators, politicians and bureaucrats have described the CDBG program as another form of "pork-barrel" politics.

- Would you describe the CDBG program as another form of pork? It is just another government program designed to helping elected officials gain visibility and votes in future elections? 
- What role, if any, do the public or community groups play in the selection of CDBG-funded projects?

- Have you ever had to respond to a community group that opposed a CDBG project allocation? Please explain:

- Would it be more difficult to administer the CDBG program if there were more council members?

- Do you think the CDBG program is administered fairly without the influences of politics, media or partisanship?

- Do you have any recommendation for improving the program? 


\section{Appendix C: CDBG Allocations for Sharon, Pennsylvania}
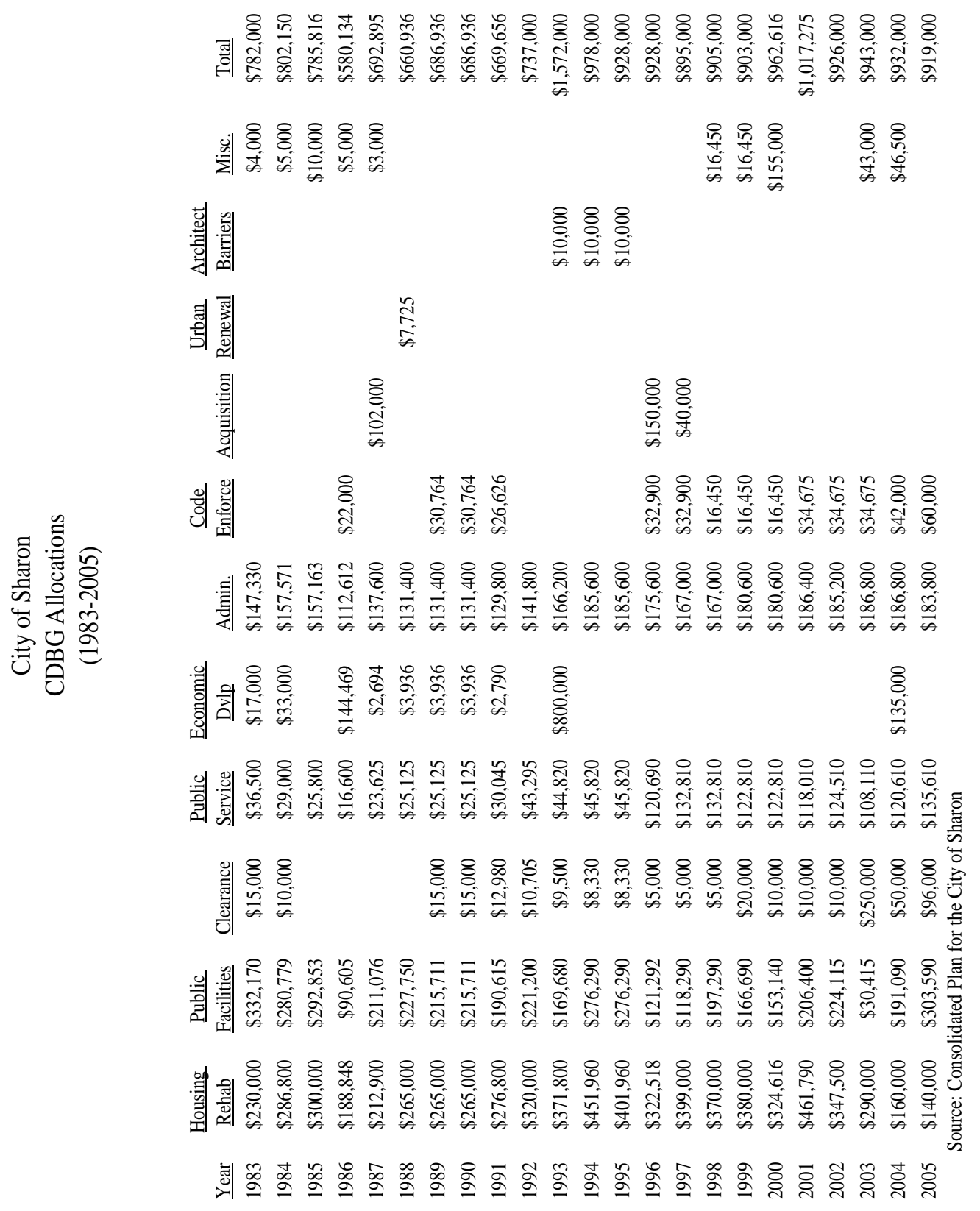


\section{Appendix D: CDBG Allocations for Altoona, Pennsylvania}

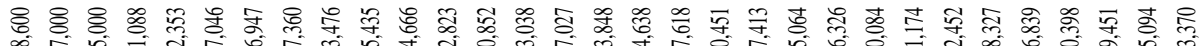

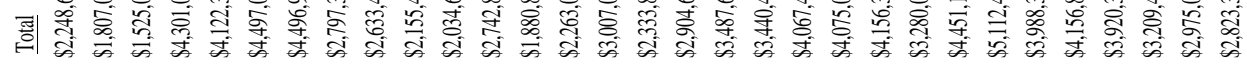

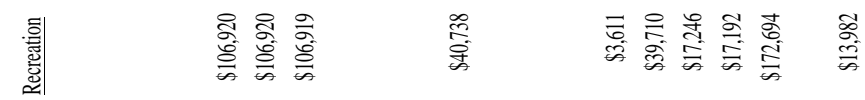

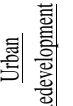

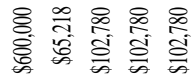

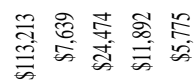

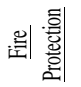

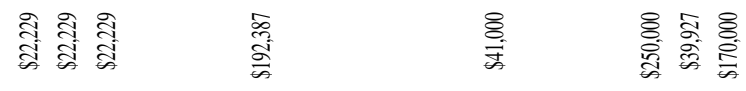

$\underset{\substack{8 \\ \infty}}{\infty}$

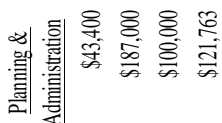

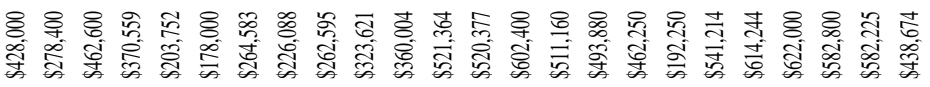

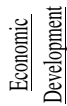

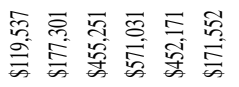

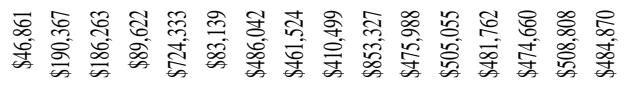

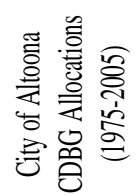

䜌

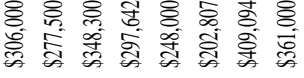

횧

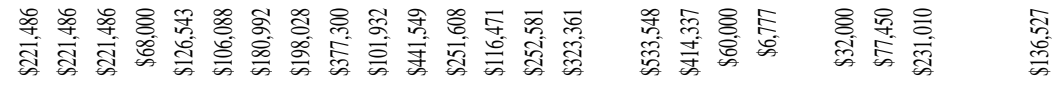

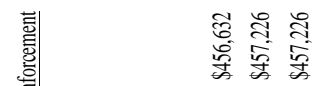

웡

器管

言

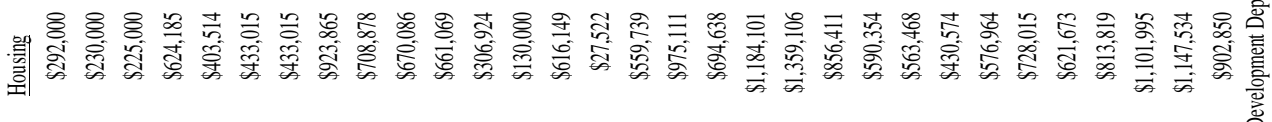

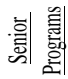

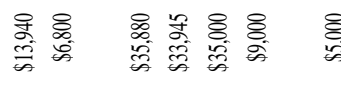

을

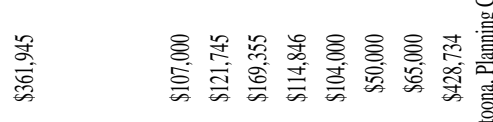

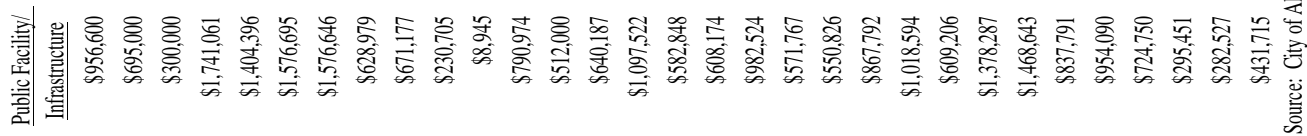

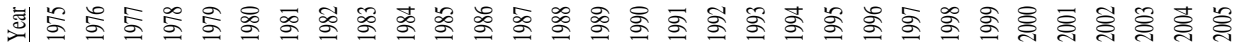




\section{Appendix E: CDBG Allocations for Pittsburgh, Pennsylvania}

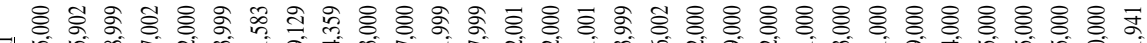

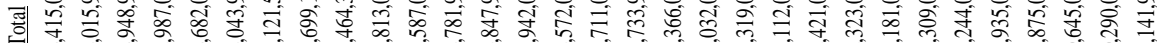

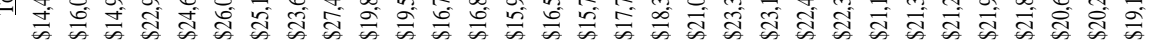

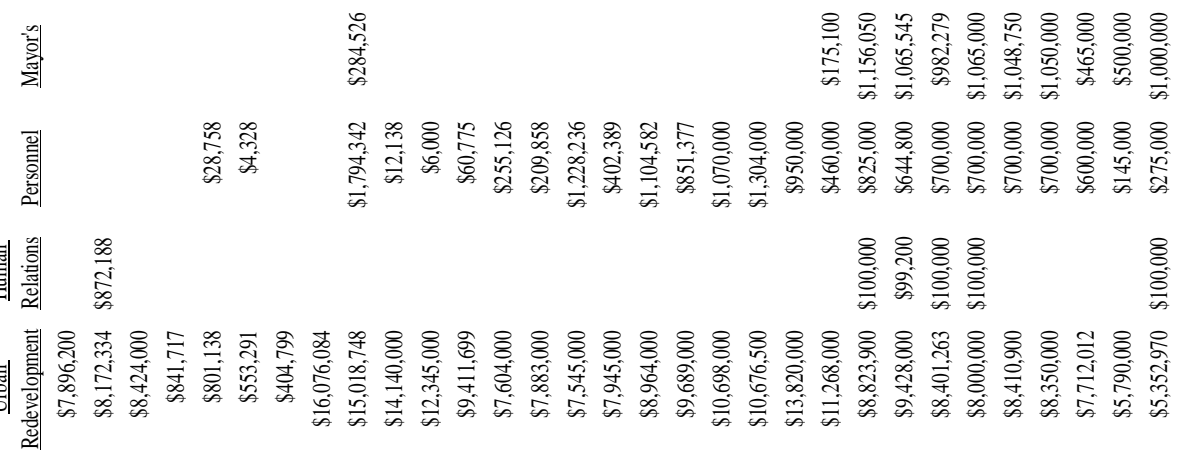

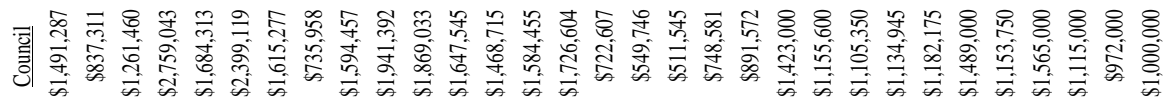

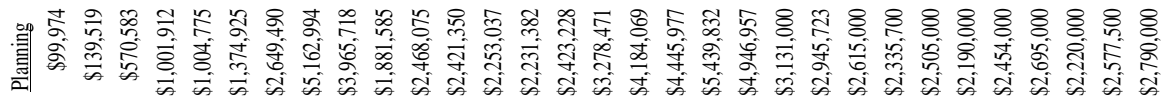

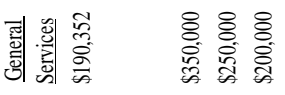

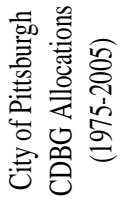

憲

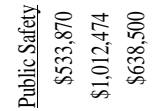

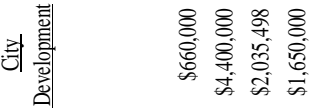

1 Mn

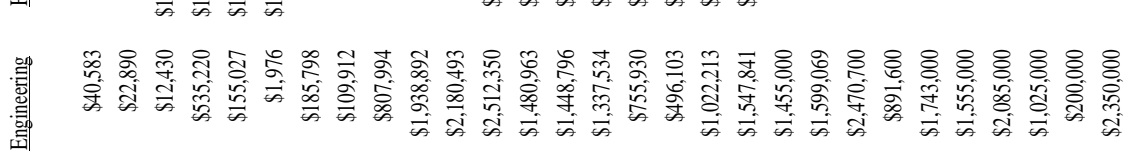

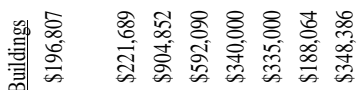

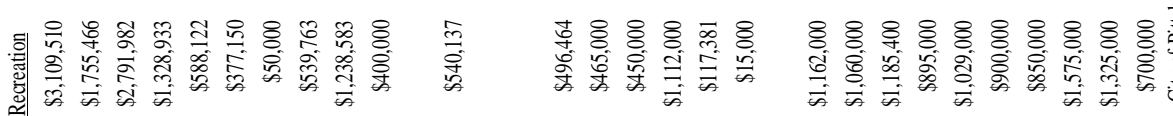

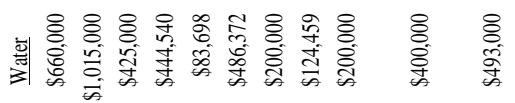

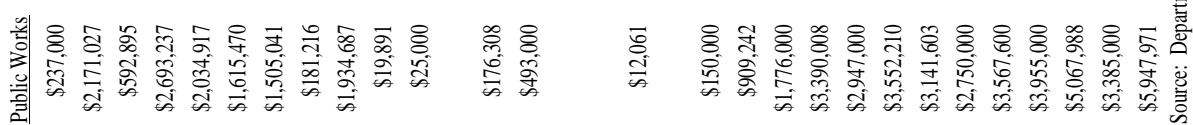

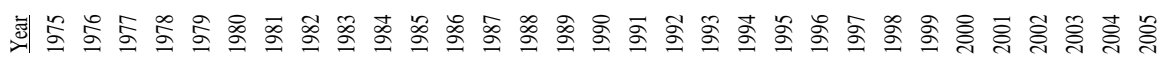

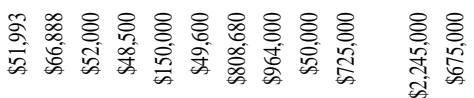

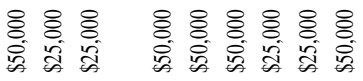

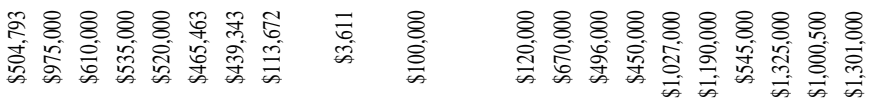




\section{Appendix F: CDBG Allocations for Philadelphia, Pennsylvania}
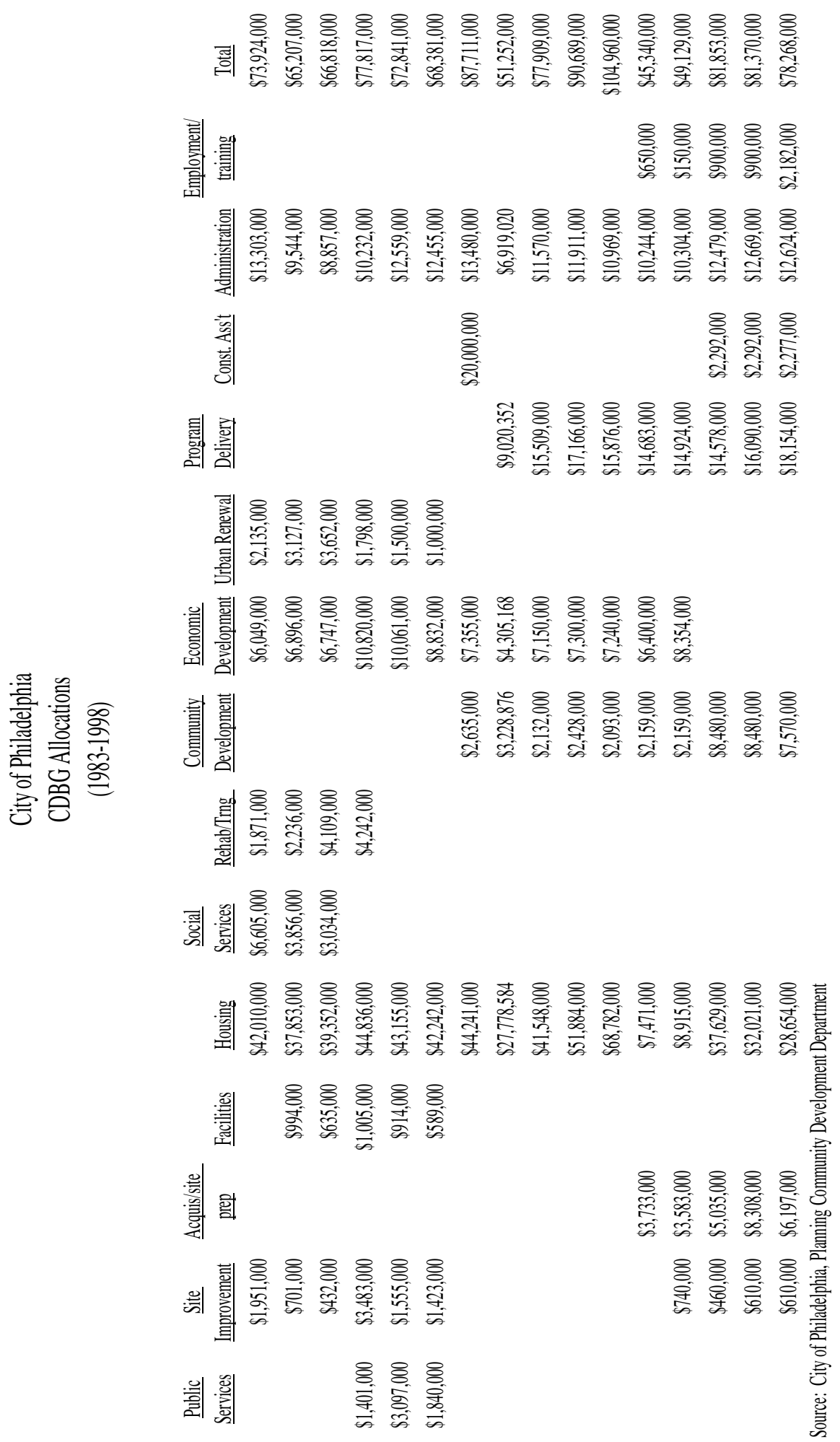

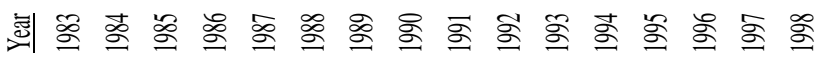




\section{Appendix G: MANOVA Results}

Multivariate Tests(c)

\begin{tabular}{|c|c|c|c|c|c|c|c|}
\hline Effect & & Value & $\mathrm{F}$ & Hypothesis df & Error df & Sig. & $\begin{array}{l}\text { Partial Eta } \\
\text { Squared }\end{array}$ \\
\hline \multirow[t]{4}{*}{ Intercept } & Pillai's Trace & .658 & $232.779(a)$ & 6.000 & 726.000 & .000 & .658 \\
\hline & Wilks' Lambda & .342 & $232.779(a)$ & 6.000 & 726.000 & .000 & .658 \\
\hline & Hotelling's Trace & 1.924 & 232.779(a) & 6.000 & 726.000 & .000 & .658 \\
\hline & Roy's Largest Root & 1.924 & $232.779(a)$ & 6.000 & 726.000 & .000 & .658 \\
\hline \multirow[t]{4}{*}{ size_sma } & Pillai's Trace & .016 & 1.914(a) & 6.000 & 726.000 & .076 & .016 \\
\hline & Wilks' Lambda & .984 & 1.914(a) & 6.000 & 726.000 & .076 & .016 \\
\hline & Hotelling's Trace & .016 & 1.914(a) & 6.000 & 726.000 & .076 & .016 \\
\hline & Roy's Largest Root & .016 & $1.914(a)$ & 6.000 & 726.000 & .076 & .016 \\
\hline \multirow[t]{4}{*}{ size_med } & Pillai's Trace & .010 & $1.266(a)$ & 6.000 & 726.000 & .271 & .010 \\
\hline & Wilks' Lambda & .990 & $1.266(a)$ & 6.000 & 726.000 & .271 & .010 \\
\hline & Hotelling's Trace & .010 & $1.266(\mathrm{a})$ & 6.000 & 726.000 & .271 & .010 \\
\hline & Roy's Largest Root & .010 & $1.266(a)$ & 6.000 & 726.000 & .271 & .010 \\
\hline \multirow[t]{4}{*}{ size_lar } & Pillai's Trace & .008 & $1.037(a)$ & 6.000 & 726.000 & .400 & .008 \\
\hline & Wilks' Lambda & .992 & $1.037(\mathrm{a})$ & 6.000 & 726.000 & .400 & .008 \\
\hline & Hotelling's Trace & .009 & $1.037(a)$ & 6.000 & 726.000 & .400 & .008 \\
\hline & Roy's Largest Root & .009 & $1.037(\mathrm{a})$ & 6.000 & 726.000 & .400 & .008 \\
\hline \multirow[t]{4}{*}{ size_vlg } & Pillai's Trace & .021 & $2.556(a)$ & 6.000 & 726.000 & .019 & .021 \\
\hline & Wilks' Lambda & .979 & $2.556(a)$ & 6.000 & 726.000 & .019 & .021 \\
\hline & Hotelling's Trace & .021 & $2.556(a)$ & 6.000 & 726.000 & .019 & .021 \\
\hline & Roy's Largest Root & .021 & $2.556(a)$ & 6.000 & 726.000 & .019 & .021 \\
\hline \multirow[t]{4}{*}{ form_may } & Pillai's Trace & .013 & $1.562(a)$ & 6.000 & 726.000 & .155 & .013 \\
\hline & Wilks' Lambda & .987 & $1.562(a)$ & 6.000 & 726.000 & .155 & .013 \\
\hline & Hotelling's Trace & .013 & $1.562(\mathrm{a})$ & 6.000 & 726.000 & .155 & .013 \\
\hline & Roy's Largest Root & .013 & $1.562(a)$ & 6.000 & 726.000 & .155 & .013 \\
\hline \multirow[t]{4}{*}{ hou_75_150 } & Pillai's Trace & .016 & $1.954(a)$ & 6.000 & 726.000 & .070 & .016 \\
\hline & Wilks' Lambda & .984 & 1.954(a) & 6.000 & 726.000 & .070 & .016 \\
\hline & Hotelling's Trace & .016 & 1.954(a) & 6.000 & 726.000 & .070 & .016 \\
\hline & Roy's Largest Root & .016 & $1.954(\mathrm{a})$ & 6.000 & 726.000 & .070 & .016 \\
\hline \multirow[t]{4}{*}{ hou_150kmo } & Pillai's Trace & .015 & $1.882(a)$ & 6.000 & 726.000 & .081 & .015 \\
\hline & Wilks' Lambda & .985 & $1.882(a)$ & 6.000 & 726.000 & .081 & .015 \\
\hline & Hotelling's Trace & .016 & $1.882(a)$ & 6.000 & 726.000 & .081 & .015 \\
\hline & Roy's Largest Root & .016 & $1.882(a)$ & 6.000 & 726.000 & .081 & .015 \\
\hline \multirow[t]{4}{*}{ RACE59_3 } & Pillai's Trace & .010 & $1.211(\mathrm{a})$ & 6.000 & 726.000 & .298 & .010 \\
\hline & Wilks' Lambda & .990 & $1.211(\mathrm{a})$ & 6.000 & 726.000 & .298 & .010 \\
\hline & Hotelling's Trace & .010 & $1.211(\mathrm{a})$ & 6.000 & 726.000 & .298 & .010 \\
\hline & Roy's Largest Root & .010 & $1.211(\mathrm{a})$ & 6.000 & 726.000 & .298 & .010 \\
\hline \multirow[t]{4}{*}{ RACE85_6 } & Pillai's Trace & .013 & $1.546(\mathrm{a})$ & 6.000 & 726.000 & .160 & .013 \\
\hline & Wilks' Lambda & .987 & $1.546(a)$ & 6.000 & 726.000 & .160 & .013 \\
\hline & Hotelling's Trace & .013 & $1.546(a)$ & 6.000 & 726.000 & .160 & .013 \\
\hline & Roy's Largest Root & .013 & $1.546(\mathrm{a})$ & 6.000 & 726.000 & .160 & .013 \\
\hline
\end{tabular}




\begin{tabular}{|c|c|c|c|c|c|c|c|}
\hline \multirow[t]{4}{*}{ unem_3.1per } & Pillai's Trace & .003 & $.392(a)$ & 6.000 & 726.000 & .884 & .003 \\
\hline & Wilks' Lambda & .997 & $.392(a)$ & 6.000 & 726.000 & .884 & .003 \\
\hline & Hotelling's Trace & .003 & $.392(a)$ & 6.000 & 726.000 & .884 & .003 \\
\hline & Roy's Largest Root & .003 & $.392(a)$ & 6.000 & 726.000 & .884 & .003 \\
\hline \multirow[t]{4}{*}{ unem_3.9p } & Pillai's Trace & .007 & $.871(\mathrm{a})$ & 6.000 & 726.000 & .515 & .007 \\
\hline & Wilks' Lambda & .993 & $.871(\mathrm{a})$ & 6.000 & 726.000 & .515 & .007 \\
\hline & Hotelling's Trace & .007 & $.871(\mathrm{a})$ & 6.000 & 726.000 & .515 & .007 \\
\hline & Roy's Largest Root & .007 & $.871(\mathrm{a})$ & 6.000 & 726.000 & .515 & .007 \\
\hline \multirow[t]{4}{*}{ PER_18_1 } & Pillai's Trace & .020 & $2.502(a)$ & 6.000 & 726.000 & .021 & .020 \\
\hline & Wilks' Lambda & .980 & $2.502(a)$ & 6.000 & 726.000 & .021 & .020 \\
\hline & Hotelling's Trace & .021 & $2.502(a)$ & 6.000 & 726.000 & .021 & .020 \\
\hline & Roy's Largest Root & .021 & $2.502(a)$ & 6.000 & 726.000 & .021 & .020 \\
\hline \multirow[t]{4}{*}{ PERCA_30 } & Pillai's Trace & .019 & $2.329(a)$ & 6.000 & 726.000 & .031 & .019 \\
\hline & Wilks' Lambda & .981 & $2.329(a)$ & 6.000 & 726.000 & .031 & .019 \\
\hline & Hotelling's Trace & .019 & $2.329(a)$ & 6.000 & 726.000 & .031 & .019 \\
\hline & Roy's Largest Root & .019 & $2.329(a)$ & 6.000 & 726.000 & .031 & .019 \\
\hline \multirow[t]{4}{*}{ pov_8_9 } & Pillai's Trace & .013 & $1.594(\mathrm{a})$ & 6.000 & 726.000 & .146 & .013 \\
\hline & Wilks' Lambda & .987 & 1.594(a) & 6.000 & 726.000 & .146 & .013 \\
\hline & Hotelling's Trace & .013 & 1.594(a) & 6.000 & 726.000 & .146 & .013 \\
\hline & Roy's Largest Root & .013 & $1.594(\mathrm{a})$ & 6.000 & 726.000 & .146 & .013 \\
\hline \multirow[t]{4}{*}{ pov_14_2 } & Pillai's Trace & .018 & $2.209(\mathrm{a})$ & 6.000 & 726.000 & .040 & .018 \\
\hline & Wilks' Lambda & .982 & $2.209(a)$ & 6.000 & 726.000 & .040 & .018 \\
\hline & Hotelling's Trace & .018 & $2.209(a)$ & 6.000 & 726.000 & .040 & .018 \\
\hline & Roy's Largest Root & .018 & $2.209(a)$ & 6.000 & 726.000 & .040 & .018 \\
\hline \multirow[t]{4}{*}{ cou_atla } & Pillai's Trace & .010 & $1.175(a)$ & 6.000 & 726.000 & .318 & .010 \\
\hline & Wilks' Lambda & .990 & $1.175(\mathrm{a})$ & 6.000 & 726.000 & .318 & .010 \\
\hline & Hotelling's Trace & .010 & $1.175(a)$ & 6.000 & 726.000 & .318 & .010 \\
\hline & Roy's Largest Root & .010 & $1.175(\mathrm{a})$ & 6.000 & 726.000 & .318 & .010 \\
\hline \multirow[t]{4}{*}{ cou_both } & Pillai's Trace & .007 & $.840(a)$ & 6.000 & 726.000 & .539 & .007 \\
\hline & Wilks' Lambda & .993 & $.840(a)$ & 6.000 & 726.000 & .539 & .007 \\
\hline & Hotelling's Trace & .007 & $.840(a)$ & 6.000 & 726.000 & .539 & .007 \\
\hline & Roy's Largest Root & .007 & $.840(a)$ & 6.000 & 726.000 & .539 & .007 \\
\hline \multirow[t]{4}{*}{ Region } & Pillai's Trace & .075 & 3.128 & 18.000 & 2184.000 & .000 & .025 \\
\hline & Wilks' Lambda & .926 & 3.138 & 18.000 & 2053.923 & .000 & .025 \\
\hline & Hotelling's Trace & .078 & 3.145 & 18.000 & 2174.000 & .000 & .025 \\
\hline & Roy's Largest Root & .045 & $5.403(b)$ & 6.000 & 728.000 & .000 & .043 \\
\hline
\end{tabular}

a Exact statistic

b The statistic is an upper bound on F that yields a lower bound on the significance level.

c Design:

Intercept+size_sma+size_med+size_lar+size_vlg+form_may+hou_75_150+hou_150kmo+RACE59_3+RAC E85_6+unem_3.1per+unem_3.9p+PER_18_1+PERCA_30+pov_8_9+pov_14_2+cou_atla+cou_both+region 
Tests of Between-Subjects Effects

\begin{tabular}{|c|c|c|c|c|c|c|c|}
\hline Source & Dependent Variable & $\begin{array}{l}\text { Type III Sum } \\
\text { of Squares }\end{array}$ & $\mathrm{df}$ & Mean Square & $\mathrm{F}$ & Sig. & $\begin{array}{l}\text { Partial } \\
\text { Eta } \\
\text { Squared }\end{array}$ \\
\hline \multirow[t]{6}{*}{ Corrected Model } & Acquisition Allocation & $3004.352(a)$ & 20 & 150.218 & 1.411 & .109 & .037 \\
\hline & $\begin{array}{l}\text { Administrative \& Planning } \\
\text { Allocation }\end{array}$ & $881.231(b)$ & 20 & 44.062 & .793 & .724 & .021 \\
\hline & $\begin{array}{l}\text { Economic Development } \\
\text { Allocation }\end{array}$ & $3318.746(\mathrm{c})$ & 20 & 165.937 & 1.762 & .021 & .046 \\
\hline & Housing Allocation & $36606.681(d)$ & 20 & 1830.334 & 3.164 & .000 & .080 \\
\hline & $\begin{array}{l}\text { Public Improvements } \\
\text { Allocation }\end{array}$ & 19889.783(e) & 20 & 994.489 & 2.131 & .003 & .055 \\
\hline & Public Service Allocation & $3102.828(f)$ & 20 & 155.141 & 3.021 & .000 & .076 \\
\hline \multirow[t]{6}{*}{ Intercept } & Acquisition Allocation & 1437.694 & 1 & 1437.694 & 13.508 & .000 & .018 \\
\hline & $\begin{array}{l}\text { Administrative \& Planning } \\
\text { Allocation }\end{array}$ & 9287.330 & 1 & 9287.330 & 167.207 & .000 & .186 \\
\hline & $\begin{array}{l}\text { Economic Development } \\
\text { Allocation }\end{array}$ & 267.844 & 1 & 267.844 & 2.844 & .092 & .004 \\
\hline & Housing Allocation & 23107.001 & 1 & 23107.001 & 39.948 & .000 & .052 \\
\hline & $\begin{array}{l}\text { Public Improvements } \\
\text { Allocation }\end{array}$ & 33927.389 & 1 & 33927.389 & 72.689 & .000 & .090 \\
\hline & Public Service Allocation & 3351.379 & 1 & 3351.379 & 65.264 & .000 & .082 \\
\hline \multirow[t]{6}{*}{ size_sma } & Acquisition Allocation & 21.936 & 1 & 21.936 & .206 & .650 & .000 \\
\hline & $\begin{array}{l}\text { Administrative \& Planning } \\
\text { Allocation }\end{array}$ & 15.536 & 1 & 15.536 & .280 & .597 & .000 \\
\hline & $\begin{array}{l}\text { Economic Development } \\
\text { Allocation }\end{array}$ & 16.527 & 1 & 16.527 & .175 & .675 & .000 \\
\hline & Housing Allocation & 240.455 & 1 & 240.455 & .416 & .519 & .001 \\
\hline & $\begin{array}{l}\text { Public Improvements } \\
\text { Allocation }\end{array}$ & 2516.926 & 1 & 2516.926 & 5.392 & .020 & .007 \\
\hline & Public Service Allocation & 113.747 & 1 & 113.747 & 2.215 & .137 & .003 \\
\hline \multirow[t]{6}{*}{ size_med } & Acquisition Allocation & 47.013 & 1 & 47.013 & .442 & .507 & .001 \\
\hline & $\begin{array}{l}\text { Administrative \& Planning } \\
\text { Allocation }\end{array}$ & 5.236 & 1 & 5.236 & .094 & .759 & .000 \\
\hline & $\begin{array}{l}\text { Economic Development } \\
\text { Allocation }\end{array}$ & 6.925 & 1 & 6.925 & .074 & .786 & .000 \\
\hline & Housing Allocation & 325.101 & 1 & 325.101 & .562 & .454 & .001 \\
\hline & $\begin{array}{l}\text { Public Improvements } \\
\text { Allocation }\end{array}$ & 2511.318 & 1 & 2511.318 & 5.380 & .021 & .007 \\
\hline & Public Service Allocation & 19.251 & 1 & 19.251 & .375 & .541 & .001 \\
\hline \multirow[t]{5}{*}{ size_lar } & Acquisition Allocation & .354 & 1 & .354 & .003 & .954 & .000 \\
\hline & $\begin{array}{l}\text { Administrative \& Planning } \\
\text { Allocation }\end{array}$ & 41.713 & 1 & 41.713 & .751 & .386 & .001 \\
\hline & $\begin{array}{l}\text { Economic Development } \\
\text { Allocation }\end{array}$ & 38.121 & 1 & 38.121 & .405 & .525 & .001 \\
\hline & Housing Allocation & 580.634 & 1 & 580.634 & 1.004 & .317 & .001 \\
\hline & $\begin{array}{l}\text { Public Improvements } \\
\text { Allocation }\end{array}$ & 1618.736 & 1 & 1618.736 & 3.468 & .063 & .005 \\
\hline
\end{tabular}




\begin{tabular}{|c|c|c|c|c|c|c|c|}
\hline \multirow{7}{*}{ size_vlg } & Public Service Allocation & 6.037 & 1 & 6.037 & .118 & .732 & .000 \\
\hline & Acquisition Allocation & 56.613 & 1 & 56.613 & .532 & .466 & .001 \\
\hline & $\begin{array}{l}\text { Administrative \& Planning } \\
\text { Allocation }\end{array}$ & 20.924 & 1 & 20.924 & .377 & .540 & .001 \\
\hline & $\begin{array}{l}\text { Economic Development } \\
\text { Allocation }\end{array}$ & 60.777 & 1 & 60.777 & .645 & .422 & .001 \\
\hline & Housing Allocation & 138.534 & 1 & 138.534 & .240 & .625 & .000 \\
\hline & $\begin{array}{l}\text { Public Improvements } \\
\text { Allocation }\end{array}$ & 3396.053 & 1 & 3396.053 & 7.276 & .007 & .010 \\
\hline & Public Service Allocation & 320.583 & 1 & 320.583 & 6.243 & .013 & .008 \\
\hline \multirow[t]{6}{*}{ form_may } & Acquisition Allocation & .601 & 1 & .601 & .006 & .940 & .000 \\
\hline & $\begin{array}{l}\text { Administrative \& Planning } \\
\text { Allocation }\end{array}$ & 5.087 & 1 & 5.087 & .092 & .762 & .000 \\
\hline & $\begin{array}{l}\text { Economic Development } \\
\text { Allocation }\end{array}$ & 242.012 & 1 & 242.012 & 2.570 & .109 & .004 \\
\hline & Housing Allocation & 3260.362 & 1 & 3260.362 & 5.637 & .018 & .008 \\
\hline & $\begin{array}{l}\text { Public Improvements } \\
\text { Allocation }\end{array}$ & 263.279 & 1 & 263.279 & .564 & .453 & .001 \\
\hline & Public Service Allocation & 88.398 & 1 & 88.398 & 1.721 & .190 & .002 \\
\hline \multirow[t]{6}{*}{ hou_75_150 } & Acquisition Allocation & 212.583 & 1 & 212.583 & 1.997 & .158 & .003 \\
\hline & $\begin{array}{l}\text { Administrative \& Planning } \\
\text { Allocation }\end{array}$ & 3.980 & 1 & 3.980 & .072 & .789 & .000 \\
\hline & $\begin{array}{l}\text { Economic Development } \\
\text { Allocation }\end{array}$ & 293.039 & 1 & 293.039 & 3.111 & .078 & .004 \\
\hline & Housing Allocation & 2481.969 & 1 & 2481.969 & 4.291 & .039 & .006 \\
\hline & $\begin{array}{l}\text { Public Improvements } \\
\text { Allocation }\end{array}$ & 205.368 & 1 & 205.368 & .440 & .507 & .001 \\
\hline & Public Service Allocation & 160.792 & 1 & 160.792 & 3.131 & .077 & .004 \\
\hline \multirow[t]{6}{*}{ hou_150kmo } & Acquisition Allocation & 424.321 & 1 & 424.321 & 3.987 & .046 & .005 \\
\hline & $\begin{array}{l}\text { Administrative \& Planning } \\
\text { Allocation }\end{array}$ & .278 & 1 & .278 & .005 & .944 & .000 \\
\hline & $\begin{array}{l}\text { Economic Development } \\
\text { Allocation }\end{array}$ & 436.509 & 1 & 436.509 & 4.635 & .032 & .006 \\
\hline & Housing Allocation & 748.751 & 1 & 748.751 & 1.294 & .256 & .002 \\
\hline & $\begin{array}{l}\text { Public Improvements } \\
\text { Allocation }\end{array}$ & 35.703 & 1 & 35.703 & .076 & .782 & .000 \\
\hline & Public Service Allocation & 77.679 & 1 & 77.679 & 1.513 & .219 & .002 \\
\hline \multirow[t]{6}{*}{ RACE59_3 } & Acquisition Allocation & 239.363 & 1 & 239.363 & 2.249 & .134 & .003 \\
\hline & $\begin{array}{l}\text { Administrative \& Planning } \\
\text { Allocation }\end{array}$ & .120 & 1 & .120 & .002 & .963 & .000 \\
\hline & $\begin{array}{l}\text { Economic Development } \\
\text { Allocation }\end{array}$ & 255.305 & 1 & 255.305 & 2.711 & .100 & .004 \\
\hline & Housing Allocation & 1555.899 & 1 & 1555.899 & 2.690 & .101 & .004 \\
\hline & $\begin{array}{l}\text { Public Improvements } \\
\text { Allocation }\end{array}$ & 64.155 & 1 & 64.155 & .137 & .711 & .000 \\
\hline & Public Service Allocation & 12.136 & 1 & 12.136 & .236 & .627 & .000 \\
\hline \multirow[t]{2}{*}{ RACE85_6 } & Acquisition Allocation & 187.511 & 1 & 187.511 & 1.762 & .185 & .002 \\
\hline & $\begin{array}{l}\text { Administrative \& Planning } \\
\text { Allocation }\end{array}$ & 125.719 & 1 & 125.719 & 2.263 & .133 & .003 \\
\hline
\end{tabular}




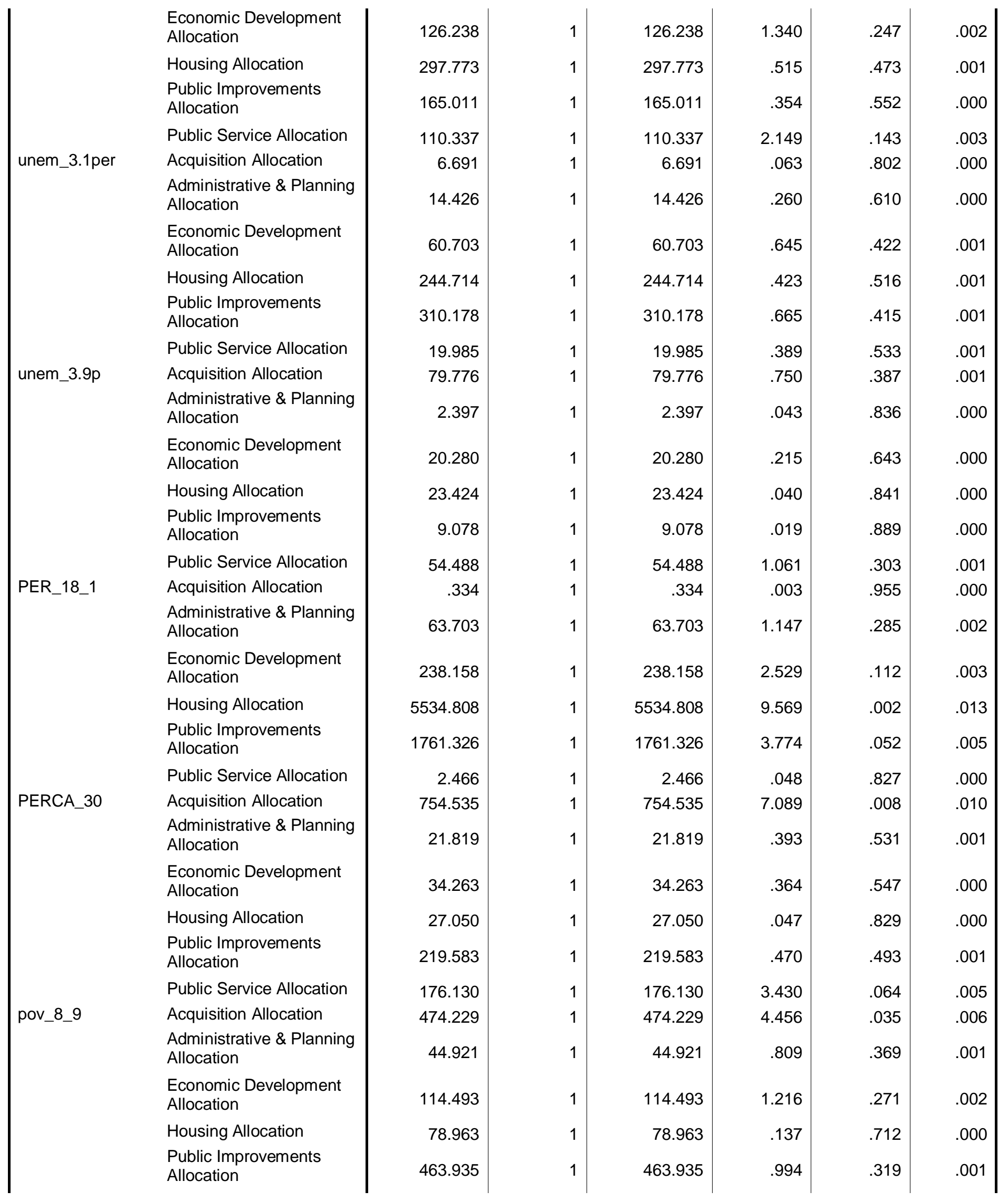




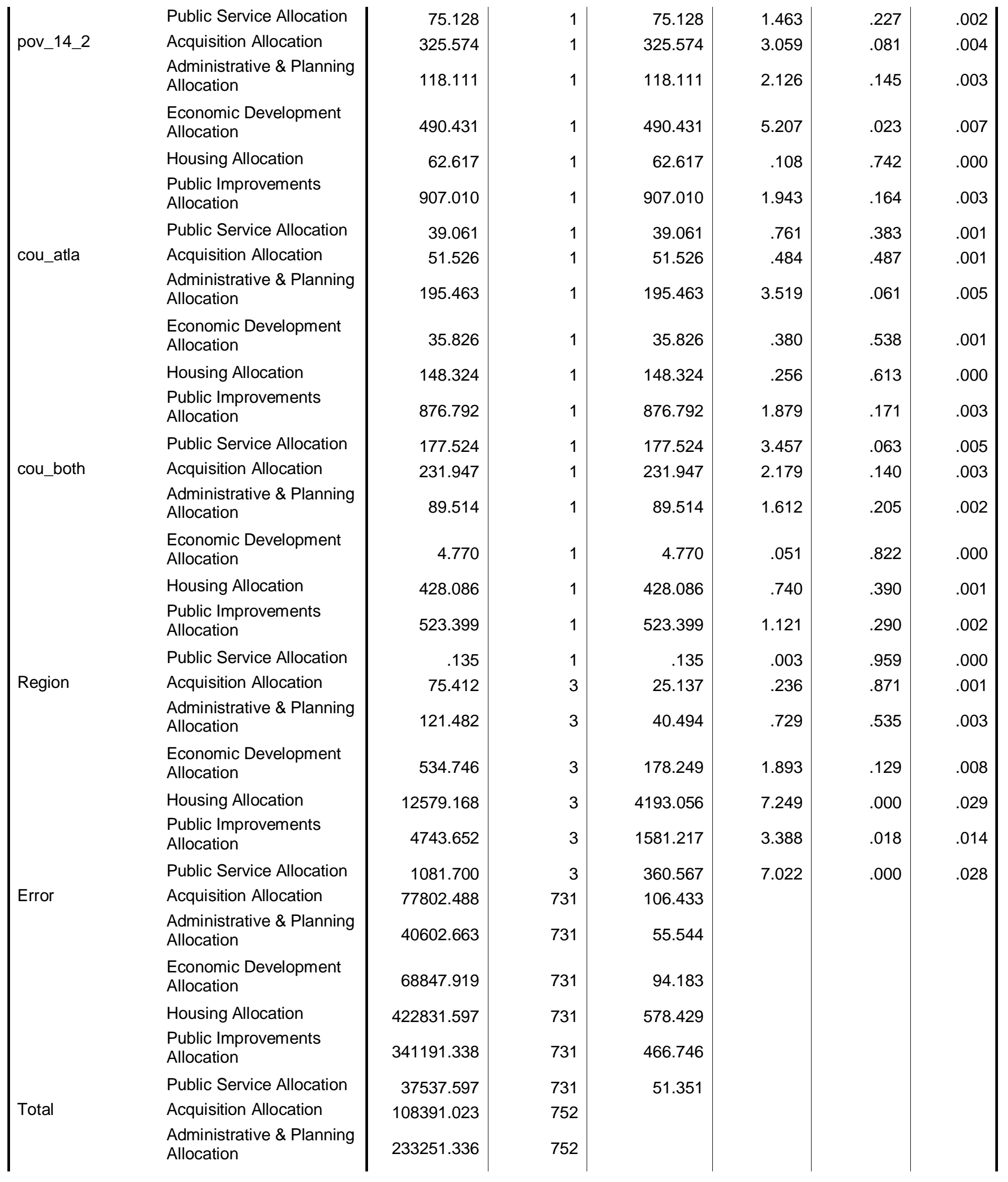




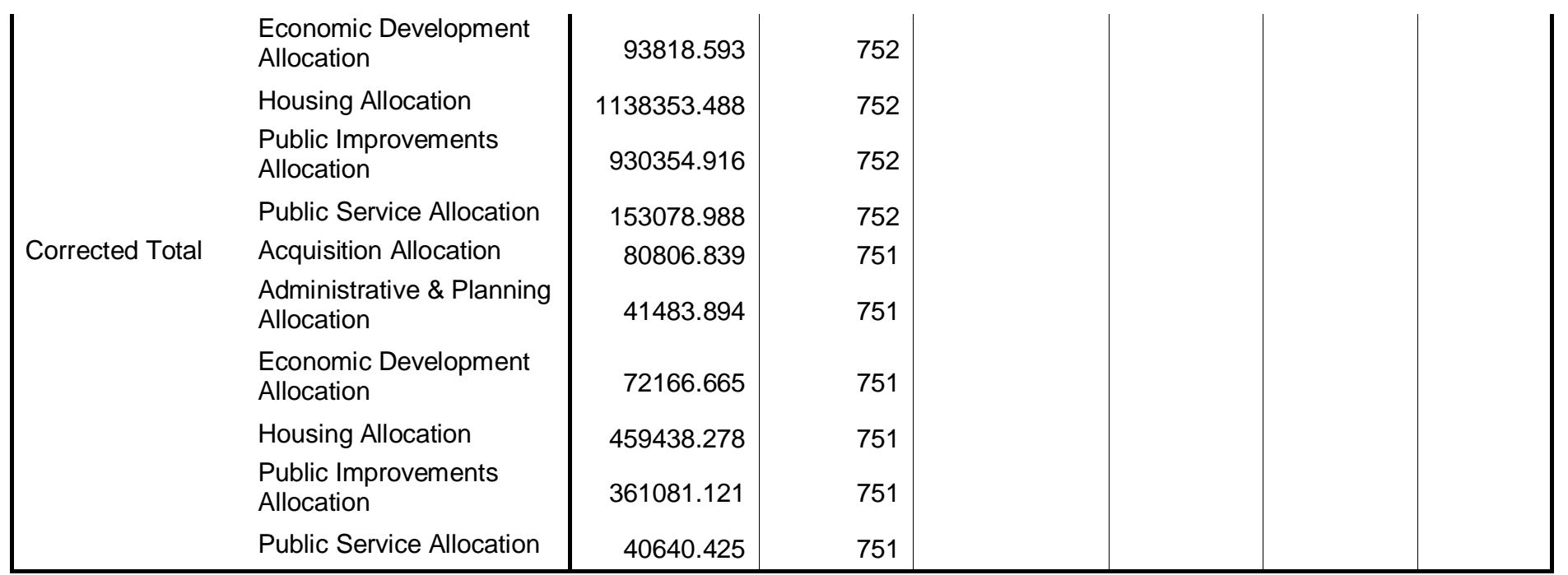
a R Squared $=.037$ (Adjusted R Squared $=.011$ )
b R Squared $=.021$ (Adjusted R Squared $=-.006$ )
c R Squared $=.046$ (Adjusted R Squared $=.020$ )
d R Squared $=.080$ (Adjusted R Squared $=.054$ )
e R Squared $=.055$ (Adjusted R Squared $=.029$ )
f R Squared $=.076$ (Adjusted R Squared $=.051$ ) 


\section{Appendix H: Explanation of Variables}

The listing below shows the variable name and a brief definition of each dependent and independent variable.

\section{- Independent variables}

State.

Stabbre.

Cityname.

Region.

Reg_mid.

Reg_sout.

Reg_nort.

Reg_west.

City_pop.

Citysize.

Size_ver.

Size_sma.

Size_med.

Size_lar

Size_vlg.

Form_gov.

Form_wea.

Form_com

Form_tow.

Form_may.

Hous_val.

Hou_quar

Per-whit.

Per-blac.

Per-indi.

Per-asia.

Per-hisp.
Name of state.

State abbreviation

CDBG entitlement City taken from the 2000 U.S. census.

Region as defined by 2000 U.S. census: midwest, southern, northeastern, western.

Midwest region.

Southern region.

Northeastern region.

Western region.

Population of CDBG entitlement city.

Size of CDBG eligible city: very small, small, Medium, large, very large.

Very small entitlement city with a population less than 75,000 .

Small entitlement city with a population between 75,001 and 150,000 .

Medium entitlement city with a population between 150,001 and 250,000 .

Large entitlement city with a population between 250,001 and 500,000 .

Very large entitlement city with a population greater than 500,001.

Form of government: council-manager, mayor-council,

Commissioner, Town Manager, other.

Council-manager with a weak mayor form of government.

Commissioner form of government.

Town manager form of government.

Mayor-council with a strong mayor form of government.

Housing value of each CDBG entitlement city based on the 2000

U.S. census.

Housing value categories.

Percentage white population for each CDBG entitlement city based on the 2000 U.S. census.

Percentage black population for each CDBG entitlement city based on the 2000 U.S. census.

Percentage American Indian and Alaska Native population for each CDBG entitlement city based on the 2000 U.S. census. Percentage Asian population for each CDBG entitlement city based on the 2000 U.S. census.

Percentage Hispanic or Latino population for 2 races reported (2000 U.S. census) 

Race
White vs. non-white populations.
Unemploy. Unemployment rate for each CDBG entitlement city based on the 2000 U.S. census.
Unem_cat Unemployment categories.
Percapit. Per capita income for each CDBG entitlement city based on the 2000 U.S. census.
Percap_c Poverty rate categories.
Poverty. Poverty rate for individuals 18 years or older for each CDBG entitlement city based on the 2000 U.S. census.
Pove_cat poverty categories.
Cou-elec. Electing city-council by-district, at-large, both (by-district \& at- large).
Cou_dist. $\quad$ Elect city-council elected by district
Cou_atla. Elect city-council at-large.
Cou_both. Elect city-council by district and at-large

\section{- Dependent Variables}

Aquisiti. $\quad$ CDBG funding allocation for acquiring property in low-income neighborhoods

Admplng. $\quad$ CDBG funding allocation for administration \& planning purposes Econdvlp. $\quad$ CDBG funding allocation for economic development activities Housing. $\quad$ CDBG funding allocation for housing purposes Pubimp. $\quad$ CDBG funding allocations for public improvement projects Pubserv. $\quad$ CDBG funding allocations for public service projects

Data Sources:

- U.S. Census - 2000

- U.S. Department of Housing and Urban Development (HUD). Grantee Use of CDBG Funds by Matrix Code web site: (http://www.hud.gov/offices/cpd/communitydevelopment/budget/disbursementrep orts/)

- Fact finder

- League of cities data

- Websites for U.S. cities

- 2001 Municipal Yellow Book

- City Clerk office for CDBG entitlement city

Population of Interest

- CDBG entitlement cities

Number of Observations:

- 758 CDBG entitlement cities (2001) 